QA: QA

TDR-MGR-SE-000010 REV 03 ICN 01

December 2001

\title{
Monitored Geologic Repository Test \& Evaluation Plan
}

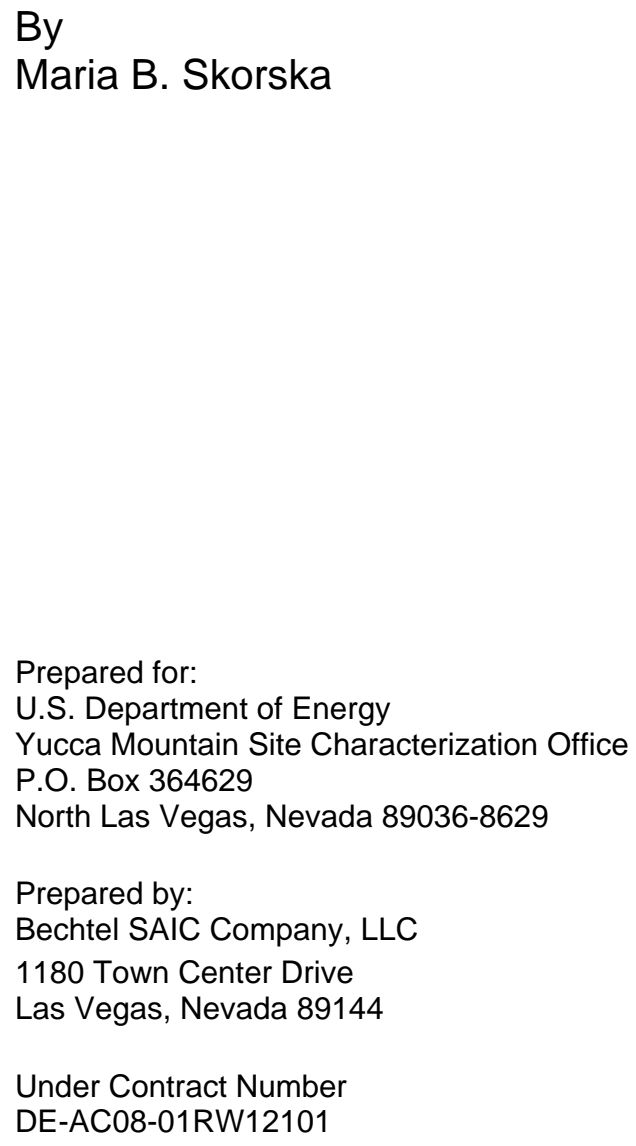




\section{DISCLAIMER}

This report was prepared as an account of work sponsored by an agency of the United States Government. Neither the United States Government nor any agency thereof, nor any of their employees, nor any of their contractors, subcontractors or their employees, makes any warranty, express or implied, or assumes any legal liability or responsibility for the accuracy, completeness, or any third party's use or the results of such use of any information, apparatus, product, or process disclosed, or represents that its use would not infringe privately owned rights. Reference herein to any specific commercial product, process, or service by trade name, trademark, manufacturer, or otherwise, does not necessarily constitute or imply its endorsement, recommendation, or favoring by the United States Government or any agency thereof or its contractors or subcontractors. The views and opinions of authors expressed herein do not necessarily state or reflect those of the United States Government or any agency thereof. 
Prepared by:

Maño B. Shôrohe

M.B. Skorska

Test \& Evaluation Lead

Checked by:

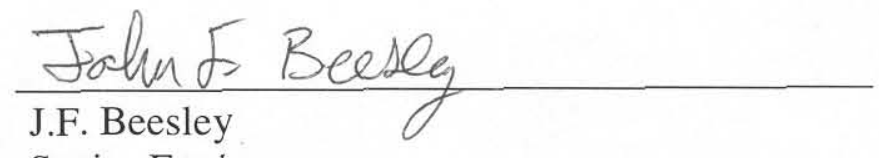

Senior Engineer

Approved by:

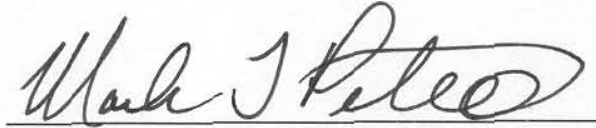

M.T. Peters, Manager

Science and Engineering Testing
$|2-| 2-0 \mid$

Date 


\section{CHANGE HISTORY}

\begin{abstract}
Revision Interim Effective
Number Change Date Description of Change

1

$03 / 31 / 98$

The Viability Assessment Mined Geologic Disposal System Test and Evaluation Plan (Revision 01) updates Revision 00 of this test plan by incorporating the latest design information used for the Viability Assessment and refines the test description sheets contained in Appendix B. These refinements are also reflected/incorporated into the Preliminary Test and Evaluation Matrix (Appendix A) and the Test Descriptions (Appendix B). Revision 01 also updates descriptions of the Mined Geologic Disposal System Test and Evaluation Program objectives and goals, the organization and responsibilities, general test planning, and the Mined Geologic Disposal System Testing. Discussions of requirements have been updated to incorporate the most current requirement documentation that was used to perform the test planning analysis reflected in Revision 01.

\section{1, DCN 1}

$03 / 31 / 98$

2

$06 / 05 / 98$

Test Director will report to the Office of the Assistant General Manager.

The Monitored Geologic Repository Test and Evaluation Plan (Revision 02) updates Revision 01, DCN 1 by changing the title of the deliverable to Monitored Geologic Repository Test and Evaluation Plan and changed all references in the document accordingly. Editorial changes were made to sections describing test objectives, test organization, and test area descriptions. References were also updated to reflect current formatting and referencing conventions.

09/25/2000 The Monitored Geologic Repository Test \& Evaluation Plan (Revision 03) updates Revision 02 (B00000000-01717-570500058) by reflecting the Site Recommendation design and providing a formal process for confirmation verification analysis. This revision also identifies near-term test working groups for implementing test planning analysis and integration activities. This revision also describes test activities focusing on ensuring repository safety and operational readiness to include a conduct of operations for startup activities and operational testing. Appendices have also been added that propose near-term testing to reduce design risk and support the licensing process.
\end{abstract}




\title{
CHANGE HISTORY (Continued)
}

\author{
Revision Interim Effective \\ Number Change Date \\ No. \\ $3 \quad 1 \quad 12 / 21 / 2001$ \\ Description of Change \\ The Monitored Geologic Repository Test \& Evaluation Plan, \\ Revision 03, ICN 01 updates Revision 03 by reflecting the \\ regulatory requirements in 10 CFR 63, "Disposal of \\ High-Level Radioactive Waste in a Proposed Geologic \\ Repository at Yucca Mountain, Nevada". Editorial changes \\ made to incorporate changes with other Site Recommendation \\ documents.
}




\section{INTENTIONALLY LEFT BLANK}




\section{EXECUTIVE SUMMARY}

\section{TEST PROGRAM OVERVIEW}

The Monitored Geologic Repository test \& evaluation program will specify tests, demonstrations, examinations, and analyses, and describe procedures to conduct and document testing necessary to verify meeting Monitored Geologic Repository requirements for a safe and effective geologic repository for radioactive waste. This test program will provide assurance that the repository is performing as designed, and that the barriers perform as expected; it will also develop supporting documentation to support the licensing process and to demonstrate compliance with codes, standards, and regulations. This comprehensive program addresses all aspects of verification from the development of test requirements to the performance of tests and reporting of the test results.

\section{TEST PLAN PURPOSE}

The Monitored Geologic Repository Test \& Evaluation Plan provides a detailed description of the test program approach necessary to achieve the above test program objectives. This test plan incorporates a set of test phases focused on ensuring repository safety and operational readiness and implements a project-wide integrated product management team approach to facilitate test program planning, analysis, and implementation. The following sections provide a description of the individual test phases, the methodology for test program planning and analyses, and the management approach for implementing these activities.

\section{TEST PHASES}

The following test phases are governed by the test program planning, analysis, and implementation approach described in the following subsections:

Development Testing will primarily support the design development and integration processes by confirming design concepts, evaluating alternative design concepts, and investigating the availability of needed technology. This test phase will also support system verification by demonstrating system requirements that cannot be easily confirmed in a pre-operational site environment. Another objective of development testing is to resolve any outstanding design issues. This may include resolving critical but unverified design parameters, and conducting modeling and analyses to support and substantiate preclosure licensing arguments. This test phase will also employ proof of concept prototype testing to reduce design and integration risk by investigating new technologies or design solutions that have little or no nuclear history of testing or use at existing storage facilities or power plants.

Component Testing includes qualification, acceptance, installation, and checkout. Qualification testing verifies, on a limited sampling basis, the proper component operation with respect to extreme bounds (as defined by specifications). Acceptance testing is performed for key parameters, and establishes confidence that the manufacturing process is producing the correct product. The component vendor, with quality assurance (i.e., authorized customer representative) oversight and concurrence, performs qualification and acceptance testing. Installation and checkout testing will verify that systems, structures, and components are correctly installed and are operational. If required, the managing and operating contractor, with 
vendor support, will perform this testing during the construction phase. Installation and checkout testing will also ensure that installation of hardware and software is consistent with drawings and specifications of the baseline configuration.

Pre-operational Testing includes system, integration, mockup, and cold startup test activities. System and integration testing will verify the operational readiness of structures, systems, components, and procedures. It will be performed for operations and procedures involved in receiving, preparing, emplacing, and moving waste (i.e., for recovery or retrieval). Mockup testing will support system and integration testing by providing a testbed for operational requirements verification, procedure development, and training. Cold startup testing is the final integration test and precedes waste receipt and hot startup testing. Cold startup employs operational and support personnel working with actual operational and support procedures. Hot startup follows cold testing and is preceded by readiness reviews to ensure that facilities and systems needed for waste receipt are complete and installation and checkout test results are acceptable. Hot startup testing will verify that operation and maintenance systems work properly and confirm that exposure times and radiation levels fall within acceptable limits during actual repository operations.

Periodic Performance Testing and Monitoring will ensure continued license operations and safe working conditions. Periodic performance and surveillance testing will verify that system performance continues to comply with preclosure requirements and ensures continued proper functioning of structures, systems, and components important to radiological safety, waste isolation, fire protection, non-nuclear safety, and repository operations. Monitoring of surface and subsurface environments will be performed to ensure safe working conditions and to document continuing compliance with existing regulatory standards for air, water, and radiological considerations. Monitoring will also be performed for disruptive events with significant postclosure implications.

Performance Confirmation Testing will monitor repository performance, perform tests, collect data, and analyze and evaluate results in order to assess whether postclosure conditions with long-term performance sensitivity will behave as expected. Testing will provide data that will evaluate the accuracy and adequacy of the information used to determine that the postclosure total system performance objective will be met. Evaluations can include the use of process models and total system performance assessments. The performance confirmation program is a sub-tier overlay on the overall Monitored Geologic Repository test \& evaluation program consisting of tests driven solely by performance confirmation objectives in conjunction with tests conducted for multiple test objectives and purposes.

\section{INTEGRATED TEST PLANNING, ANALYSIS, AND INTEGRATION}

A project-wide integrated product management team approach facilitates coordination, oversight, and monitoring of the various test activities described above, as well as the verification functions described below:

Confirmation Verification Analyses: This function provides a consistent and structured methodology for determining which test activity or combination of test activities described above will verify safety requirements and proper structures, systems, and components operation. 
Integrated Test Planning: Proposed tests will undergo integration analysis to optimize test performance in meeting objectives. This will eliminate redundant unnecessary testing and analyses, which will minimize cost and schedule impacts of test performance in meeting defined milestones.

Detailed Test Planning, Test Conduct, and Reporting: Processes are identified and interfaces established to provide assurance that detailed test planning, conduct, and reporting are performed under the appropriate quality assurance, management, and technical controls.

Oversight and Readiness Reviews: Test working group (described below) oversight and readiness reviews will provide continued test program focus to project/licensing goals and test program objectives, and will ensure the validity of test documentation to adequately support the licensing process and repository operations.

\section{TEST PROGRAM IMPLEMENTATION}

Immediate initiatives to facilitate test planning analysis and integration activities described above involve the increased efforts by test integrated product teams known as test working groups to perform verification analysis and to obtain comprehensive visibility for all of the current test planning and test activities across the project. The organizations referenced below support these integrated product management teams:

- Waste Package (WP)

- Repository Subsurface Design

- Repository Surface Design

- $\quad$ Environmental, Safety and Health $(\mathrm{ES} \& \mathrm{H})$

- $\quad$ Science and Engineering Testing

Interactions with customer organizations including performance assessment, process modeling, design, and licensing groups provide a mechanism to ensure that customer needs and test objectives are well defined and that tests will be limited to only those necessary and sufficient to satisfy the needs and objectives. Near-term test planning and integration activities focus on design development, prototype, and pre-emplacement test definition, planning, and execution.

In conclusion, the Monitored Geologic Repository Test \& Evaluation Plan provides a description of the test program phases, planning and integration activities, and implementation approach necessary to ensure repository safety and operational readiness. The intent is to revise the Monitored Geologic Repository Test \& Evaluation Plan so that it contains the detail necessary to meet the needs to support the appropriate sections of the License Application, and to implement the plan in accordance with the contents herein. 


\section{INTENTIONALLY LEFT BLANK}




\section{CONTENTS}

Page

ACRONYMS AND ABBREVIATIONS ..................................................................... xvi

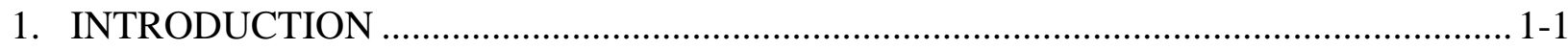

1.1 OVERVIEW AND PURPOSE ...................................................................... 1-1

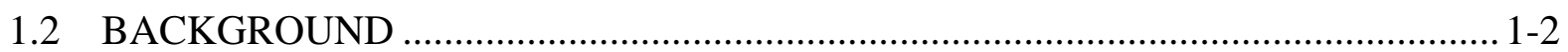

1.3 OBJECTIVES ................................................................................................ $1-2$

1.4 GOVERNING DOCUMENTS AND REGULATIONS ….............................. 1-3

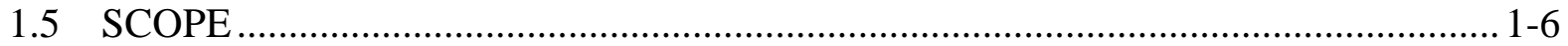

1.6 QUALITY ASSURANCE ................................................................... 1-6

2. MGR TEST PHASES AND ACTIVITIES …....................................................... 2-1

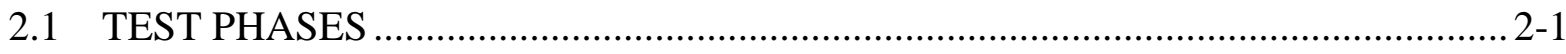

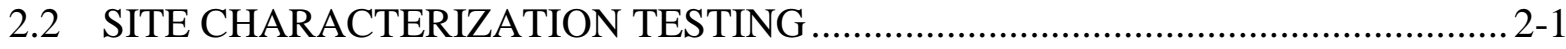

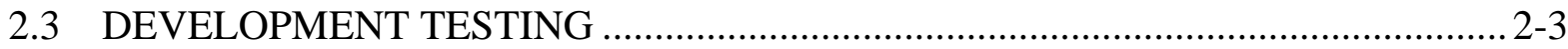

2.3.1 Design Evaluation.............................................................................. 2-3

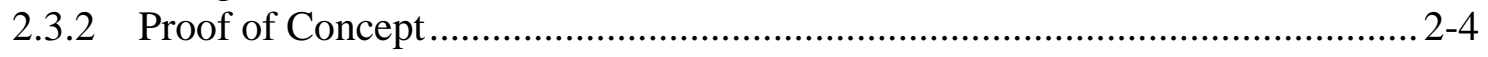

2.3.3 Pre-Emplacement.......................................................................... 2-4

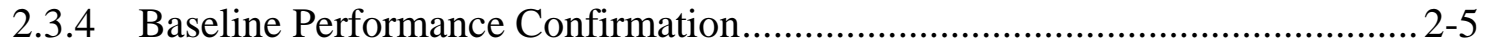

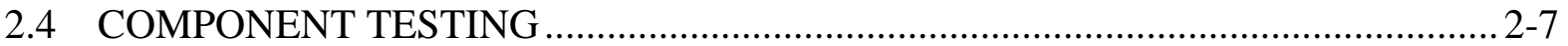

2.5 PRE-OPERATIONAL AND STARTUP TESTING .......................................... 2-7

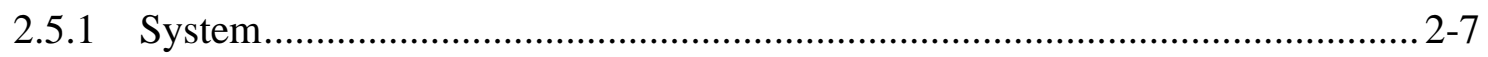

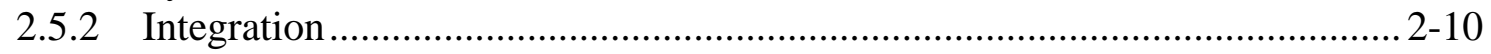

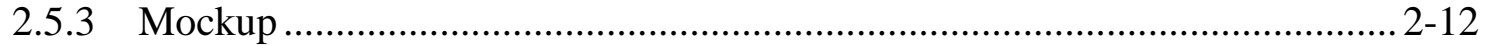

2.5.4 Startup ...................................................................................... 2-12

2.6 PERIODIC PERFORMANCE TESTING AND MONITORING .......................... 2-14

2.6.1 Periodic Performance and Surveillance ..................................................... 2-14

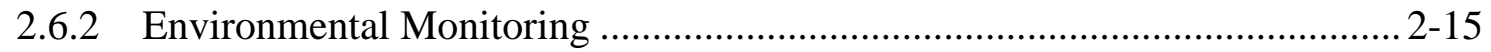

2.6.3 Post-Emplacement Research and Development ....................................... 2-15

2.7 CORE PERFORMANCE CONFIRMATION TESTING ....................................... 2-16

2.7.1 Process Confirmation......................................................................... 2-16

2.7.2 Postclosure Simulation ............................................................................. 2-17

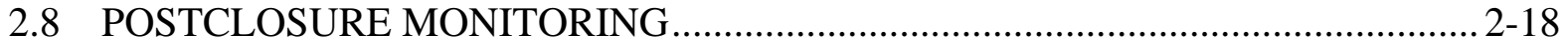

3. TEST PROGRAM PLANNING AND IMPLEMENTATION ..................................... 3-1

3.1 OVERVIEW .................................................................................. $3-1$

3.1.1 Test Planning Analysis ........................................................................ $3-1$

3.1.2 Detailed Test Planning ..................................................................... $3-4$

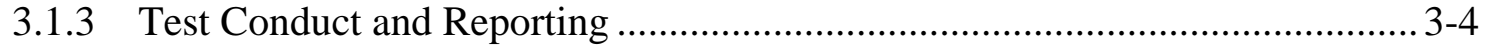

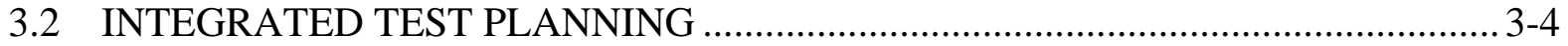

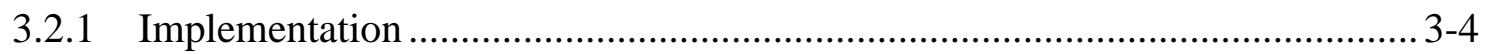

3.2.2 Integrated Test Schedules ................................................................ 3-5

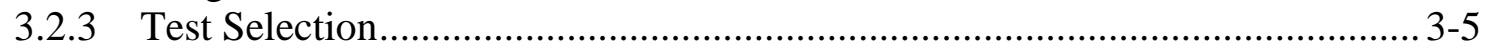




\section{CONTENTS (Continued)}

Page

3.3 CONFIRMATION VERIFICATION ANALYSIS …........................................... $3-5$

3.3.1 Confirmation Verification Matrix......................................................................... 3-7

3.3.2 Test Planning Analysis Record .................................................................. 3-8

3.3.3 Prototype Test Identification .................................................................. 3-9

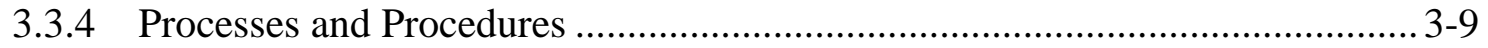

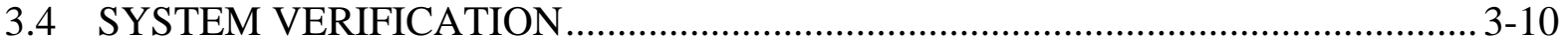

3.4.1 Startup Test Working Group.................................................................. 3-10

3.4.2 Test Director ..................................................................................... 3-10

3.4.3 Test Conduct ..................................................................................... 3-11

3.4.4 Review, Evaluation, and Approval of Test Results ................................... 3-12

3.4.5 Periodic Performance Testing and Monitoring......................................... 3-12

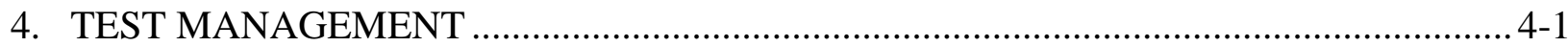

4.1 INTEGRATED PRODUCT TEAM APPROACH ................................................... 4-1

4.2 CONFIRMATION VERIFICATION GROUP ….............................................. $4-1$

4.3 THE TEST INTEGRATION WORKING GROUP …....................................... 4-2

4.4 TEST INTEGRATION DEPARTMENT ............................................................... 4-3

4.5 TEST \& EVALUATION/PERFORMANCE CONFIRMATION DEPARTMENT.... 4-3

4.6 TEST PLANNING, INTEGRATION, AND IMPLEMENTATION TOOLS AND PRODUCTS ........................................................................................ $4-4$

5. CONCLUSIONS AND RECOMMENDATIONS …................................................

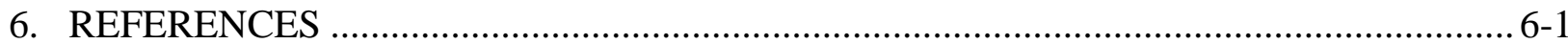

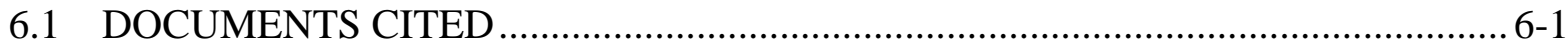

6.2 CODES, STANDARDS, REGULATIONS, AND PROCEDURES ........................ 6-3

APPENDIX A - VERIFICATION CRITERIA …......................................................... A-1

APPENDIX B - PROPOSED PRELIMINARY DESIGN ANALYSIS/EVALUATION ......... B-1

APPENDIX C - PROPOSED PROTOTYPE TESTS ................................................... C-1

APPENDIX D - NEAR-TERM PRE-EMPLACEMENT TESTING .................................... D-1 


\section{FIGURES}

Page

2-1. Monitored Geologic Repository Test Program.....................................................2-2

2-2. Monitored Geologic Repository Test Program Schedule ……....................................... 2-6

3-1. Integrated Approach for Product and System Verification............................................... 3-3

| 3-2. Confirmation Verification Process …………............................................................. 3-6

4-1. Test and Evaluation Program Document Hierarchy ……................................................... 4-7

A-1. Design Evaluation Requirements Verification Testing ……………………….......... A-2

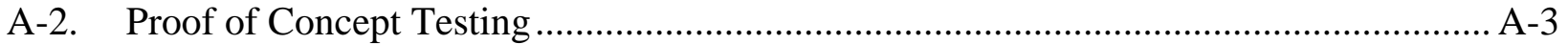

A-3. Pre-Emplacement Test Development Methodology ………………………................ A-6

A-4. Baseline Performance Confirmation Test Development Methodology .......................... A-8

A-5. Component Test Selection ................................................................................ A-10

A-6. Installation and Checkout Test Selection................................................................. A-11

A-7. System and Integration Testing ………………….............................................. A-12

A-8. Startup Testing .................................................................................................. A-13

A-9. Design Basis Event Testing ……………………………………………………... A-14

A-10. Assessing Mockup Test Capability ........................................................................... A-15

A-11. Pre-Operational Testing .................................................................................. A-16

A-12. Environmental Monitoring Development ............................................................... A-17

A-13. Disruptive Events Monitoring Development ....................................................... A-18

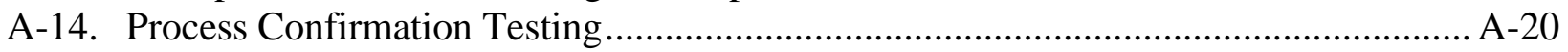

A-15. Postclosure Simulation Testing....................................................................... A-22

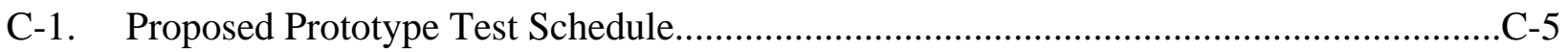

D-1. Near-Term Pre-Emplacement Test Schedule........................................................... D-10 


\section{INTENTIONALLY LEFT BLANK}




\section{TABLES}

Page

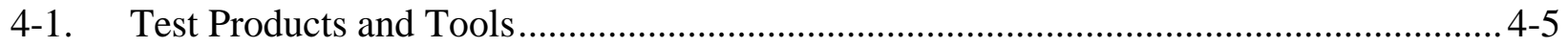

B-1. Candidate Design Analyses ................................................................................ B-2

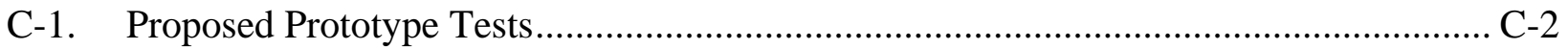

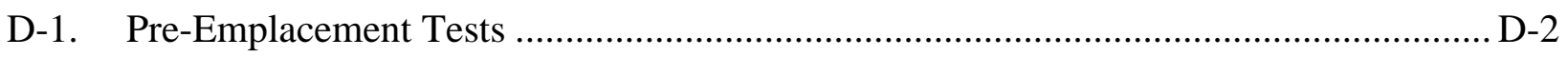




\section{INTENTIONALLY LEFT BLANK}




\section{ACRONYMS AND ABBREVIATIONS}

\begin{tabular}{|c|c|}
\hline A & Analysis \\
\hline $\mathrm{ACC}$ & Accession Number \\
\hline ALARA & As Low As Is Reasonably Achievable \\
\hline AMR & Analysis Model Report \\
\hline $\mathrm{CA}$ & Construction Authorization \\
\hline CRWMS-RD & Civilian Radioactive Waste Management System Requirements Document \\
\hline CSNF & Commercial Spent Nuclear Fuel \\
\hline CVG & Confirmation Verification Analysis Test Working Group \\
\hline CVM & Confirmation Verification Matrix \\
\hline $\mathrm{D}$ & Demonstration \\
\hline DBE & Design Basis Event \\
\hline $\mathrm{DC}$ & Disposal Container \\
\hline DOE & U.S. Department of Energy \\
\hline $\mathrm{E}$ & Examination \\
\hline EBS & Engineered Barrier System \\
\hline EIS & Environmental Impact Statement \\
\hline EPA & Environmental Protection Agency \\
\hline ESF & Exploratory Studies Facility \\
\hline ES\&H & Environmental, Safety and Health \\
\hline HMI & Human-Machine Interface \\
\hline HVAC & Heating, Ventilation, Air Conditioning \\
\hline $\mathrm{I} \& \mathrm{C}$ & Instrumentation and Control \\
\hline $\mathrm{I} \& \mathrm{CO}$ & Installation and Checkout \\
\hline ISM & Integrated Safety Management \\
\hline KTI & Key Technical Issue \\
\hline LA & License Application \\
\hline $\mathrm{M} \& \mathrm{O}$ & Management and Operating Contractor \\
\hline MGR & Monitored Geologic Repository \\
\hline MGR-PDD & Monitored Geologic Repository Project Description Document \\
\hline MTHM & Metric Tonnes of Heavy Metal \\
\hline N/A & Not Applicable \\
\hline NRC & U.S. Nuclear Regulatory Commission \\
\hline $\begin{array}{l}\mathrm{PA} \\
\mathrm{PC}\end{array}$ & $\begin{array}{l}\text { Performance Assessment } \\
\text { Performance Confirmation }\end{array}$ \\
\hline
\end{tabular}




\title{
ACRONYMS AND ABBREVIATIONS (Continued)
}

\author{
PDD Monitored Geologic Repository Project Description Document \\ PMR Process Model Report \\ QA Quality Assurance \\ ROV Remotely Operated Vehicle \\ | RSS Repository Safety Strategy: Plan to Prepare the Safety Case to Support Yucca \\ Mountain Site Recommendation and Licensing Considerations \\ SAR Safety Analysis Report \\ SDD System Description Document \\ SR Site Recommendation \\ SSC Structure, System, and Component \\ STE Special Test Equipment \\ SWG Startup Test Working Group \\ SZ Saturated Zone \\ T\&EP Test and Evaluation Plan \\ $\mathrm{T} \quad$ Test (Functional) \\ TDMS Technical Data Management System \\ TIG Test Integration Working Group \\ TPA Test Planning Analysis \\ TSE Test Support Equipment \\ TSLCC Total System Life Cycle Cost \\ TSPA Total System Performance Assessment \\ UZ Unsaturated Zone \\ VA Viability Assessment \\ WP Waste Package \\ YMP Yucca Mountain Site Characterization Project \\ YMP-RD Yucca Mountain Site Characterization Project Requirements Document
}




\section{INTRODUCTION}

\subsection{OVERVIEW AND PURPOSE}

The Monitored Geologic Repository (MGR) test \& evaluation program will specify tests, demonstrations, examinations, and analyses, and will describe procedures to conduct and document testing necessary to verify meeting MGR requirements for a safe and effective geologic repository for radioactive waste. The MGR test $\&$ evaluation program will provide assurance that the repository is performing as designed, and that the barriers perform as expected; it will also develop documentation for supporting the licensing process and for demonstrating compliance with codes, standards, and regulations. This comprehensive program addresses all aspects of verification from the development of test requirements to the performance of tests and reporting of the test results. (Note: In order to simplify and condense text, the term "test" will encompass the various verification methodologies of functional test, demonstration, examination, and analysis).

The Monitored Geologic Repository Test \& Evaluation Plan (MGR T\&EP) provides a description of the test program phases, planning and integration activities, and implementation approach necessary to ensure the above test program objectives. The current version of the MGR T\&EP will also support the licensing process and near-term test planning and integration activities by:

- Providing the methodology for implementing test activities for ensuring preclosure safety

- Providing the process for test planning analysis for verifying system and subsystemlevel requirements

- Providing a reference for supporting test program estimates contained in the total system life cycle cost (TSLCC) estimates

- Describing the management structure for overseeing current test planning and ensuring integrated cost effective test implementation

- Providing plans for startup activities and testing

- Providing plans for periodic and surveillance testing

- Identifying near-term testing and analysis for supporting the License Application (LA) submittal

- Facilitate short-term test planning, integration of ongoing tests, and adjustments required due to changes in future test phases.

This current version of the MGR T\&EP is based on the Site Recommendation (SR) design and reflects, to the extent possible, the test planning and analysis that can be reasonably conducted given the current status of the MGR requirements and design maturity. The intent is to revise the 
MGR T\&EP so that future revisions contain the detail necessary to meet the needs to support the appropriate sections of the LA.

\subsection{BACKGROUND}

Revision 3 of the MGR T\&EP superseded an earlier version of the Monitored Geologic Repository Test and Evaluation Plan (CRWMS M\&O 1998a). Revision 3 reflected the Site Recommendation design, and provided a formal process for confirmation verification analysis. Revision 3 was cited as one of the Yucca Mountain Science and Engineering Report (DOE 2001b) references. Prior revisions are listed and briefly discussed below.

- Mined Geologic Disposal System Viability Assessment Test and Evaluation Plan (CRWMS M\&O 1997).

Revision 00 of this test plan provided a description of the test planning analysis process and proposed major system tests.

- Viability Assessment Mined Geologic Disposal System Test and Evaluation Plan (CRWMS M\&O 1998b).

Revision 01 DCN 1 of this test plan provided test description sheets identifying those structures, systems, and components (SSCs) that required development testing and described ongoing and proposed testing to support design activities and to reduce design risk.

- Monitored Geologic Repository Test and Evaluation Plan (CRWMS M\&O 1998a)

Revision 02 changed the title of the deliverable, and made editorial changes to sections describing test objectives, test organization, and test area descriptions.

\subsection{OBJECTIVES}

As stated in Section 1.1, the MGR test \& evaluation program will specify tests and analyses and will describe procedures to conduct and document testing necessary to fulfill MGR requirements for a safe and effective geologic repository for radioactive waste. This comprehensive program addresses all aspects of verification from the development of test requirements to the performance of tests and reporting of the test results. This program will achieve the following objectives (DOE 1995, Section 3.2):

1) Ensure that the repository is performing as designed.

2) Ensure that items that are important to safety meet all acceptance criteria (i.e., test objectives) necessary to support the licensing process.

3) Determine if the engineered and natural barriers are performing as expected. 
4) Develop supporting documentation for demonstrating system verification, supporting the licensing process (to include applicable regulations, codes, and standards), and providing "traceability" to requirements.

5) Provide programs for startup and periodic performance and surveillance testing.

6) Ensure that all activities associated with test planning, conduct, analysis, and reporting comply with quality controls and adhere to Integrated Safety Management (ISM) principles and functions (Anderson 2001).

7) Maximize test program effectiveness, and minimize cost, and schedule impacts of test performance in meeting project milestones.

The MGR T\&EP provides a documented basis to facilitate integration of the objectives, scope, and planning methodology for this test program.

\subsection{GOVERNING DOCUMENTS AND REGULATIONS}

The MGR T\&EP will use as inputs the requirements and information contained in the following MGR system and subsystem project documents (a document hierarchy is provided in Section 4.6):

- Civilian Radioactive Waste Management System Requirements Document (CRWMSRD) (DOE 2001a)

- Yucca Mountain Site Characterization Project Requirements Document (YMP-RD) (YMP 2001b)

- Monitored Geologic Repository Project Description Document (MGR-PDD) (Curry 2001)

- System Description Documents (SDDs)

- Repository Safety Strategy: Plan to Prepare the Safety Case to Support Yucca Mountain Site Recommendation and Licensing Considerations (RSS) (CRWMS M\&O 2001).

In addition to these project-level documents, this plan will also consider requirements derived from waste acceptance, national transportation, Nevada transportation, interactions with the U.S. Nuclear Regulatory Commission (NRC), and from data needs and natural barrier considerations. 
The MGR test \& evaluation program will comply with NRC codes, standards, and regulations that drive and are the basis for the test and evaluation program. These codes and regulations are captured in the program- and project-level requirements documents mentioned earlier. For the purposes of this document, regulatory requirements are taken from U.S. Nuclear Regulatory Commission (NRC) Regulations in 10 CFR 63, "Disposal of High-Level Radioactive Wastes in a Proposed Geologic Repository at Yucca Mountain, NV (66 FR 55732).” Pertinent regulatory requirements for MGR test and evaluation consist of the following:

- Subpart D, Section 63.74 requires that tests deemed appropriate by the NRC be performed and must include a performance confirmation (PC) program to evaluate the accuracy and adequacy of the information used to determine whether the performance objective for the period after permanent closure will be met.

- Subpart B, Section 63.21(c)(15) requires that "Analyses and models that will be used to assess performance of the geologic repository must be supported by using an appropriate combination of such methods as field tests, in situ tests, laboratory tests that are representative of field conditions, monitoring data, and natural analog studies".

- Subpart B, Section 63.21(c)(16) requires "An identification of those structures, systems, and components of the geologic repository, both surface and subsurface that require research and development to confirm the adequacy of design. For structures, systems, and components important to safety and for the engineered and natural barriers important to waste isolation, DOE shall provide a detailed description of the programs designed to resolve safety questions..."

- Subpart B, Section 63.21(c)(22)(iv) relates to the content of the Safety Analysis Report SAR and requires "Plans for startup activities and startup testing."

- Subpart B, Section 63.21(c)(22)(v) relates to the content of the SAR and requires "Plans for conduct of normal activities, including ...surveillance and periodic testing of structures, systems, and components of the geologic repository operations area."

- Subpart B, Section 63.21(c)(6) calls for "A description of the program for control and monitoring of radioactive effluents and occupational radiological exposures to maintain such effluents and exposures in accordance with ..."

- Subpart B, Section 63.32(b)(4) requires DOE to furnish periodic or special reports regarding "Results of research and development programs being conducted to resolve safety questions."

- Subpart B, Section 63.43(b) includes, as a condition for license, requirements related to testing, calibration, or inspection, to assure that specified restrictions are observed.

- Subpart B, Sections 63.44(b)(1-2) specify the conditions under which DOE may conduct tests or experiments not described in the SAR, without obtaining either an amendment of construction authorization or a license amendment. 
- Subpart B, Sections 63.44(c)(1-2) requires that, for tests and experiments conducted without obtaining either an amendment of construction authorization or a license amendment, DOE shall maintain records, and no less frequently than every 24 months, DOE shall prepare a report containing a description of such tests and experiments, including a summary of the evaluation of each.

- Subpart B, Section 63.51(a)(2) calls for "A description of the program for postpermanent closure monitoring of the geologic repository."

- Subpart B, Section 63.51(a)(5) requires that an application to amend the license before permanent closure must include "the results of tests, experiments, and any other analyses relating to backfill of excavated areas, shaft, borehole, or ramp sealing, drip shields, waste packages, interactions between natural and engineered systems, and any other tests, experiments, or analyses pertinent to compliance ..."

- Subpart E, Section 63.112(e)(13) states that "the preclosure safety analysis of the geologic repository operations area must include ... consideration of... means to inspect, test, and maintain structures, systems, and components important to safety, as necessary, to ensure their continued functioning and readiness."

- Subpart G, Section 63.142(c)(3) states that the MGR quality assurance program "must take into account the need for special controls, processes, test equipment, tools, and skills to attain the required quality, and the need for verification of quality by inspection and test."

- Subpart G, Section 63.142(d)(2)(i) specifies, as a quality assurance criterion, that "the design control measures must provide for verifying or checking the adequacy of design, such as by the performance of design reviews, by the use of alternate or simplified calculational methods, or by the performance of a suitable testing program". It goes on to state that "if a test program is used to verify the adequacy of a specific design feature in lieu of other verifying or checking processes, it must include suitable qualifications testing of a prototype unit under the most adverse design conditions".

- Subpart G, Section 63.142(1) specifies, as a quality assurance criterion, that "DOE shall establish a test program to assure that all testing required to demonstrate that structures, systems, and components important to safety will perform satisfactorily in service is identified and performed in accordance with written test procedures which incorporate the requirements and acceptance limits contained in applicable design documents. (1) The test program must include, as appropriate, proof tests prior to installation, preoperational tests, and operational tests during repository operations, of structures, systems, and components. (2) Test procedures must include provisions for assuring that all prerequisites for the given test have been met, that adequate test instrumentation is available and used, and that the test is performed under suitable environmental conditions. (3) Test results must be documented and evaluated to assure that test requirements have been satisfied." 
- Subpart G, Section 63.142(m) specifies, as a quality assurance criterion, that "DOE shall establish measures to assure that tools, gages, instruments, and other measuring and testing devices used in activities affecting quality are properly controlled, calibrated, and adjusted at specified periods to maintain accuracy within necessary limits."

- Subpart G, Section 63.142(o) specifies, as a quality assurance criterion, that "DOE shall establish measures to indicate the status of inspections and tests performed on individual items of the high-level waste repository" and "these measures must provide for the identification of items that have satisfactorily passed required inspections and tests ..."

- Subpart G, Section 63.142(r) specifies, as a quality assurance criterion, that DOE shall maintain sufficient records to furnish evidence of activities affecting quality, including operating logs and the results of tests, and that test records must meet certain specified standards.

NUREG-1567, Standard Review Plan for Spent Fuel Dry Storage Facilities (NRC 2000), and NUREG-1536, Standard Review Plan for Dry Cask Storage Systems (NRC 1997), provided input to the development of the test phase and activity architecture depicted in Figure 2-1 and described in Section 2. Identification of specific application of codes and standards and their application to specific test activities will result from test planning (see Section 3.3) and design analysis.

\subsection{SCOPE}

The MGR T\&EP provides a description of the integrated test program approach necessary to achieve the objectives stated in Section 1.3 and to comply with the governing requirements and regulations cited in Section 1.4. Section 2 of the MGR T\&EP identifies the project-level test phases comprising the MGR test \& evaluation program. Section 3 describes the integrated approach for test planning analysis and implementation. Section 4 of the plan discusses the nearterm integrated product team approach for implementing the MGR test \& evaluation program. Section 5 provides conclusions and recommendations to ensure timely implementation of this plan and its objectives as stated in Section 1.3.

Appendix A provides criteria for selecting test verification activities in performing test planning analysis. Appendices $\mathrm{B}, \mathrm{C}$, and $\mathrm{D}$ respectively propose near-term testing for design and evaluation, prototype, and pre-emplacement testing as measures to reduce design risk and to support the licensing process. These test activities and corresponding parent test phases are defined in Section 2 of this plan.

\subsection{QUALITY ASSURANCE}

An activity evaluation (Sellers 2000) was performed for the development of the MGR T\&EP. The activity evaluation concluded that the development of the plan, and the plan itself, are quality affecting since the plan provides the overall vision and strategy for implementing the MGR test \& evaluation program in compliance with regulatory requirements, with implications 
| for items on the Q-List (YMP 2001a). Although the plan does not identify specific tests or test requirements for safety-related items, it does describe the guidelines and methodologies to be used to consistently identify appropriate test objectives, requirements, and activities to be executed in accordance with implementing documents.

The MGR T\&EP was developed in accordance with AP-3.11Q, Technical Reports, and appropriate quality assurance (QA) procedures were used in the preparation, review, and approval of the document. The revision 3 development of the document is described in more detail in the Technical Work Plan for: MGR Test \& Evaluation Plan (CRWMS M\&O 2000c). The interim change to this document (Revision 03, ICN 01) was prepared in accordance with Technical Work Plan for: MGR Test and Evaluation Plan (BSC 2001b).

The Quality Assurance Requirements and Description (DOE 2000) will also apply to the implementation of test planning analysis, test conduct, and reporting. The appropriate QA controls will apply to these activities.

The use of computer software for computations was not employed in the development of the MGR T\&EP. Also, a determination of importance evaluation, in accordance with NLP-2-0, Determination of Importance Evaluations, is not required for the MGR T\&EP, as the development of the plan is not a field activity. 


\section{INTENTIONALLY LEFT BLANK}




\section{MGR TEST PHASES AND ACTIVITIES}

\subsection{TEST PHASES}

To achieve the objectives stated in Section 1.3, the MGR test $\&$ evaluation program incorporates a set of integrated test phases focused on ensuring repository safety and operational readiness. The approach for defining tests necessary to verify requirements relevant to each test phase is described in Section 3.3 with additional guidance contained in Appendix A. These phases are listed below and are shown in Figure 2-1:

- Site Characterization Testing (Section 2.2)

- Development Testing (Section 2.3)

- Component Testing (Section 2.4)

- Pre-operational and Startup Testing (Section 2.5)

- Periodic Performance Testing and Monitoring (Section 2.6 )

- Core Performance Confirmation Testing (Section 2.7)

- Postclosure Monitoring (Section 2.8).

The PC program will monitor repository performance, perform tests, collect data and analyze and evaluate results in order to assess whether postclosure conditions with long-term performance sensitivity will behave as expected. PC testing is limited to those activities necessary to comply with regulatory requirements and as a result of NRC licensing conditions, with a specific focus on items important to postclosure safety. A more detailed description of these test activities is contained in the Performance Confirmation Plan (Lindner 2002, Appendix G). The relationship of the PC program to MGR T\&EP test activities is depicted in Figure 2-1. As shown in Figure 2-1, process confirmation and postclosure simulation (see Section 2.7) are conducted solely as part of the PC program. Also as depicted in Figure 2-1, the PC program takes advantage of testing performed for multiple reasons or objectives in order to make the most efficient use of time and resources. Multi-purpose test phase categories include design evaluation, proof of concept, and periodic performance testing and monitoring discussed respectively in Sections 2.3.1, 2.3.2, and 2.6.

\subsection{SITE CHARACTERIZATION TESTING}

Site Characterization was the program of exploration and research, both in the laboratory and in the field, undertaken to establish the geologic conditions and the ranges of these conditions at Yucca Mountain. The information obtained during this phase of the MGR provided the data to predict and evaluate the performance of natural and engineered barriers, and provided a basis for the site-specific milestones such as the Environmental Impact Statement (EIS), the VA (DOE 1998), and the Site Recommendation (SR). 


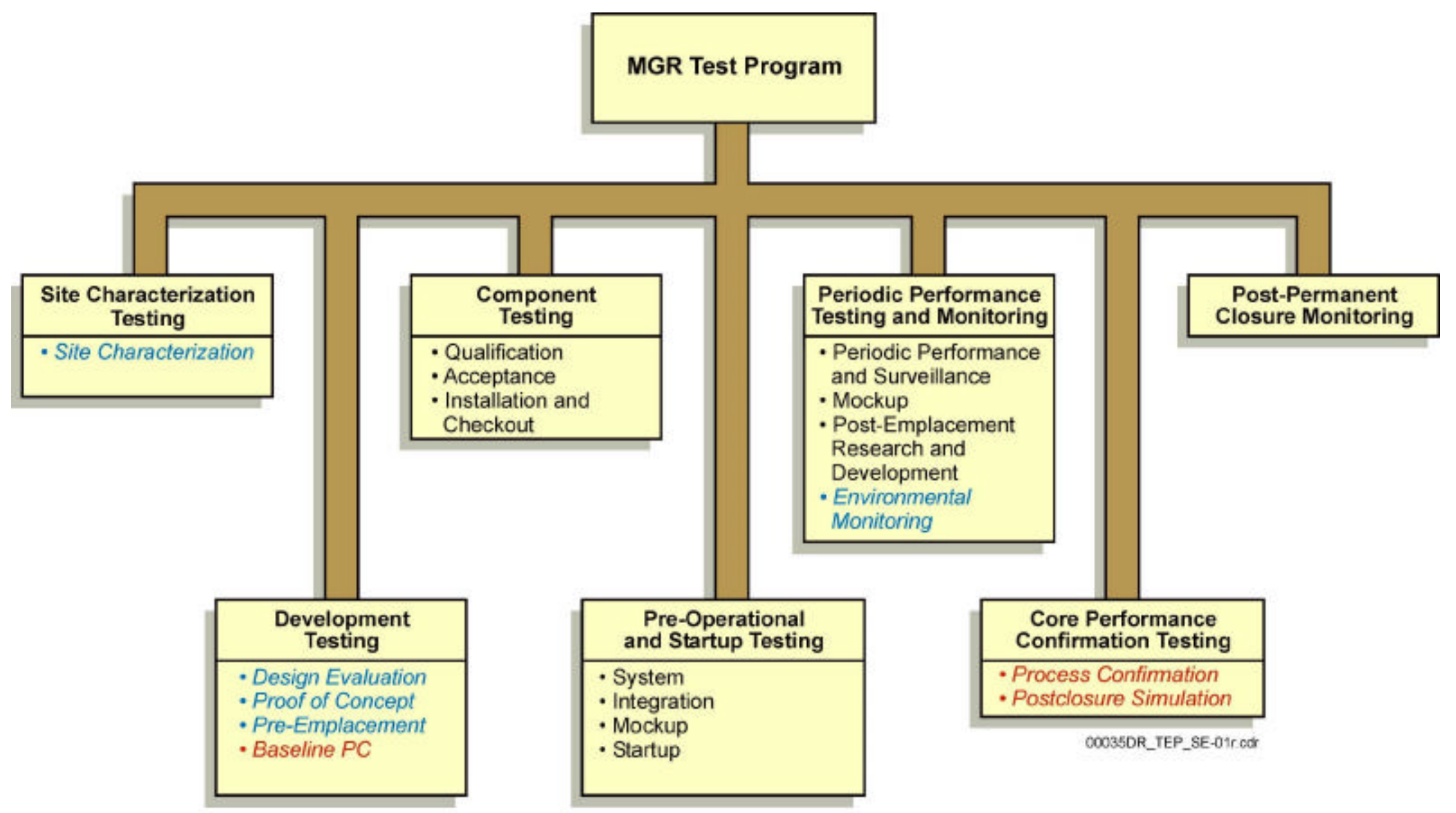

\section{LEGEND}

- Multiple use tests that also support performance confirmation

- Tests conducted solely as part of performance confirmation

- Tests that do not support performance confirmation

Figure 2-1. Monitored Geologic Repository Test Program 
Site Characterization efforts at the proposed Yucca Mountain site included the Exploratory Studies Facility (ESF) and the Enhanced Characterization of the Repository Block, together with the performance of various in situ and laboratory testing such as the Drift Scale Test. Test and evaluation activities considered during this phase include geology, geohydrology, geochemistry, geomechanics, thermal characteristics, erosion, tectonics, human interference, radiological monitoring, climate, surface characteristics, and seal and waste package (WP) characteristics. Site Characterization ends with the DOE decision on whether or not to recommend the proposed site to the President.

The above mentioned site characterization test activities were not governed by the planning, testing, and analysis described in Section 3 of the MGR T\&EP. However, the MGR T\&EP will ensure that the site characterization test results are incorporated into the test planning activities for the development test phase described below. This will minimize cost/schedule impacts in meeting licensing milestones by identifying similar, redundant, and supportive test activities that can be combined and/or phased to optimize project resources.

\subsection{DEVELOPMENT TESTING}

Development testing will primarily support the design development and integration process. However, this test phase will support system verification by performing analyses and tests of requirements that are not visible or cannot be easily confirmed in the other test phases (see Objective 4, of Section 1.3). As shown in Figure 2-1 and further described below, development testing includes design evaluation, proof of concept, pre-emplacement, and baseline PC test activities.

\subsubsection{Design Evaluation}

Design evaluation testing supports design activities by investigating potential or alternative design solutions or technologies, confirming design concepts, evaluating alternative design concepts, and investigating the availability of needed technology. For example, this test activity will help evaluate and demonstrate the suitability of ground support systems proposed for the emplacement drifts. As another example, design evaluation testing will help determine the suitability, adequacy, and availability of instrumentation, monitoring, and control technologies for use in the high-temperature and high-radiation repository environment.

Design evaluation testing may also be used to help select a technology or design concept to proceed in more detailed design efforts (i.e., may be a precursor to or may overlap proof of concept prototype testing described in Section 2.3.2.). Design evaluation testing primarily supports the design development process. However, this test activity also supports system verification by performing analyses of requirements that are not visible or cannot be easily confirmed in the other test phases (see Objective 4, Section 1.3). Appendix B provides a list of MGR system-level requirements that have been selected (via the confirmation verification process described in Section 3.3) to be verified by analysis. 


\subsubsection{Proof of Concept}

Proof of concept prototype testing follows the design evaluation test activities described above and precedes the release of final design packages. This testing is conducted at vendors, laboratories, or a dedicated test facility and is performed for the following cases:

- New technologies or design solutions that have little history of use in the nuclear industry

- Technologies or design solutions that have not been subjected to a test program qualified by the NRC, and from which accepted data were collected or analyzed and documented in a defensible source

- Complex systems that may introduce schedule risk during installation and checkout (I\&CO) and integration activities.

| The appropriate test working group (see Section 4.3) will develop and maintain status on areas related to safety features where further information is required to confirm the adequacy of design. As a minimum, this status will reflect completed, ongoing, and proposed testing to include test descriptions, period of performance, and results of test performance. This information will be tracked on the MGR test database (see Section 3.1.2).

Proof of concept prototype testing will also support one of the test program objectives (see Objective 7, Section 1.3) by reducing cost and schedule risks during construction and pre-operations. Appendix $\mathrm{C}$ provides a list of proposed near-term proof of concept prototype tests. This list includes candidate processes and operations for testing prior to final design release.

\subsubsection{Pre-Emplacement}

Site Characterization ended with the DOE decision on whether or not to recommend the proposed site to the President. A description of site characterization testing is discussed in Section 2.2. As discussed in Section 2.2, the focus of site characterization testing was to determine site suitability. A portion of tests previously conducted under the site characterization | program will be continued as pre-emplacement tests. However, pre-emplacement testing will focus on meeting different test objectives from those of site characterization. The objectives of pre-emplacement testing are to support the LA submittal and subsequent pre-emplacement licensing milestones.

These objectives are summarized as follows:

- To address residual data needs, model validation requirements, or to address model vulnerabilities that were identified through the analysis model report (AMR)/process model report (PMR) development process.

- To resolve significant design assumptions or to make design decisions important to the LA. 
- To pursue additional postclosure safety margin, additional defense in depth, or to enhance the postclosure safety case.

- To address or resolve key technical issues or other commitments or concerns from oversight agencies as a result of interactions between the DOE and the NRC.

These objectives provide a means to constrain the continuation of tests previously conducted under the site characterization program and may necessitate the development of some new tests. Information from pre-emplacement testing will be used to support the LA submittal, post-LA interactions with the NRC, and anticipated licensing conditions. If the testing pertains to items important to postclosure safety, it will be included in the PC program (see Section 2.7) as baseline information or to satisfy confirmation testing requirements. Pre-emplacement testing ends at the time of emplacement, with the likely continuation of portions of the testing conducted in this area under post-emplacement research and development testing or the PC program described in Sections 2.6.3 and 2.7, respectively, and depicted in Figure 2-1. Appendix D contains a proposed list of near-term pre-emplacement testing to support the LA submittal and anticipated interactions during the licensing process.

\subsubsection{Baseline Performance Confirmation}

Baseline PC test activity includes testing, monitoring, and analysis to establish a baseline for PC predictions. This baseline consists of expected value and associated tolerances for PC and technical specification parameters, including initial condition of subsurface stratigraphy. While the bulk of PC baseline data sets are expected to draw from site characterization data, additional baseline data is anticipated to be obtained in conjunction with pre-emplacement testing and to develop, measure, or confirm initial conditions prior to construction and emplacement alterations to the site.

The baseline, established during site characterization, will be expanded and modified as additional data on subsurface conditions are obtained during subsequent repository phases. The baseline development will incorporate, as appropriate, data from pre-emplacement activities (see Figure 2-2), and will continue to be modified until the completion of the subsurface construction, incorporating data from subsurface mapping and observations. A more detailed description of

this test activity is provided in the Performance Confirmation Plan (Lindner 2002, Section 2, and Appendix G). 


\section{Fiscal Year (FY)}

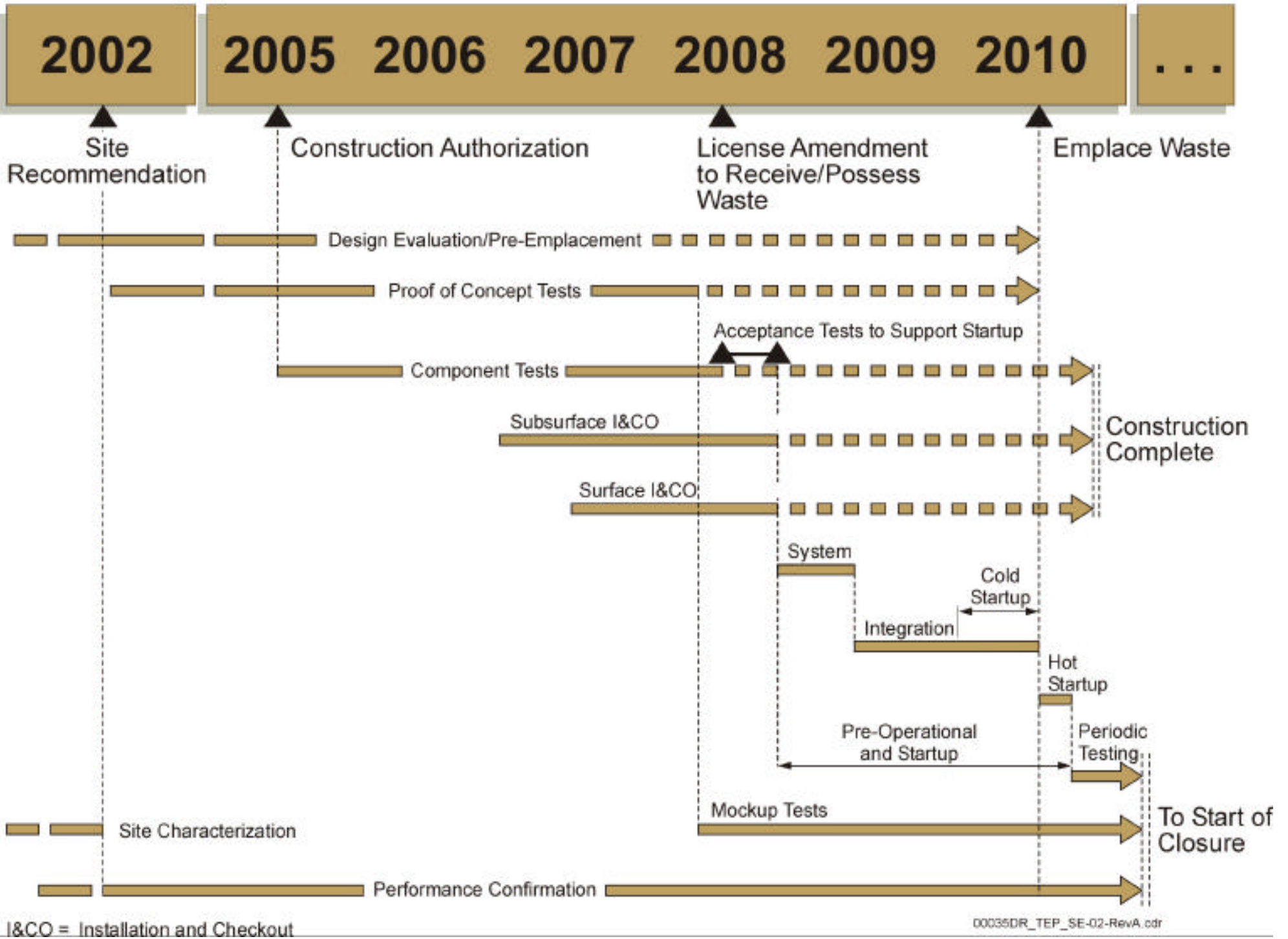

Figure 2-2. Monitored Geologic Repository Test Program Schedule 


\subsection{COMPONENT TESTING}

Component testing supports Objective 1 of Section 1.3 by ensuring that SSCs are designed as specified. Component testing includes qualification, acceptance, and installation and checkout (I\&CO).

Qualification and acceptance testing are performed as part of the procurement process, if required, to establish equipment compliance to the applicable quality level. Qualification testing verifies, on a limited sampling basis, the proper component operation with respect to extreme bounds (as defined by specifications). Acceptance testing is performed for key parameters, and establishes confidence that the manufacturing process is producing the correct product. The component vendor, with quality assurance oversight (i.e., authorized customer representation) and concurrence, performs component testing. This testing starts at the beginning of fabrication and is completed before installation.

I\&CO testing will verify that SSCs are correctly installed and are operational. If required, the managing and operating contractor, with vendor support, will perform this testing during the construction phase. I\&CO testing will also ensure that installation of hardware and software is consistent with drawings and specifications of the baseline configuration.

I\&CO testing includes such activities as:

- Initial calibration of instrumentation

- Hydrostatic testing

- Valve testing

- Verification of electrical wiring and systems

- Verification of component construction and operability.

\subsection{PRE-OPERATIONAL AND STARTUP TESTING}

This test phase will address Objectives 1 and 2 of Section 1.3, by evaluating MGR compliance with design and its impact on the environment while operational. As shown in Figure 2-2, this test phase will begin during repository construction and includes test activities for system, integration, and operational startup testing. Mockup testing is also discussed in Section 2.5.3. Testing will utilize the physical architecture depicted in the MGR-PDD (Curry 2001, Section 4.1) to help identify appropriate test candidates as described in Appendix A.

\subsubsection{System}

System tests are intermediate tests conducted during repository construction. Testing is preceded by construction readiness reviews (see Section 3.1.3) to ensure that facilities and SSCs needed for startup activities are complete and I\&CO test results are acceptable. These system tests verify safety requirements and system operations for surface and subsurface facilities.

\subsubsection{Surface Facility System Testing}

For the surface facilities, system testing will verify the performance of material handling processes, including remote operations, and lifting or material transport devices. System testing 
at the surface facilities will also ensure proper functioning of (1) local monitoring and control systems; (2) system/subsystem interfaces; (3) environmental and radiological protection and planning systems; and (4) safety, fire protection, and security functions. (CRWMS M\&O 2000a, Attachment II)

Testing for surface facilities will begin after the successful completion of I\&CO tests of the material handling equipment. System testing will verify acceptability of all material handling processes, including:

- Cask preparation

- Cask handling

- Cask and WP handling process including:

- Cask unloading

- Assembly and canister handling

- Assembly staging

- Disposal container handling

- Non-standard waste handling

- Welding and weld acceptance of WP closure

- WP remediation

- WP placement on transporter

- Secondary waste transfer.

Testing for surface facilities will also include testing of pool water treatment and cooling and decontamination systems, including resin bed functions and associated components. Cranes and lifting or material transport devices will also be tested to demonstrate that they do not lose control of the load if power is lost while the load is in transport. Specifically, tests will demonstrate that the devices will bring the load to a safe, controlled halt given a power loss. Testing will be directly observed, but operations that will normally be controlled remotely will be controlled remotely during testing. Instrumentation necessary for the remote operation of handling processes will be tested to ensure that it works as designed and that the design is adequate for the activities being performed.

Testing must not only demonstrate an adequate interface between facilities, but must also ensure that interfaces are operational between key facility subsystems that control the processes listed above. Integration testing for each facility will also ensure that mechanical and electrical systems used to control personnel access for radiological or security reasons function as intended. Radiation monitoring instruments and alarms will be tested to ensure that they function as designed, that personnel radiological dose limits will not be exceeded, and that as low as is reasonably achievable (ALARA) goals can be implemented. The applicable heating, ventilation, and air conditioning systems (HVAC) will be tested to verify their ability to:

- Limit the spread of contamination under normal and abnormal conditions

- Isolate fire zones

- Remove smoke 
- Maintain temperature and humidity requirements.

Testing of the HVAC systems must also demonstrate compliance with fire protection requirements. Testing of these systems will demonstrate their ability to perform their safety functions in the normal mode of operation and under emergency power after a design basis event (DBE) has occurred.

Hardware and software security systems will be tested to ensure their surveillance and protection functions can be performed under normal and abnormal operating conditions and after DBEs. Facility envelope and boundary and isolation devices within the facility, including doors, dampers, and valves, will be functionally tested after their installation. Fire protection SSCs, including those that provide detection, isolation, and suppression functions, will be functionally tested after installation. Power supplies will be functionally tested; including all automatically initiated start functions. Communications systems will be tested to ensure that the data transmission, public address, radio, and telephone systems are fully operational.

Additional description of pre-operational and startup activities are contained in the Standard Review Plan for Spent Fuel Dry Storage Facilities (NRC 2000, pp. 10-9, 10-10, 10-16, and 1017) and Standard Review Plan for Dry Cask Storage Systems (NRC 1997).

\subsubsection{Subsurface Facilities Testing}

Subsurface facility testing will be conducted for each emplacement drift panel and for the South Portal facilities. Testing will ensure safe emplacement operations and proper functioning of instrumentation, local monitoring, environmental control, radiological protection, air filtration, security, and fire protection systems. Testing for the subsurface facilities will include testing to ensure that doors and barriers function properly. Proper functioning of doors and barriers is necessary to isolate areas in the subsurface facilities from each other to minimize the spread of contamination and prevent unplanned access to radiological areas, and to isolate the subsurface facilities from the surface environment. This testing includes remote operation of doors and barriers for both normal and abnormal conditions.

The transporter and the locomotives must demonstrate their ability to operate in the subsurface facilities. This testing will be directly observed, but operations that will be controlled remotely in normal and abnormal operations will be controlled remotely during testing. Instrumentation necessary for the remote operation of locomotives, WP transporters, and gantries will be tested to ensure that they work as designed and that the design is adequate for the activities performed. For a description of system functions and design criteria, see the Waste Emplacement/Retrieval System Description Document (BSC 2001c, Section 1).

Radiation monitoring instrumentation and alarms will be tested to ensure that ALARA goals and radiological protection and isolation criteria are met. Air supply filter systems will be tested to ensure bypass and flow filtration efficiency requirements are met. HVAC systems must demonstrate their ability to meet fire protection requirements. Testing will demonstrate the ability of these systems to perform as designed under normal operational conditions and under emergency power after DBEs have occurred. Each time the configuration of the subsurface facility is changed by adding a new emplacement drift panel, the ventilation system will be 
re-tested to ensure it meets all applicable flow and isolation requirements. Testing will confirm that airflow paths will control airborne contaminants and demonstrate that no air flows from the emplacement side to the construction side of the facility. For a description of system functions and design criteria, see the Subsurface Ventilation System Description Document (BSC 2001a, Section 1).

Subsurface facilities testing will ensure that mechanical and electrical systems used to control personnel and material access for radiological or security reasons are functioning properly. Hardware/software security functions will be tested to ensure their surveillance and protection functions can be performed under normal and abnormal operating conditions and after DBEs. Radiological and fire protection SSCs, including those that provide detection, alarm, isolation, and suppression functions as appropriate, will be functionally tested after installation. Power supplies and distribution systems will also be functionally tested. For a description of system functions and design criteria, see the Monitored Geologic Repository Operations Monitoring and Control System Description Document (CRWMS M\&O 2000b, Section 1).

\subsubsection{Integration}

Overall integration testing for the surface and subsurface facilities will begin after the successful completion of system testing of the major facilities and will precede cold startup testing. A facility readiness review will be conducted (see Section 3.1.3) transferring facility operations from the management and operating contractor to the operating staff. The operating staff will have responsibility for the conduct of integration and subsequent test activities with the management and operating contractor assuming a support role. This will provide permanent operating staff practical experience in the operations and maintenance of SSCs. This will also serve to:

- Run in new equipment to detect and correct any design, manufacturing, or installation defects before startup activities.

- Provide baseline test and operating data on SSCs (with emphasis on those classified as important to safety and waste isolation) for future reference during startup activities and operations.

Integration test activities include instrumentation and control (I\&C), DBE recovery, and integrated cold startup testing.

\subsubsection{Instrumentation and Control Integrated Testing}

Instrumentation and control (I\&C) integrated testing for the surface facilities will begin after the testing and turnover of the major facilities. Subsurface facility integration testing will begin after turnover of the first emplacement drift panel and of the south portal facilities. I\&C testing will precede DBE recovery and integrated cold startup testing (see Sections 2.5.2.2 and 2.5.2.3). I\&C testing will demonstrate proper functioning of instrument and system controls in different combinations of logic and limits. Specific monitoring and control functions to be tested will be identified during the confirmation verification analysis activity described in Section 3.3. For a description of system functions and design criteria, see the Monitored Geologic Repository 
Operations Monitoring and Control System Description Document (CRWMS M\&O 2000b, Section 1).

\subsubsection{Design Basis Event Recovery Testing}

DBE recovery testing validates the proper functioning of safety systems involved in DBEs. This testing also demonstrates cost and schedule viability for recovery from postulated event scenarios. Testing is identified as a result of cost/benefit trade-off checks between event prevention and event recovery in which recovery is selected as the preferred strategy (CRWMS M\&O 1999).

DBE recovery testing will demonstrate event detection capabilities, recovery procedures, and failure recovery. It will also include demonstration of proper functioning of recovery equipment to assure that equipment performs as designed. Individual tests will include drills to verify that procedures and system capabilities work together to meet requirements. Where applicable, requirements for radiological protection criteria, including radiological emergency planning and ALARA radiological guidelines, will be verified. Relevant operational procedures will be updated after the successful completion of these tests

\subsubsection{Integrated Cold Startup Testing}

"Cold testing" will verify the operational readiness of SSCs, procedures, and plans (for example, maintenance plans). Testing will be performed for key operations and procedures involved in receiving, preparing, emplacing, and moving waste (i.e., for recovery or retrieval). Protocols and procedures for offsite communications and interfaces between testing and radiological emergency planning will also be addressed (NRC 2000, Section 10.4.2).

Testing will involve operational and support personnel working with actual operational and support procedures (Curry 2001, Section 2.4). Cold startup is the final pre-operational test before waste receipt and operational startup.

This demonstration will focus on operation of the waste handling system. The waste handling system includes the carrier/cask handling system, the assembly transfer system, the canister transfer system, and the disposal container handling system in the surface facilities and the waste emplacement and retrieval systems in the subsurface facilities. Cold startup testing in the subsurface portion of the repository can begin once that portion of the facility is complete and turned over for testing. Since the subsurface is to be constructed in panels (sections), maximum distances for transportation of WPs will need to be simulated using available access mains and emplacement drifts to satisfy testing requirements.

Support activities will be performed fully in this demonstration, including quality assurance, radiation protection, and safety. Testing will also address some abnormal conditions, such as correcting or rewelding faulty WP welds.

Testing will use mock waste forms simulating the sizes and shapes of waste forms that will be received at the repository, as well as the corresponding WP for each waste form. Mock waste forms will be selected based on initial waste stream requirements. 
Test reports expected from the startup demonstration include the test records, analyses of test data, anomaly reports, a summary account of the test, and conclusions and recommendations concerning readiness to proceed to operational startup.

\subsubsection{Mockup}

As shown in Figure 2-2, mockup testing follows proof of concept prototype testing described in Section 2.3.2 and involves simulation or demonstration with operational realism. This testing activity will serve to maximize test program effectiveness and minimize cost and schedule impacts (see Objective 7 of Section 1.3) by providing alternative test bed support to pre-operational and operational activities, such as:

- Training

- Throughput confirmation test and evaluation support

- Procedure and plan development

- Schedule integration

- SSCs verification for compliance against requirements

- Anomaly resolution

- Modification of SSCs and its impact on design basis

- Facility problem recovery verification (post-modification only).

As illustrated in Figure 2-1 and as shown in Figure 2-2, mockup testing extends into the periodic performance testing and monitoring phase.

\subsubsection{Startup}

To the extent practical, pre-operational testing, as described above, will verify compliance with repository performance requirements to ensure that radiological conditions meet ALARA goals. Operational ("hot") startup testing begins after a license to receive and possess waste is obtained. Startup testing will verify that operation and maintenance systems work properly and will confirm that personnel radiation exposure and radiation levels fall within acceptable regulatory limits during actual repository operations.

As shown in Figure 2-2, operational startup testing begins after the successful completion (and recording) of applicable component and pre-operational test activities. Prior to testing, a startup readiness review (see Section 3.1.3) will ensure that:

1) Component, construction, and pre-operational test activities have been completed.

2) There is a resolution process in place to record and address non-conforming acceptance criteria and other pre-operational problems or design deficiencies.

3) Operation and maintenance procedures, including alarm response, surveillance, and emergency response procedures, have been tested and approved.

4) Radiological controls (e.g., radiation posting, monitoring equipment, spill kits) are in place and are operational. 
5) Construction has been certified as complete and engineering drawings have been entered into the appropriate documentation and control system.

6) Material control and accountability systems are in place, are operational, and show current repository status.

7) Spare parts have been identified and inventoried for availability.

8) Site operational personnel are trained to the currently approved procedures.

9) Fire protection and emergency response systems are in place, personnel have been trained in fire protection and emergency response procedures, and appropriate drills have been performed.

Testing will include the following activities (NRC 2000, Section 10.4.2):

Testing and confirming personnel radiation exposures including:

- Monitoring exposure rates during waste transport, handling, and emplacement operations (and confirming timelines by comparing them to exposure times established during pre-operational testing).

- Measuring and recording personnel radiation doses during operations.

- Confirming that exposure rates are acceptable and that actual dose rates and personnel radiation exposures agree with predicted levels established by analysis.

- Confirming the accuracy of radiation alarm, instrument, and monitoring systems.

Verifying heat removal features, cooling systems, and expected thermal outputs by:

- Directly monitoring temperatures with auxiliary instruments in spent fuel pool and WP interfaces (e.g., gantry lifting mechanism and emplacement drift support structure) and confirming that temperatures are within acceptable ranges.

- Confirming that operations and surveillance equipment can accurately measure, record, and report the status of temperature-related repository functions.

- Confirming operation and calibration of instruments and monitors.

- Confirming thermal outputs of WPs and in-drift thermal loads are within limits. Indrift testing will be continued during the periodic performance testing and monitoring (see Section 2.6). 


\section{Confirming acceptable radiation exposure levels by:}

Measuring and confirming radiation levels by directly monitoring pools, ventilation exhausts (i.e., transfer cell and subsurface ventilation systems), facility shielding, WPs, and surface and subsurface waste handling operations with auxiliary instruments and measuring devices.

\subsection{PERIODIC PERFORMANCE TESTING AND MONITORING}

During emplacement and long-term monitoring, periodic performance testing and repository operational area monitoring will be conducted to ensure continued license operations and to ensure safe working conditions.

\subsubsection{Periodic Performance and Surveillance}

| Periodic performance and surveillance testing will verify that system performance continues to comply with preclosure requirements and ensures continued proper functioning of SSCs important to radiological safety, waste isolation, fire protection, non-nuclear safety, and repository operations. As shown in Figure 2-2, periodic performance testing will begin at the receipt of waste and will continue until closure.

Periodic performance testing and surveillance will accomplish the following (NRC 1997, Section 9):

1) Confirm that pressure differentials, ambient temperatures, and humidity throughout the facilities are maintained within specific regulatory limits under normal conditions and can be maintained after DBEs.

2) Demonstrate that security and personnel access surveillance and controls are maintained.

3) Verify that radiation and alarm SSCs, both central and local, are calibrated and functioning, and that they regularly test exhaust stacks, effluent control systems, continuous air monitors, general area monitors, and the centralized alarm system.

4) Ensure that the areas where high-level radioactive waste is handled or stored are adequately isolated to minimize the potential spread of radioactive contamination.

5) Verify the effectiveness of all radiological effluent control systems.

6) Periodically demonstrate the effective functioning of radiological emergency planning.

7) Maintain the habitability of the control areas during normal conditions and after the occurrence of DBEs.

8) Demonstrate that equipment that lifts, transports, or handles high-level radioactive waste shipping or storage containers, or that performs a safety related function, is 
maintained and load tested such that it can perform its intended function during normal conditions and after the occurrence of DBEs.

9) Verify that SSCs important to fire protection continue to function as required.

10) Verify that emergency power SSCs necessary for facility safety functions, including power distribution equipment or switch gear that perform or support safety functions, will perform as required under both normal and DBE conditions.

Confirmation verification analysis activities described in Section 3.3 will identify hardware and software component and system testing to be conducted periodically or as needed. This testing will verify reliability, maintainability, warranty, operational, and procedural requirements. This testing will also be performed after maintenance and repair activities, per procedural requirements. Results of this testing will support the identification of potential anomalies in SSCs. Testing results will also support the identification and implementation of procedural changes and of necessary upgrades through engineering change proposals.

\subsubsection{Environmental Monitoring}

Monitoring of surface and subsurface environments will be performed to ensure safe working conditions and to document the continuing compliance with existing regulatory standards for air, water, and radiological conditions at the site. This monitoring may include air quality, noise level, and radon testing in various subsurface locations, as well as surface seismic monitoring and monitoring radioactivity levels in surface waste handling areas.

Environmental monitoring will also be performed to evaluate the potential for the occurrence of disruptive events. For environmental monitoring activities for items significant to postclosure performance, these activities will be included in the PC program. Current examples of such PC monitoring (Lindner 2002, Appendix G) include:

- Groundwater Quality. Active monitoring of the uppermost aquifer will be performed using a series of both upgradient and downgradient wells.

- Groundwater Level and Temperature. In coordination with groundwater quality measurements, the in situ temperature and the elevation of the groundwater within wells will be measured and compared to prior measurements to determine potential changes in rock stratigraphy or subsurface flow.

- Surface Uplift. Uplift monitoring will be conducted by periodic precise measurements for the elevation grid of reference points on the surface above the repository horizon.

- Subsurface Seismic. Subsurface seismic monitoring will be conducted to measure the occurrence and magnitude of seismic events at repository depth.

\subsubsection{Post-Emplacement Research and Development}

Although still conceptual, post-emplacement studies and development testing are being considered as potential activities that would provide an opportunity to further evaluate the 
potential for additional defense-in-depth performance and to continue evaluation of natural analogues to increase certainty and confidence in licensing models and very long-term postclosure predictions. Cost effective adjustments to the design that could impact the LA during the post-emplacement period would also be evaluated in this activity.

\subsection{CORE PERFORMANCE CONFIRMATION TESTING}

As mentioned in Section 2.1, the PC program will monitor repository performance, perform tests (where practical), collect data, and analyze and evaluate results in order to assess whether conditions with long-term performance sensitivity will behave as expected. A more detailed description of these postclosure test activities is contained in the Performance Confirmation Plan (Lindner 2002, Appendix G). Information from tests will be used to help provide reasonable assurance that the postclosure total system performance objective will be met. Test results can also be used in performance analysis to reduce uncertainty in the assessment of postclosure performance. Evaluations can include the use of process models and Total System Performance Assessments (TSPAs). As part of the PC program, core test activities will be implemented and include process confirmation and postclosure simulation.

\subsubsection{Process Confirmation}

Process confirmation will monitor and test processes that are identified as important by the licensing strategy and that require confirmation during preclosure period. Process monitoring starts with waste emplacement and focuses on the key factors or processes that may change with time. Specific tests are driven by the important factors of the RSS (CRWMS M\&O 2001, Volume II, Section 4) together with testing to meet regulatory requirements. The current Performance Confirmation Plan (Lindner 2002, Appendix G) identifies several areas of process confirmation monitoring, including:

- Seepage Monitoring: This monitoring evaluates the ambient flow of water into excavations (i.e., seepage) and will also include testing of the seepage threshold concept arising from capillary barrier mechanisms.

- In Situ Waste Package Monitoring: Remotely operated inspection gantries (also termed remotely operated vehicles or ROVs) will be used to conduct remote visual, thermal, and radiological inspection of the WPs, as well as to collect and place material samples or coupons.

- Long-Term Materials Testing: Long-term laboratory studies of the waste form, WP, and drip shield materials are to be conducted to obtain data on various degradation and corrosion phenomena.

- Ventilation Monitoring: The emplacement drift environment will be monitored by sampling the ventilation air that goes into and comes out of each emplacement drift.

- Rock Mass Monitoring: The coupled thermal-mechanical-hydrological response of the rock mass around emplacement drifts will be monitored to confirm the conceptual 
understandings and numerical simulations of coupled processes considered in performance assessments.

- In-Drift Monitoring: To monitor the conditions within emplacement drifts on a continual basis, a limited number of in-drift instrument areas will be installed within emplacement drifts.

- Introduced Materials Monitoring: This monitoring evaluates the impact that introduced materials (e.g., water from construction activities, fire suppression, hydrocarbons, concrete, steel, ground support, and railcars) will have on the postclosure performance of the repository if these materials remain in the repository after closure.

- Recovered Material Coupon Testing: This testing involves the placing of nonradioactive WP material specimens at different locations in the emplacement drifts to expose the specimens to different environmental conditions. The specimens are retrieved after a defined period (using the inspection gantry) for laboratory examination at the surface or at offsite facilities.

- Dummy Waste Package Testing: This activity entails the construction of dummy WPs (which may have internal electrical heaters) of the same external materials, dimensions, and configuration as the real WP but without any radioactive waste. Dummy packages can be retrieved for detailed evaluation if other measurements suggest such evaluations are warranted.

- Recovered Waste Package Testing: In the event of the recovery of a WP for remedial purposes, activities will be defined on a contingency basis to examine and test the WP for potential surface or weld degradation and to section and examine the failed area and the waste.

\subsubsection{Postclosure Simulation}

Postclosure simulation testing will confirm that the measured conditions within a simulated postclosure drift are within the ranges consistent with those assumed in the LA. The testing would be conducted after the start of waste emplacement, allowing for the potential use of actual waste in addition to dummy WPs equipped with heaters. A single test drift will be employed, separated into test sections allowing for the simulation of several different test cases within the single test drift. The postclosure configuration will be constructed in the section with dummy (or actual) WPs, drip shield, backfill (if employed), and will employ expected postclosure technology and equipment. The test sections will be monitored for a period of several decades, and then de-constructed to evaluate barrier response (Lindner 2002, Section 5.3.2 and Appendix G).

As mentioned above and discussed in Section 2.1, PC testing is limited to those activities necessary to comply with regulatory requirements and as a result of NRC licensing conditions, with a specific focus on items important to postclosure safety. The relationship of the PC program to MGR T\&EP test activities is depicted in Figure 2-1. As shown in Figure 2-1, process confirmation and postclosure simulation (see Section 2.7) are conducted solely as part of the PC 
program. Also as depicted in Figure 2-1, the PC program takes advantage of testing performed for multiple reasons or objectives in order to make the most efficient use of time and resources.

\subsection{POSTCLOSURE MONITORING}

Permanent closure of the repository will include closing the subsurface facilities, decontaminating and decommissioning the surface facilities, reclaiming the site, and establishing institutional barriers. As part of the definition of institutional barriers, provisions may be added for post-permanent closure monitoring, as indicated in current regulations (66 FR 55732, 10 CFR 63.51(a)(2)). Post-permanent closure monitoring of the facility would include all monitoring activities conducted around the repository after the facility has been closed and sealed.

Aspects of the post-permanent closure monitoring program would be defined in the future, and would be described in detail in the license amendment submitted to obtain authorization to close the facility. Deferring the detailed definition of this program to the closure period would allow for the use of data from the PC program. It would also allow the identification of the appropriate sensing technology for the program, including technology that may not be currently available.

The test and evaluation, PC, and postclosure monitoring programs will each have specific goals and objectives. However, they will also be designed to be flexible so that DOE can respond to new information acquired as the repository system is observed during and after construction and operation. If any unanticipated conditions are encountered or observed, the monitoring programs will provide a means for assessing their impact, if any, on long-term performance. 


\section{TEST PROGRAM PLANNING AND IMPLEMENTATION}

\subsection{OVERVIEW}

To achieve the objectives stated in Section 1.3 and to comply with the regulations cited in Section 1.4, the MGR test \& evaluation program prescribes a set of test phases described in Section 2 and implements a project-wide integrated approach for test program planning and implementation. Sections 3.2 and 3.3 will discuss the methodology for test program planning and implementation to ensure structure, system, and component (SSC) and total system verification (see Figure 3-1). The intent is to provide a detailed discussion of the near-term test planning and analysis functions for integrated test planning and confirmation verification analysis. Sections 3.1.1 through 3.1.3 refer to Figure 3-1 and tie test planning analysis into the subsequent test function of detailed test planning, conduct, and reporting. A more detailed description of the processes for detailed test planning, conduct, and reporting will be provided to the extent necessary to support the appropriate section of the LA (see Section 3.4) and to the extent reasonable considering the MGR program and design maturity.

\subsubsection{Test Planning Analysis}

As stated in Section 1.4, MGR top-level requirements and project documents will capture the necessary and sufficient codes and regulations for a safe and licensable repository. As shown in Figure 3-1, test planning analysis will consider these top-level requirements and strategy documents to help define overall test program objectives, to identify test activities, and to allocate objectives to the appropriate activities. In turn, the resulting definition/scope of the test program and activities will define programmatic functions and project commitments and will provide input to the appropriate project-level documents.

As depicted in Figure 3-1, proposed tests will undergo integrated test planning analysis in order to optimize test performance in meeting objectives. This will eliminate redundant and unnecessary testing which will minimize cost and schedule impacts of test performance in defined milestones. The integrated test planning activity shown in Figure 3-1 will incorporate project planning to develop a set of integrated test schedules. These schedules will marry test performance with procurement, construction, training, and operations and support activities to minimize the degree of schedule interference and to ensure that licensing and project milestones are met. As noted previously, this effort will also minimize cost impacts in meeting these milestones by identifying similar, redundant, and supportive activities that can be combined and/or phased to optimize project resources. Section 3.2 provides a description of the integrated test planning activity.

The confirmation verification analysis activity depicted in Figure 3-1 provides a consistent and structured methodology for determining which test activity or combination of test activities and analyses will verify nuclear and non-nuclear (i.e., related to environmental, safety, and health) requirements and proper SSC operation. Results of the above analyses will be captured in a confirmation verification matrix (CVM) (see Curry 2001, Table 7-1). 
INTENTIONALLY LEFT BLANK 


\section{Integrated Approach for Product and System Verification}

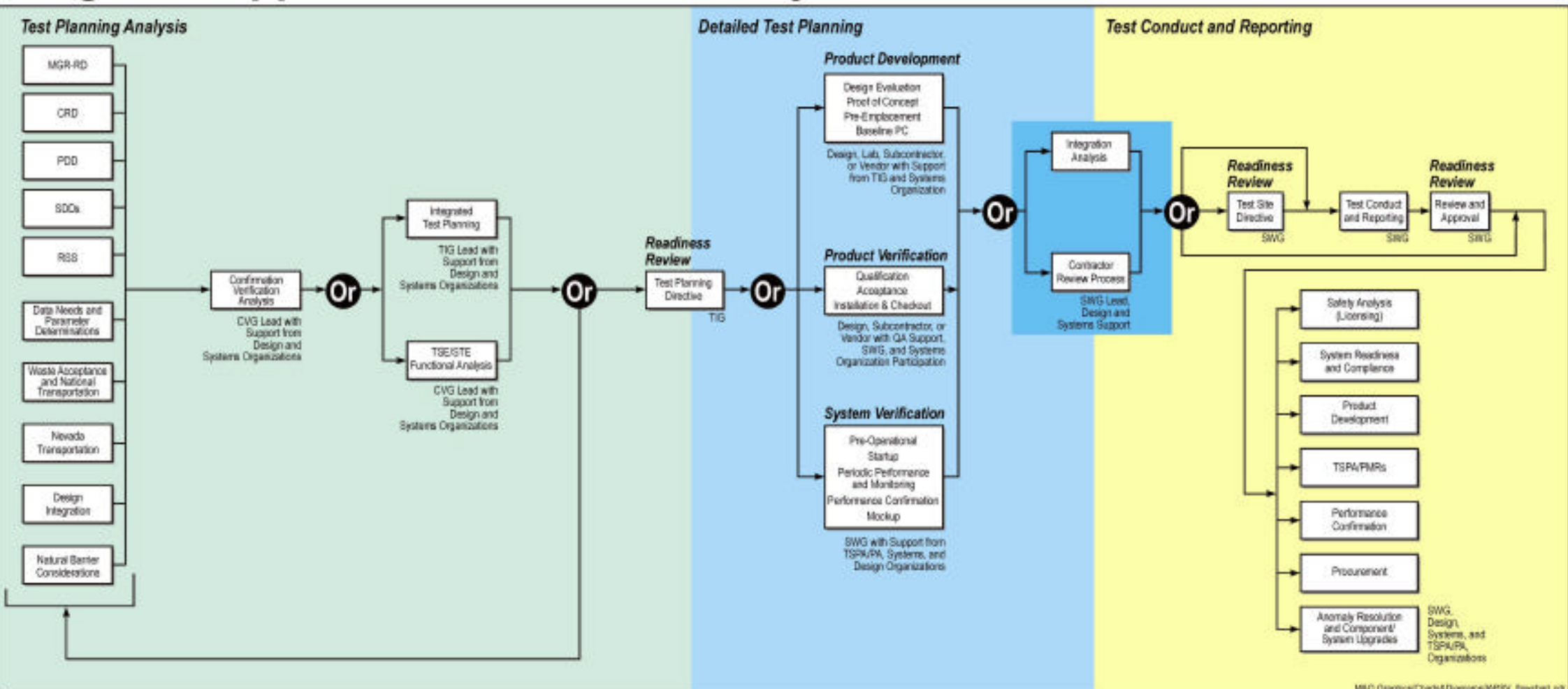




\subsubsection{Detailed Test Planning}

Associated test methodologies and objectives developed during detailed test planning will be tracked on a tiered down version of the CVM. This will comprise the MGR test database (see Section 4.6). The intent is to update this database with test results during the test conduct and reporting (see Figure 3-1). This database will provide test "traceability" to requirements and history for SSC performance as called for by Objective 4 of Section 1.3. The technical data management system (TDMS) is an example of a current database capability for providing update and "traceability" functions. The test database will be made available to support the licensing process, product development, system readiness, and other functions shown in Figure 3-1 (to include maintenance, anomaly identification and resolution, upgrades, and support functions).

\subsubsection{Test Conduct and Reporting}

Figure 3-1 shows several checkpoints where readiness reviews are mandated. These reviews occur prior to detailed test planning and prior to and after test conduct. The purpose of these reviews is to provide continued focus to project/licensing goals and test program objectives stated in Section 1.3. These reviews will also ensure that all test and evaluation functions and test activities (described in this document and depicted in Figure 3-1) are performed under the appropriate QA, ISM, and technical controls as stated in Objective 6 of Section 1.3. Section 3.2 provides a description of test conduct and reporting for system verification activities during the construction and operational phases.

\subsection{INTEGRATED TEST PLANNING}

A well-integrated approach for planning and implementing the overall test program facilitates the effective and efficient use of limited test resources. Opportunities to serve multiple customers and to accomplish multiple objectives with fewer tests are more likely to be identified if testing across the program is well communicated between the testing and customer organizations. Furthermore, the potential for similar or duplicative tests is greatly reduced in a well-integrated test program. A well-integrated approach for identifying and planning potential tests helps ensure consistent application of methodologies and processes and increases the probability that similar results will be derived by different organizations to achieve common objectives. Test integration activities will be conducted in a timely manner to support the annual planning process.

\subsubsection{Implementation}

Test integration is accomplished through a variety of communication approaches and organizational structure concepts; each interrelated to help ensure effective integration of the program. Communication of the test planning and implementation strategy, development process, and execution is conducted formally through documentation in the form of this test program plan, test planning analyses, and technical work planning packages, each of which are developed using various documentation procedures on the project. Planned activities are documented in the form of integrated test schedules that provide input to the project planning schedules. Informal communication is conducted through management briefings presented during the development of the strategy, approach, and processes with more focused 
communication across organizations using cross-functional integrated product teams. The organizational structure necessary to execute a well-integrated test program involves participation from all affected implementing and customer elements across the organization. The current organizational structure and integrated product team concept for doing so is identified in Section 4 .

\subsubsection{Integrated Test Schedules}

Test program development activities, as well as the necessary testing identified through test planning analyses are captured in tiered integrated test schedules (see Section 4.6). The top tier of the schedule provides a template for the major test activities across the program life cycle, while lower tiers provide insight to the timing and duration of specific test phases, and ultimately, individual test activities. The top tier integrated test program schedule is illustrated in Figure 2-2. Preliminary lower tier schedules for near-term test phases have also been developed and are illustrated in the Appendices. Each of these comprises inputs to the overall project schedule and provides a basis for implementing organization activities. As mentioned in Section 3.2 , test integration activities will be conducted in a timely manner to support the annual planning process.

\subsubsection{Test Selection}

Results of the confirmation verification analysis described in Section 3.3 will be used during the integrated test planning to select tests requiring detailed test planning (see Section 4.3). This activity will mostly be performed for the system verification function shown in Figure 3-1 and described in Section 3.4. For product verification activities (i.e., component testing), integrated test planning will identify and ensure that safety and performance test objectives are adequately verified by vendors or subcontractors to ensure operations of SSCs and that adequate test detail and documentation to support the licensing process is developed. This will be accomplished as part of the procurement process during the development of procurement specifications and during the review process depicted in Figure 3-1 and described in Section 3.1.3. Results of this testing will also be tracked in the test database (see Section 3.1.2).

\subsection{CONFIRMATION VERIFICATION ANALYSIS}

Confirmation verification analysis provides a consistent and structured methodology for determining which test activity or combination of test activities will verify nuclear and nonnuclear (i.e., related to environmental, safety, and health) requirements and proper SSC operation. Test working groups comprised of the appropriate test, systems, and design engineers will perform and update these analyses as the design matures (see Sections 4.2 and 4.3). Figure | 3-2 illustrates how confirmation verification matures with a maturing requirements definition and design. 


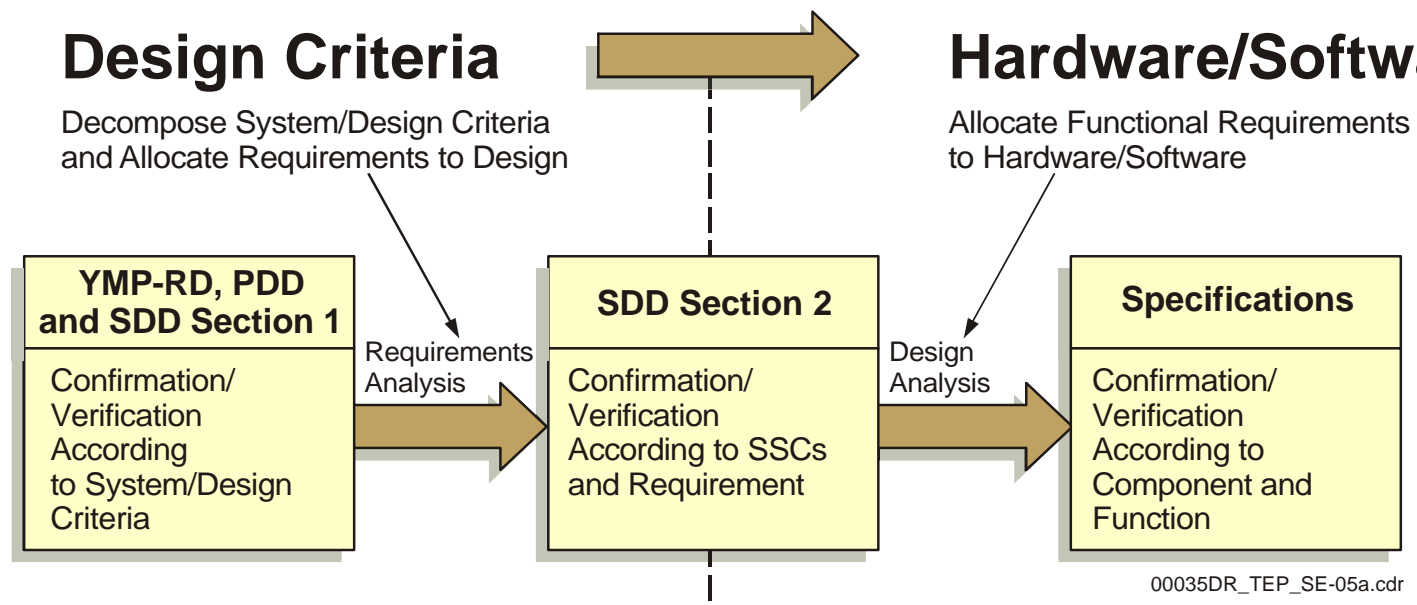

Figure 3-2. Confirmation Verification Process

As shown in Figure 3-1, as the requirement definition process matures, top-level requirements (current requirements captured in the YMP-RD (YMP 2001b), MGR-PDD (Curry 2001) and SDDs) will be decomposed via design analysis into derived requirements. Derived requirements (via confirmation verification analyses) will be assigned a test phase (see Figure 2-1) and verification methodology (see Section 3.3.1) that will be captured in a confirmation verification matrix (CVM) discussed in Section 3.3.1. Appendix A provides criteria for selecting test verification activities in performing near-term confirmation verification analysis. The appropriate test working group will use the criteria and processes provided in Appendix A to select one or more of the different test activities depicted in Figure 2-1 and described in Section 2 of this test plan (see Sections 4.2 and 4.3).

Confirmation verification analyses will also assign to each verification noted on the CVM, test objectives (acceptance criteria) and test methodology. This information will be tracked on a test planning analysis (TPA) form. The CVM and TPA will support the integrated test planning (see Section 3.2) by identifying similar, redundant and supportive test activities that can be combined and/or phased to optimize project resources. As mentioned in Section 3.2.3, the results of confirmation verification analysis (i.e., TPA) will be used to select test methodologies requiring detailed test planning. As the design process matures (see Figure 3-2), functional requirements will be allocated to all SSCs. CVMs will now track verification according to hardware/software | (i.e., SSCs). The Q-List (YMP 2001a) will identify those SSCs that are part of the licensed facility and that have been identified for application of the Office of Civilian Radioactive Waste Management Quality Assurance (QA) program. The Q-list (YMP 2001a) will also identify the quality level of an SSC, which is a measure of QA commensurate with an item's importance to safety or waste isolation that is evaluated in a classification analysis.

The quality level will be used to establish the level of design, procurement, construction, and maintenance requirements, procedural controls, and test requirements, which will be applied to these SSCs using a graded approach (see Section 3.3.3). Test working groups comprised of the appropriate test, systems, and design engineers will utilize these controls as inputs to confirmation verification analysis for Q-list (YMP 2001a) items (see Sections 4.2 and 4.3). As 
shown in Figure 3-2, the results of confirmation verification analysis will be used in procurement specifications to indicate component testing (see Section 2.4).

As depicted in Figure 3-1, test functional analysis will identify component testability requirements to be incorporated into the appropriate SDD design criteria. This analysis will also identify requirements for test support equipment (TSE) and special test equipment (STE) (to include software) that will be put under configuration management and subject to baseline control. This analysis will be performed during the requirements and design analysis functions depicted in Figure 3-2.

\subsubsection{Confirmation Verification Matrix}

The CVM (Curry 2001, Table 7-1) represents the format and detail for near-term TPA activities. The objectives of the confirmation verification planning activity are to:

- Support YMP-RD (YMP 2001b) and MGR-PDD (Curry 2001) development by providing confirmation verification of design criteria (see Figure 3-2).

- Identify MGR system-level requirements and proposed near-term (i.e., prior to LA) design analysis to verify these requirements (see Appendix B).

- Support the requirement allocation process by identifying criteria that require decomposition in order to facilitate verification (see middle box of Figure 3-2).

Verification of design criteria will be according to test phases. The design criteria comes from the MGR-PDD (Curry 2001, Section 5). Each criterion may be verified during one or more test phases. However, only one (i.e., the primary) verification methodology is selected for a given test phase (see Curry 2001, Table 7-1). Verification will be accomplished by the following methodologies: Analysis (A); Examination (E); Demonstration (D); and Test (i.e., functional test) $(\mathrm{T})$. These methodologies are described below:

- Analysis: Analysis is the process of accumulating results and conclusions intended to verify that a requirement has been satisfied. Analytical verification of compliance may include compilation and interpretation of results of tests, demonstrations, and examinations of lower-level components of the system. Analysis may also include logical arguments, modeling, calculations, trade-off studies, reports (design and/or trade-off), and other relevant information to verify compliance with a requirement, when physical testing of a system is impracticable.

- Examination: Examination is the process of conducting careful observation and inspection, without use of special laboratory appliances and procedures, to verify compliance with specified requirements. Examination is a relatively direct method, involving, at most, simple physical manipulation or measurement. It is generally nondestructive and does not necessarily involve operation of the system being evaluated.

- Demonstration: Demonstration is the qualitative process of displaying or operating a system or item in or near its operational environment to verify compliance with 
requirements. It differs from testing in that it is generally a qualitative and direct determination of the performance of a function and is performed without special instrumentation or other special equipment.

- Test: Test is the quantitative process whereby data are collected, under controlled conditions, to document the performance of a product with respect to a standard. Manipulation and analysis of data derived from testing is an integral part of the method. Special instrumentation and scientific procedures are commonly employed. A test may be conducted in a laboratory or in the field (in situ).

As mentioned in Section 3.1.2, associated test methodologies and acceptance will be tracked on a tiered down version of the CVM. This will comprise the MGR test database. The intent is to update this database with test results of the activities shown in Figure 2-1. This database will provide test "traceability" to requirements and history for SSC performance. It will be made available to support the licensing process and operations (to include maintenance, anomaly identification and resolution, upgrades, and support functions).

\subsubsection{Test Planning Analysis Record}

Test Planning Analysis (TPA) records will be created to support near-term activities. The information contained in the records will track criteria from the CVM (Curry, Table 7-1) and will record the following information::

- Requirement: The criteria as stated in the requirements document including the applicable revision and number identification. Enough document identification information shall be provided to ensure traceability.

- Test Phase: The test phase selected to verify the requirement. Also entered is the test phase objective that was used to match to the requirement and select the test phase. Processes and guidelines for selecting which test phase or multiple test phases should be used for verifying a requirement is provided in Appendix A. These provide a uniform and consistent set of selection criteria that will be used by the test working groups (see Sections 4.2 and 4.3) to perform confirmation verification analysis. Selection criteria are closely tied to ensuring verification of safety requirements and operational readiness. These criteria will be updated to reflect requirement definition, design maturity, and CVM detail required to support the product and system verification process depicted in Figure 3-1 and described in Section 3.4.

- Test Requirement: The test objective to be met ensuring that the requirement is verified. The test requirement will identify and quantify (if possible) functions, variables, and processes that need to be tested or demonstrated. For SSCs important to safety, test requirements are synonymous to licensing acceptance criteria that will be provided in the LA.

- Test Methodology: Captures and provides a top-level description of the methodology used to verify the requirement. The test methodology will identify a particular test 
activity within the test phase (see Figure 2-1). Although this is not a detailed test plan, the test requirement described above needs to be visible in the methodology.

\subsubsection{Prototype Test Identification}

The MGR test phase identifies two types of prototype testing to include proof of concept (see Section 2.3.2) and mockup (see Section 2.5.3). Although primarily not intended as verification activities, "prototyping" represents near-term testing, analysis, or demonstrations that support verification by mitigating design and integration risk that may be evident in future component, pre-operational, or periodic testing. Appendix A also provides a methodology for determining the need for prototype testing. As part of the confirmation verification process, prototype testing will be identified and recorded. Appendix $\mathrm{C}$ provides a description of proposed prototype testing to reduce design risk and to support the licensing process.

\subsubsection{Processes and Procedures}

An effective test and evaluation program requires identification of a number of different individual tasks within that program as well as integration of test program interfaces with related program activities, such as design, procurement, and field test implementation. Future revisions of the MGR T\&EP (and subordinate test planning and implementation documents) will address specific processes formalized as procedures to effectively define and coordinate these tasks and interfaces. These processes include:

- Identifying design requirements (e.g., capacities, limitations)

- Specifying design processes (e.g., analyses, specifications, and drawings) to incorporate design requirements into design features (e.g., limit switches, governors, sizing, etc.)

- Identifying safety functions related to the design

- Assuring testability of these safety functions in the design of the SSCs

- Developing a qualification strategy specifying qualification levels for component and/or system testing

- Identifying objectives, acceptance criteria, and methods for testing safety functions

- Specifying test methods to field test organization(s) (e.g., test abstracts or test procedures)

- Scheduling and performance of testing

- Reviewing test results

- Feedback of results to the design organization (potential design modification). 


\subsection{SYSTEM VERIFICATION}

Section 2 discusses the test activities to be conducted during pre-operational, startup, and periodic and performance test phases, with references to a test working organization that would support these future test activities. These test activities are also depicted in Figure 2-1. The following subsections discuss a proposed conduct of operations that would support system verification during these test activities and phases. Product verification (and development) are supported by the near-term test planning analysis activities discussed in Sections 3.2 and 3.3. The purpose of providing a separate, detailed section on system verification is to provide a direct reference for chapters/sections of the LA needed to address the above proposed interim guidance sections.

\subsubsection{Startup Test Working Group}

The Startup Test Working Group (SWG) ensures that startup activities and testing are conducted in an efficient, safe, and timely manner. The SWG is part of the Management and Operating Contractor $(\mathrm{M} \& \mathrm{O})$ or equivalent during the construction phase and is responsible for planning, executing, and documenting pre-operational test activities that occur during construction and prior to the start of MGR operations. The group will consist of individuals from various disciplines and may also include staff from the plant-constructor operations staff, design organizations, vendors, and the DOE. While the SWG will be responsible for observing, recording, and conducting pre-operational testing, the operations staff will be included in as many aspects of these activities as practical. As stated in Section 2.5.2, this will provide the operations staff practical experience in the operations and maintenance of SSCs.

The responsibility for conducting tests will transition to the regular operations staff with the initiation of integration test activities (see Section 2.5.2). After this transition, the SWG will assist in performance, reporting, and anomaly resolution activities as depicted in Figure 3-1. At the completion of startup testing and activities, the SWG will be dissolved and the operations staff will assume responsibility for MGR operations. Transition of responsibilities will be discussed in the Startup Administrative Manual (see Section 3.4.3). Other concerned parties outside the SWG and operations staff, such as the constructor and vendors, will be involved in the testing program to various degrees. Involvement may be in a direct role in the SWG previously, or in an indirect role, offering consultation, or technical direction concerning testing.

\subsubsection{Test Director}

The Test Director reports to the General Manager (or equivalent) of the site management and operating contractor and serves as a member of the SWG. Duties will include:

1) Ensuring that pre-operational and startup test objectives are met

2) Ensuring that tests are sufficiently protective from non-nuclear hazards and comply with environment, safety, and health codes

3) Ensuring that test performance complies with applicable occupational safety and health standards 
4) Ensuring test activities are performed under the appropriate QA, ISM, and technical controls

5) Reviewing and approving test procedures, changes to test procedures, and test results

6) Coordinating test planning, schedules, and support requirements with the site manager (or equivalent)

7) Providing liaison support between site test activities and off-site contractor support to ensure rapid and effective solutions to problems and anomalies that cannot be solved on site

8) Working with DOE test management to facilitate coordination, oversight, and monitoring of startup activities and testing.

\subsubsection{Test Conduct}

The SWG will conduct pre-operational and startup tests in accordance with the Startup Administrative Manual, which contains the administrative procedures and requirements that govern the activities of the SWG and its interfaces with other organizations (see Section 4.6). It describes the pre-operational and startup test phases and establishes the requirements for progressing from one phase to the next, as well as those for moving beyond selected hold-points or milestones within a given phase. The manual also describes how site organizations will coordinate to review and approve test schedules and quickly make changes in construction or testing activities to assist in executing test phases. It establishes the following:

1) Format and content of pre-operational and startup test procedures

2) Review and approval process for initial test procedures and subsequent revisions

3) Review and approval process for test results

4) Resolution process for acceptance criteria failures and other operational problems or design deficiencies

5) Controls governing the tracking of test status and modifications, including retest requirements

6) Qualifications and responsibilities of SWG personnel.

In addition to the Startup Administrative Manual, pre-operational and startup test specifications will also be provided. Test specifications identify individual pre-operational and startup tests, test objectives, test methods, and acceptance criteria, and describe the site conditions that will support test conduct. Startup Administrative Manual and test specifications will be available to the NRC for inspection at the time of LA update to receive and possess waste (see Section 4.6). 
Detailed written procedures will guide the conduct of each pre-operational and startup test. These test procedures will specify:

- $\quad$ Testing prerequisites

- Initial conditions and the methods that will be used to control test performance, including sequencing of tests

- The acceptance criteria that will be used to evaluate test results

- The format for recording data and observations

- Interfacing support system requirements.

Test procedures will be developed and reviewed by personnel with appropriate technical backgrounds and experience. They will receive final approval from the test director and the site management personnel identified in the Startup Administrative Manual. Approved preoperational and startup procedures (see Section 4.6) will be available to the NRC for inspection before their intended use.

\subsubsection{Review, Evaluation, and Approval of Test Results}

Figure 3-1 shows several checkpoints where readiness reviews are mandated. During preoperations and startup, the SWG will conduct readiness reviews to evaluate individual test results. Anomalies from test expectations, predictions, and acceptance criteria will be communicated to the affected and responsible organizations, which will assist in their resolution. DOE management, management and operating contractor, and site operations staff, as appropriate, will also have the opportunity to review test results for conformance to expectations, predictions, and acceptance criteria. The test director and appropriate managers, as defined in the Startup Administrative Manual, have final approval responsibility for test results, including resolution of failures to meet acceptance criteria.

Initial test program results are compiled and maintained according to the Startup Administrative Manual, applicable procedures, and regulatory requirements. Test records that demonstrate the adequacy of SSCs important to safety will be retained for the life of the repository and recorded in the MGR test database (see Section 4.6). Other test records will be retained according to the need to document initial MGR performance characteristics. All test planning, conduct, reporting, and analysis activities will be conducted in accordance with applicable guidance and standards documents.

\subsubsection{Periodic Performance Testing and Monitoring}

The SWG is responsible for initial MGR periodic performance and monitoring test planning activities, including developing operational test specifications and procedures. Test specifications document the test requirements and identify the methods and acceptance criteria used to verify that the requirements have been met; they will be available to the NRC for inspection at the time of LA update to support waste emplacement. Operational test specifications shall include: 
- Operational limits established by technical specifications that have been approved by NRC

- Safety and operational test objectives/requirements derived from confirmation verification analysis (see Section 3.3)

- NRC and Environmental Protection Agency (EPA) environmental monitoring standards for air, water, and radiological considerations

- PC monitoring program (see Section 2.6.2) goals and objectives.

The SWG is also responsible to see that detailed test procedures to implement test methods are developed. The plant operating staff shall conduct periodic and surveillance testing in accordance with approved test procedures and license specifications, and they will record the results. Test records that demonstrate the adequacy of SSCs important to safety will be retained for the life of the repository in the MGR test database (see Section 3.1.2). To the extent practicable, test planning, conduct, reporting, and analysis activities will be conducted in accordance with applicable regulatory guidance, industry standards, and manufacturer recommendations. A detailed description of acceptance criteria and test methodology (including testing periods) will be developed as part of the test specifications and will be available to support the licensing process. 


\section{INTENTIONALLY LEFT BLANK}




\section{TEST MANAGEMENT}

\subsection{INTEGRATED PRODUCT TEAM APPROACH}

More immediate initiatives to facilitate short-term test planning analysis described in Section 3.3 and integration of ongoing tests are already being pursued. These involve test working groups (described in Sections 4.2 and 4.3) whose main purpose is to perform verification analysis and to obtain comprehensive visibility for all of the test planning and test activities across the project. By doing so, these teams can assess the plans and activities for potential disconnects with customer groups and can reduce the probability for duplication between tests.

| Participation and interactions by each of the major organizations listed below helps ensure all test activities are considered:

- Waste Package (WP)

- Repository Subsurface Design

- Repository Surface Design

- Environmental, Safety and Health (ES\&H)

- Science and Engineering Testing.

Interactions with customer organizations (including performance assessment, process modeling, design, and licensing groups) provides a mechanism to ensure customer needs and test objectives are well defined and that tests will be limited to only those necessary and sufficient to satisfy the needs and objectives. Near-term activities focus on design development, prototype, and preemplacement test definition, planning, and execution (see respectively Appendices B, C, and D). Opportunities for improvements or adjustments can be communicated to affected Directors by the team.

The organizations referenced above support the test working groups defined in Sections 4.2 and 4.3. Given the current organizational structure, the test working groups' charter, conduct, and recommendations are developed in an ad hoc manner as resources permit. The conduct of these test working groups precedes more formalized versions of the organizational structure adjustments advocated by this plan.

\subsection{CONFIRMATION VERIFICATION GROUP}

The functions of the Confirmation Verification Analysis Test Working Group (CVG) includes:

- Perform confirmation verification analyses (shown in Figure 3-1) to verify safety requirements and proper SSC operations. The MGR T\&EP (Section 3.3 and Appendix A) provides processes and guidelines for conducting verification analyses and describes the products provided by these analyses such as the CVM. The organizations identified in Section 4.1 provide integrated product team support to the CVG to conduct verification analysis and to review the CVM. As described in Section 3.3, the results of these analyses will also be captured in the MGR-PDD (Curry 2001) and SDDs and will be reflected in the testing specified in procurement specifications. 
- Maintain, refine, and update CVM criteria and methodologies to be used to determine specific test activity or activities that will verify safety and operational requirements. This will be captured in future updates of the MGR T\&EP.

- Use the results of TPA to determine testability requirements and system verification to support the development of system and subsystem-level requirements documents.

- Use the results of TPA to update the system test portion of the TSLCC as needed. Systems Engineering will use the test activities and general TPA to scope work packages for ongoing and future project cost estimates and efforts. The CVG will support the development of a test database that will provide cost factors and historical backup to support cost modeling and costing exercises.

- Perform functional analysis to identify component testability requirements to be incorporated into the appropriate SDD design criteria. This analysis will also identify requirements for test support equipment (TSE) and STE (to include software) that will be put under configuration management and will be subject to baseline control.

- Support the licensing process by providing input and references to sections of the LA and develop supporting documentation for demonstrating compliance with regulations, codes, standards, and licensing requirements and for implementation of safe repository operation. Licensing is represented on the CVG to provide guidance to test planning for safety verification activities and processes.

\subsection{THE TEST INTEGRATION WORKING GROUP}

The functions of the Test Integration Working Group (TIG) are listed below:

- Implement test integration as defined in Section 3.2 in order to optimize test performance in meeting objectives and multiple customer needs (such as PC, Performance Assessment [PA], and Total System Performance Assessment [TSPA]). This will eliminate redundant and unnecessary testing and analyses and will minimize cost and schedule impacts of test performance in meeting defined milestones. The identified organizations provide integrated product team support to the TIG to provide oversight for the MGR test \& evaluation program. The TIG meets as needed to review ongoing and proposed testing and to support readiness reviews. The TIG will review and support the maintenance (i.e., provide input as requested) of the tools and products of this function such as integrated test schedules and the test database.

- Identify/scope testing needed to support risk mitigation of LA issues associated with pre-emplacement test definition, planning, and execution (see Section 2.3.3 and Appendix D).

- Examine design, integration, and operational risk for implementation of safety and performance requirements and propose the appropriate prototype testing to reduce risk and support the licensing process and repository operations. This includes selecting long lead items, setting-up and performing testing, identifying problems and fixes, and 
validating those fixes (see Section 2.3.2 and Appendix C). For the purpose of supporting future MGR updates and near-term project planning, the TIG will identify potential risks and propose candidate prototype testing.

- Identify testing requiring detailed test planning and coordinate with the appropriate design or systems test groups to ensure that testing is planned and implemented in a timely manner. This activity will mostly be performed for the system verification function shown in Figure 3-1.

- Identify the process and interfaces to ensure that detailed test planning and conduct and reporting are performed under the appropriate QA, ISM, and technical controls. The identified organizations will provide integrated product team support to the TIG in supporting the development of quality procedures governing system verification, test conduct, conduct of readiness reviews, and the development of test documentation.

- Provide status on areas related to safety features where further information is required to confirm the adequacy of design (see Section 2.3.2). As a minimum, this status will reflect completed, ongoing, and proposed testing to include test descriptions, period of performance, and results of test performance. This information will be tracked on the MGR test database (see Section 3.1.2).

As noted in Figure 3-1, the CVG and the TIG will work with various organizations (i.e., design, performance assessment, systems, vendors, and national labs) in order to facilitate near-term confirmation verification and integration activities. These product teams will also work with DOE to facilitate coordination, oversight, and monitoring of the various ongoing and proposed tests and analyses, detailed test planning and test conduct, and review and reporting activities, and to ensure the validity of test documentation to adequately support the licensing process and repository operations.

\subsection{TEST INTEGRATION DEPARTMENT}

This department is responsible for the technical integration of science, construction, and design organizations and Science and Engineering Testing operations engaged in field testing at Yucca Mountain. This department is also responsible for laboratory test coordination such as the testing conducted at the Atlas Test Facility.

\subsection{TEST \& EVALUATION/PERFORMANCE CONFIRMATION DEPARTMENT}

The Test \& Evaluation/Performance Confirmation Department is responsible for developing and maintaining the MGR T\&EP and the Performance Confirmation Plan (Lindner 2002). These top-level plans define test program objectives, test planning and implementation processes, and test activities and deliverables. They respectively provide the strategy to confirm that preclosure and postclosure safety goals are met. Both plans will be updated as the design matures to support the licensing process (i.e., providing the approved references to support LA). 
The Test \& Evaluation/Performance Confirmation Department will also develop and maintain the various test tools referenced in the MGR T\&EP such as integrated schedules, test databases, and confirmation verification matrixes.

\subsection{TEST PLANNING, INTEGRATION, AND IMPLEMENTATION TOOLS AND PRODUCTS}

The previous sections of this plan identify various tools and products. These items range from the integrated schedules and CVMs employed by the test working groups to support near-term test planning and integration to startup manuals, procedures, and scoping documents that will be used by the SWG to conduct operational testing. Table 4-1 provides a summary of these tools/documents, identifies the developer and primary user and licensing milestone supported, and describes the time period when the tools/documents are to be developed. Note that the dates shown for a document in the "development period" column refer to the development of a specific version or revision of the document itself and not the associated activities (as in a test plan).

Figure 4-1 provides a document hierarchy showing the relationship of tools/documents identified in the MGR T\&EP and described in Table 4-1. The documents can be conceptualized as part of a test document hierarchy as shown in Figure 4-1. The MGR T\&EP is a controlled document that defines the scope of test and monitoring activities in the context of the program-level OCRWM Test and Evaluation Master Plan (TEMP) (DOE 1995). A dashed connecting line indicates that the TEMP is used for guidance only.

The MGR T\&EP is developed to provide support and guidance for the development of the CVM as well as the PC plan, both of which are shown as sub-tier documents in Figure 4-1. The development of the Plan meets the applicable requirements for the program, as defined in the regulations and applicable project and program requirements documents. The CVM in turn defines the applicable testing that will be incorporated into the Startup Administrative Manual and defines the types of testing that is to be addressed by detailed test procedures and the integrated test schedule. Finally, as test and monitoring activities are performed, analysis and integration summaries will be incorporated into the test databases to provide referenceable documents to support design, licensing, procurement, and construction. 
Table 4-1. Test Products and Tools

\begin{tabular}{|c|c|c|}
\hline SECTION & PRODUCT DESCRIPTION & $\begin{array}{c}\text { DEVELOPMENT } \\
\text { PERIOD }\end{array}$ \\
\hline 1.1 & $\begin{array}{l}\text { MGR Test and Evaluation Plan (Rev 04): Developed and maintained by the } \\
\text { Test Evaluation/Performance Confirmation Department. The MGR T\&EP } \\
\text { provides a detailed description of the test program approach and is used by the } \\
\text { various test working groups to guide the performance of test planning and } \\
\text { integration activities. The MGR T\&EP also defines the strategy to confirm that } \\
\text { preclosure performance and safety goals are met. This plan will be updated as } \\
\text { the design matures to support the licensing process (i.e., providing the approved } \\
\text { references to support LA). }\end{array}$ & $\begin{array}{l}\text { FY 2001-2002 } \\
\text { activity, to support } \\
\text { LA revision with } \\
\text { subsequent } \\
\text { revisions as } \\
\text { necessary. }\end{array}$ \\
\hline 2.3 .4 & $\begin{array}{l}\text { Performance Confirmation Plan (Rev 02): Developed and maintained by the } \\
\text { Test Evaluation/Performance Confirmation Department. The Performance } \\
\text { Confirmation (PC) Plan specifies monitoring, testing, and analysis activities to be } \\
\text { conducted for evaluating the information used in the LA with regard to } \\
\text { postclosure repository safety. This document will be used by systems and } \\
\text { design organizations as a basis for detailed planning of PC program test } \\
\text { activities and as a basis for identification of design requirements in the SDDs for } \\
\text { PC systems. This plan will be updated as the design matures to support the } \\
\text { licensing process (i.e., providing the approved references to support LA). }\end{array}$ & $\begin{array}{l}\text { FY 2001-2002 } \\
\text { activity, to support } \\
\text { LA revision with } \\
\text { subsequent } \\
\text { revisions as } \\
\text { necessary. }\end{array}$ \\
\hline $\begin{array}{l}3.3 .1 \text { and } \\
3.3 .2\end{array}$ & $\begin{array}{l}\text { Confirmation Verification Matrix (CVM): This product and the supporting test } \\
\text { planning analysis records are respectively described in Sections 3.3.1 and 3.3.2. } \\
\text { Development and coordination of the CVM will be the responsibility of the Test } \\
\text { Evaluation/Performance Confirmation department supported by the CVG and will } \\
\text { be performed according to the appropriate quality procedures. The CVM is a } \\
\text { test working group internal document and not a "stand alone" formal document } \\
\text { or deliverable. However, it will be used (i.e., results of analysis incorporated) to } \\
\text { support the development of other products and deliverables such as test } \\
\text { planning analyses summaries (described below), requirement documents, } \\
\text { licensing acceptance criteria (for items important to safety), and procurement } \\
\text { specifications. The CVM will also be used by the TIG to help identify system } \\
\text { verification testing requiring detailed test planning. The CVM will also be used to } \\
\text { develop licensing acceptance criteria for items important to safety provided at } \\
\text { LA. }\end{array}$ & $\begin{array}{l}\text { FY } 2001 \text { activity } \\
\text { that will continue } \\
\text { until construction } \\
\text { authorization (CA). }\end{array}$ \\
\hline 3.1 .2 & $\begin{array}{l}\text { Test Database: Near-term implementation responsibility for the test database } \\
\text { will belong to the Science and Engineering Testing organization. The intent is to } \\
\text { have the SWG assume management responsibility during construction and } \\
\text { operations. As stated in Section 3.1.2, this database will provide test } \\
\text { "traceability" to requirements and history for SSC performance as called for by } \\
\text { Objective } 4 \text { of Section 1.3. It will be made available to support the licensing } \\
\text { process, product development, system readiness, and other functions shown in } \\
\text { Figure } 3-1 \text { (to include maintenance, anomaly identification and resolution, } \\
\text { upgrades, and support functions). Near-term test integration activities will } \\
\text { involve developing an LA test database that will capture test methodologies and } \\
\text { acceptance criteria on a tiered down version of the CVM. Test activity costs will } \\
\text { be incorporated to support ongoing TSLCC efforts. }\end{array}$ & $\begin{array}{l}\text { LA database } \\
\text { development will } \\
\text { begin in FY } 2002, \\
\text { and effort will } \\
\text { continue through } \\
\text { the LA update and } \\
\text { into operations. }\end{array}$ \\
\hline
\end{tabular}


Table 4-1. Test Products and Tools (Continued)

\begin{tabular}{|c|c|c|}
\hline SECTION & PRODUCT DESCRIPTION & $\begin{array}{c}\text { DEVELOPMENT } \\
\text { PERIOD }\end{array}$ \\
\hline 3.2 .2 & $\begin{array}{l}\text { Integrated Test Schedules: Near-term responsibility implementation for the } \\
\text { integrated test schedules will belong to the Science and Engineering Testing } \\
\text { organization and supported by the TIG. The intent is to have the SWG assume } \\
\text { management responsibility during construction and operations. Initial } \\
\text { development of test schedules will be used to support the integrated test } \\
\text { planning effort described in Section } 3.2 \text {. Schedules developed will comprise } \\
\text { inputs to the overall project schedule and provide a basis for implementing } \\
\text { organization activities within the organization. These schedules will support } \\
\text { construction, pre-operational, and operational test phase activities. These } \\
\text { schedules will optimize test performance according to test resources, site } \\
\text { availability, and project milestones. It is anticipated that these will support } \\
\text { construction and repository build-up and will therefore be implemented prior to } \\
\text { CA. Near-term and tiered schedules will support project/licensing planning; } \\
\text { however, they will not be direct inputs/references to the LA or its updates. }\end{array}$ & $\begin{array}{l}\text { FY } 2001 \text { activity } \\
\text { will support } \\
\text { planning and near- } \\
\text { term test } \\
\text { integration. Effort } \\
\text { will build up prior } \\
\text { to construction and } \\
\text { continue through } \\
\text { pre-operations and } \\
\text { operations. }\end{array}$ \\
\hline $\begin{array}{l}\text { 3.4.3 and } \\
3.4 .5\end{array}$ & $\begin{array}{l}\text { Startup Administrative Manual and Test Specifications: Development and } \\
\text { maintenance of these documents will be the responsibility of the SWG. As } \\
\text { described in Sections } 3.4 .3 \text { and 3.4.5, these documents will support pre- } \\
\text { operations and waste emplacement. Test specifications will be provided for } \\
\text { items important to safety that have been identified as the minimal design detail } \\
\text { required for LA. These specifications will identify test requirements, test } \\
\text { methodologies and acceptance criteria and will be developed by the CVG. }\end{array}$ & $\begin{array}{l}\text { FY } 2001 \text { test } \\
\text { planning analysis } \\
\text { will support LA } \\
\text { requirements. The } \\
\text { bulk of the activity } \\
\text { will support pre- } \\
\text { operations. }\end{array}$ \\
\hline $\begin{array}{l}\text { 3.4.3 and } \\
3.4 .5\end{array}$ & $\begin{array}{l}\text { Detailed Test Procedures: As described in Sections } 3.4 .3 \text { and 3.4.5, the SWG } \\
\text { is responsible for the development and coordination of test procedures for pre- } \\
\text { operational and operational test phase activities. Detailed system test planning } \\
\text { is beyond the scope of this test plan and near-term test planning and integration } \\
\text { activities described in this plan. However, as stated in Section 4.3, the TIG has } \\
\text { responsibility for ensuring that appropriate QA processes are in place governing } \\
\text { the development of detailed test procedures, test conduct, and the development } \\
\text { of test documentation. The LA revision of this plan will provide a description of } \\
\text { specific QA, ISM, and technical controls for test program implementation. }\end{array}$ & $\begin{array}{l}\text { The bulk of the } \\
\text { activity will support } \\
\text { pre-operations and } \\
\text { operations. }\end{array}$ \\
\hline 3.1 & $\begin{array}{l}\text { Test Planning Analysis and Integration Summaries: Although not specifically } \\
\text { identified as a product in this test plan, the Science and Engineering Testing } \\
\text { organization will develop summaries of the near-term confirmation verification } \\
\text { and integration efforts described in Section } 3.1 \text {. These summaries will be } \\
\text { documented in analyses and developed by the appropriate QA procedures in } \\
\text { order to provide "referenceable" documents to support design, licensing, } \\
\text { procurement, and construction activities. }\end{array}$ & $\begin{array}{l}\text { FY } 2001 \text { test } \\
\text { planning analyses } \\
\text { and integration } \\
\text { activity. } \\
\text { Subsequent } \\
\text { products to be } \\
\text { developed prior to } \\
\text { applicable test } \\
\text { phase. }\end{array}$ \\
\hline
\end{tabular}




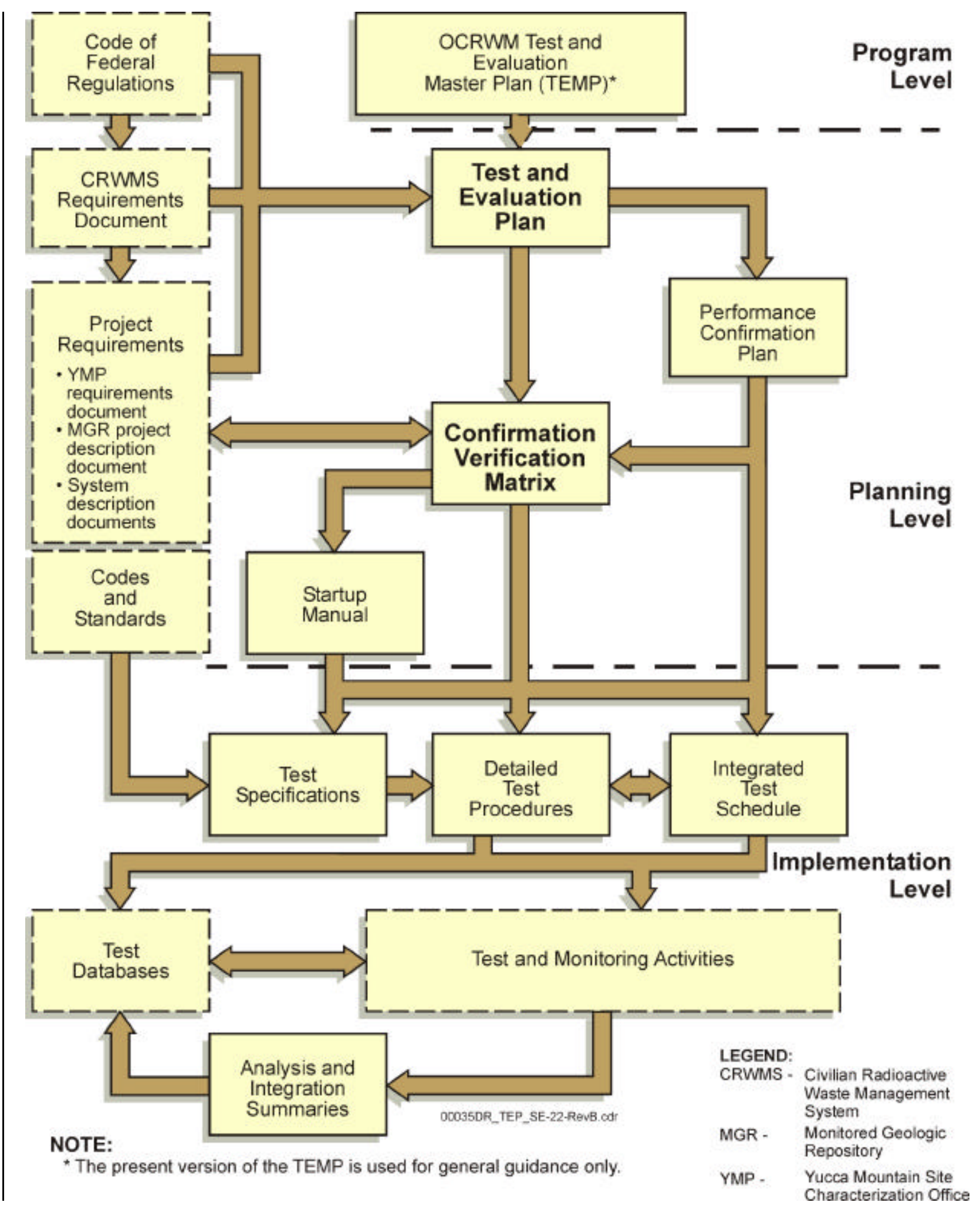

Figure 4-1. Test and Evaluation Program Document Hierarchy 


\section{INTENTIONALLY LEFT BLANK}




\section{CONCLUSIONS AND RECOMMENDATIONS}

The current version of the MGR T\&EP incorporates a set of test phases and activities focused on ensuring repository safety and operational readiness and implements a project-wide integrated product management team approach to facilitate test program planning, analysis, and implementation. In addition, Appendix A of the MGR T\&EP provides criteria for selecting test phases and activities to ensure that the MGR performs as designed and that the barriers perform as expected. Future revisions of the MGR T\&EP will contain the detail necessary to support the appropriate sections of the LA.

An effective test and evaluation program requires identification of a number of different individual tasks within that program as well as integration of test program interfaces with related program activities, such as design, procurement, and field test implementation. Future revisions of the MGR T\&EP (and subordinate test planning and implementation documents) will address specific processes formalized as procedures to effectively define and coordinate these tasks and interfaces. These processes include:

- Identifying design requirements (e.g., capacities, limitations)

- Specifying design processes (e.g., analyses, specifications, and drawings) to incorporate design requirements into design features (e.g., limit switches, governors, sizing, etc.)

- Identifying safety functions related to the design

- Assuring testability of these safety functions in the design of the SSCs

- Developing a qualification strategy specifying qualification levels for component and/or system level testing

- Identifying objectives, acceptance criteria, and methods for testing safety functions

- Specifying test methods to field test organization(s) (e.g., test abstracts or test procedures)

- Scheduling and performance of testing

- Reviewing test results

- Feedback of results to the design or user organization (potential design modification or model adjustments). 


\section{INTENTIONALLY LEFT BLANK}




\section{REFERENCES}

\subsection{DOCUMENTS CITED}

Anderson, W. 2001. Integrated Safety Management Description Document. PGM-CRW-AD000001 REV 01. Las Vegas, Nevada: Bechtel SAIC Company. ACC: MOL.20010921.0045.

BSC 2001(Bechtel SAIC Company) a. Subsurface Ventilation System Description Document. SDD-SVS-SE-000001 REV 01 ICN 01. Las Vegas, Nevada: Bechtel SAIC Company. ACC: MOL.20010927.0072.

BSC 2001b. Technical Work Plan for: MGR Test and Evaluation Plan. TWP-MGR-SE-000001 REV 01. Las Vegas, Nevada: Bechtel SAIC Company. MOL.20011119.0335

BSC 2001c. Waste Emplacement/Retrieval System Description Document. SDD-WES-SE000001 REV 01 ICN 01. Las Vegas, Nevada: Bechtel SAIC Company. ACC:

MOL.20011001.0107.

CRWMS M\&O (Civilian Radioactive Waste Management System Management and Operating Contractor) 1997. Mined Geologic Disposal System Viability Assessment Test and Evaluation Plan. B00000000-01717-5705-00058 REV 00. Las Vegas, Nevada: CRWMS M\&O. ACC: MOL.19980106.0012.

CRWMS M\&O 1998a. Monitored Geologic Repository Test and Evaluation Plan. B0000000001717-5705-00058 REV 02. Las Vegas, Nevada: CRWMS M\&O. ACC: MOL.19980729.0006.

CRWMS M\&O 1998b. Viability Assessment Mined Geologic Disposal System Test and Evaluation Plan. B00000000-01717-5705-00058 REV 01 DCN 1. Las Vegas, Nevada:

CRWMS M\&O. ACC: MOL.19981120.0025.

CRWMS M\&O 1998c. Waste Handling Equipment Development Test and Evaluation Study. BCBD00000-01717-5705-00007 REV 00 DCN 1. Las Vegas, Nevada: CRWMS M\&O. ACC: MOL.20000811.0008.

CRWMS M\&O 1999. Strategy for Recovery from High Risk Off-Normal Events. BC000000001717-5705-00023 REV 00. Las Vegas, Nevada: CRWMS M\&O. ACC:

MOL.20000306.0250.

CRWMS M\&O 2000a. Engineering Files for Site Recommendation. TDR-WHS-MD-000001 REV 00. Las Vegas, Nevada: CRWMS M\&O. ACC: MOL.20000607.0232.

CRWMS M\&O 2000b. Monitored Geologic Repository Operations Monitoring and Control System. SDD-OMC-SE-000001 REV 00 ICN 01. Las Vegas, Nevada: CRWMS M\&O. ACC: MOL.20000807.0085

CRWMS M\&O 2000c Technical Work Plan for: MGR Test \& Evaluation Plan. TWP-MGR-SE000001, REV 00. Las Vegas, Nevada: CRWMS M\&O. ACC: MOL.20000913.0076. 
CRWMS M\&O 2001 Repository Safety Strategy: Plan to Prepare the Safety Case to Support Yucca Mountain Site Recommendation and Licensing Considerations. TDR-WIS-RL-000001, REV 04 ICN 01. Two volumes. Las Vegas, Nevada: CRWMS M\&O. ACC:

MOL.20010329.0825.

Curry, P.M. 2001. Monitored Geologic Repository Project Description Document. TDR-MGRSE-000004 REV 02 ICN 02. Las Vegas, Nevada: Bechtel SAIC Company. ACC:

MOL.20010628.0224.

DOE (U.S. Department of Energy) 1995. OCRWM Test and Evaluation Master Plan (TEMP), Revision 0. DOE/RW-0478. Washington, D.C.: U.S. Department of Energy, Office of Civilian Radioactive Waste Management. ACC: MOV.19970203.0017.

DOE 1998. Viability Assessment of a Repository at Yucca Mountain. DOE/RW-0508. Washington, D.C.: U.S. Department of Energy, Office of Civilian Radioactive Waste Management. ACC: MOL.19981007.0027; MOL.19981007.0028; MOL.19981007.0029; MOL.19981007.0030; MOL.19981007.0031; MOL.19981007.0032.

| DOE 2000. Quality Assurance Requirements and Description. DOE/RW-0333P, Rev. 10. Washington, D.C.: U.S. Department of Energy, Office of Civilian Radioactive Waste Management. ACC: MOL.20000427.0422.

DOE 2001a. Civilian Radioactive Waste Management System Requirements Document. DOE/RW-0406, Rev. 5 DCN 04. Washington, D.C.: U.S. Department of Energy, Office of Civilian Radioactive Waste Management. ACC: MOL.20010628.0243.

DOE 2001b. Yucca Mountain Science and Engineering Report. DOE/RW-0539, Washington, D.C.: U.S. Department of Energy, Office of Civilian Radioactive Waste Management. ACC: MOL.20010524.0272.

Lindner, E. N. 2002. Performance Confirmation Plan. TDR-PCS-SE-000001 REV 01 ICN 02. Las Vegas, Nevada: Bechtel SAIC Company. TBV-5055

Sellers, M.D. 2000. “AP-2.21Q Evaluation for Activities within Work Package 16412235M1, MGR Test \& Evaluation Plan," Interoffice Correspondence from Mark D. Sellers (CRWMS M\&O) to Distribution (CRWMS M\&O), August 31, 2000, with enclosure. ACC: MOL.20000901.0118; ACC: MOL.20000901.0119 (enclosure).

YMP 2001 (Yucca Mountain Site Characterization Project)a. Q-List. YMP/90-55Q, Rev. 7. Las Vegas, Nevada: Yucca Mountain Site Characterization Office. ACC: MOL.20010409.0366.

YMP 2001b. Yucca Mountain Site Characterization Project Requirements Document (YMP$R D)$. YMP/CM-0025, Rev. 4, DCN 02. Las Vegas, Nevada: Yucca Mountain Site Characterization Office. ACC: MOL.20010322.0491; MOL.20011107.0002. 


\subsection{CODES, STANDARDS, REGULATIONS, AND PROCEDURES}

66 FR 55732. Disposal of High-Level Radioactive Wastes in a Proposed Geologic Repository at Yucca Mountain, NV. Final Rule 10 CFR Part 63.

AP-2.14 Q, Rev. 2, ICN 0. Review of Technical Products and Data. Washington, D.C.: U.S. Department of Energy, Office of Civilian Radioactive Waste Management.

ACC: MOL.20010801.0316.

| AP-3.11Q, Rev. 1, ICN 1. Technical Reports. Washington, D.C.: U.S. Department of Energy, Office of Civilian Radioactive Waste Management. ACC: MOL.20000714.0549.

| AP-3.11Q, Rev. 2, ICN 0. Technical Reports. Washington, D.C.: U.S. Department of Energy, Office of Civilian Radioactive Waste Management. ACC: MOL.20010405.0010.

| AP-3.15 Q, Rev. 3, ICN 0. Managing Technical Product Inputs. Washington, D.C.: U.S. Department of Energy, Office of Civilian Radioactive Waste Management. ACC: MOL.20010801.0318.

| AP-6.1Q, Rev. 6, ICN 1. Controlled Distribution. Washington, D.C.: U.S. Department of Energy, Office of Civilian Radioactive Waste Management. ACC: MOL.20011119.0331.

| NLP-2-0, Rev. 5, ICN 4. Determination of Importance Evaluations. Las Vegas, Nevada: Bechtel SAIC Company. ACC: MOL.20010801.0317.

NRC (U.S. Nuclear Regulatory Commission) 1997. Standard Review Plan for Dry Cask Storage Systems. NUREG-1536. Washington, D.C.: U.S. Nuclear Regulatory Commission. TIC: 232373.

NRC 2000. Standard Review Plan for Spent Fuel Dry Storage Facilities. NUREG-1567. Washington, D.C.: U.S. Nuclear Regulatory Commission. TIC: 247929. 


\section{INTENTIONALLY LEFT BLANK}


APPENDIX A

\section{VERIFICATION CRITERIA}




\section{CONTENTS}

Page

A1. DESIGN EVALUATION TESTING …............................................................ A-2

A2. PROOF OF CONCEPT PROTOTYPE TESTING ................................................. A-3

A3. PRE-EMPLACEMENT TESTING ..................................................................... A-4

A4. BASELINE PERFORMANCE CONFIRMATION TESTING ............................... A-7

A5. COMPONENT LEVEL TESTING …............................................................... A-9

A6. COMPONENT LEVEL TESTING - INSTALLATION AND CHECKOUT ............. A-11

A7. PRE-OPERATIONAL TESTING - SYSTEM AND INTEGRATION ..................... A-12

A8. PRE-OPERATIONAL TESTING - STARTUP TESTING ….............................. A -13

A9. DESIGN BASIS EVENT RECOVERY TESTING …........................................... A-14

A10. MOCKUP PROTOTYPE TESTING ................................................................. A-15

A11. PERIODIC PERFORMANCE AND SURVEILLANCE TESTING ........................ A-16

A12. ENVIRONMENTAL MONITORING …........................................................ A-17

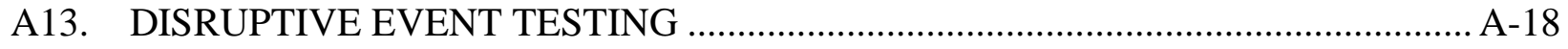

A14. PROCESS CONFIRMATION TESTING …................................................... A-19

A15. POSTCLOSURE SIMULATION TESTING ....................................................... A-21 


\section{APPENDIX A \\ VERIFICATION CRITERIA}

Appendix A provides criteria for selecting test verification activities in performing near- term confirmation verification analysis as described in Section 3.3 of the MGR T\&EP. The appropriate test working group will use the criteria, processes, and methodologies provided in Appendix A as guidance for developing more specific tests for one or more of the different test activities depicted in Figure 2-1 and described in Section 2 of this test plan. The intent is to update the material provided in Appendix A as a result of maturing design and requirements definition and test planning analysis activities. 


\section{A1. DESIGN EVALUATION TESTING}

As depicted in Figure A-1, design development testing and analysis will support the design development process by investigating potential or alternative design solutions or technologies, confirming design concepts, and investigating the availability of needed technology. The appropriate design group will identify design development testing. The integrated test planning activity described in Section 3.2 will ensure a consistent application of test methodologies across the project. This will reduce the potential for similar or duplicative testing.

Also as depicted in Figure A-1, design evaluation testing and analysis will also support confirmation verification by performing test and analysis of requirements that are not visible or cannot be easily confirmed in other test phases. As a risk mitigation effort, testing and analysis will also be conducted to ensure that planned verification activities in future test phases are successful.

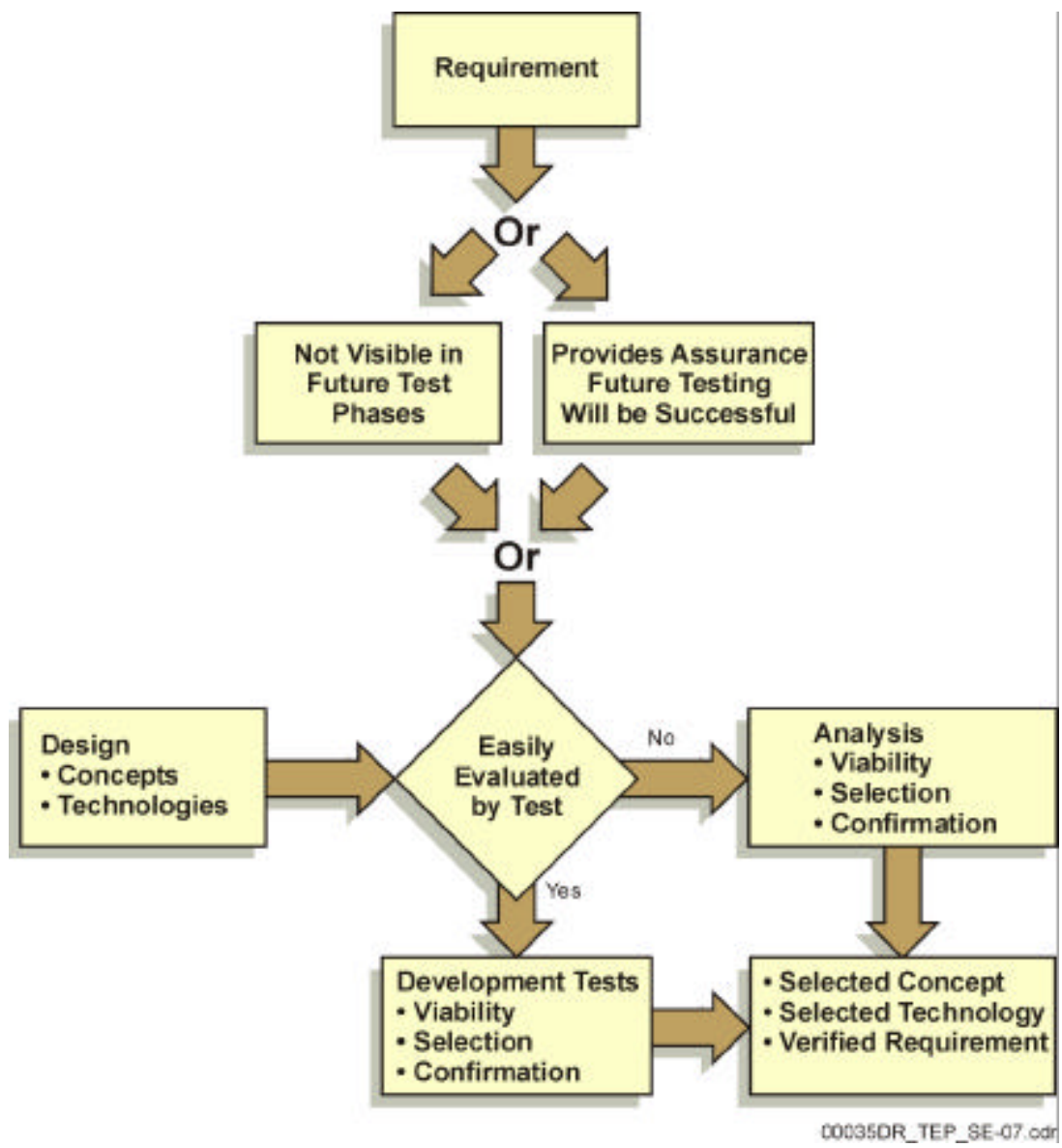

Figure A-1. Design Evaluation Requirements Verification Testing 


\section{A2. PROOF OF CONCEPT PROTOTYPE TESTING}

Proof of concept prototype testing (see Section 2.3.2) follows the design evaluation test activities described in Section 2.3.1 and precedes the release of final design packages. Testing is conducted (see Figure A-2) for the following cases:

1. New technologies or design solutions that have little or no history of use at existing nuclear facilities or power plants

2. New applications of existing technologies or complex systems that may introduce schedule risk.

Proof of concept testing is performed for any SSC (i.e., non-nuclear as well as nuclear) where significant design risk is present. Candidates for proof of concept testing are identified as a result of assessing schedule risk for integrating new applications and complex systems and the cost and time to recover from anticipated problems.

The particular scenario in Figure A-2 indicates that we cannot reasonably recover from a problem encountered during system integration testing and still maintain schedule. This would suggest the need for prototype testing to ensure that the problem does not occur during integration testing. High-complexity systems, new technology, or applications of existing technologies in new ways suggest higher probabilities of problems during system integration tests if prototype testing were not pursued early in the process (i.e., before final design and procurement).

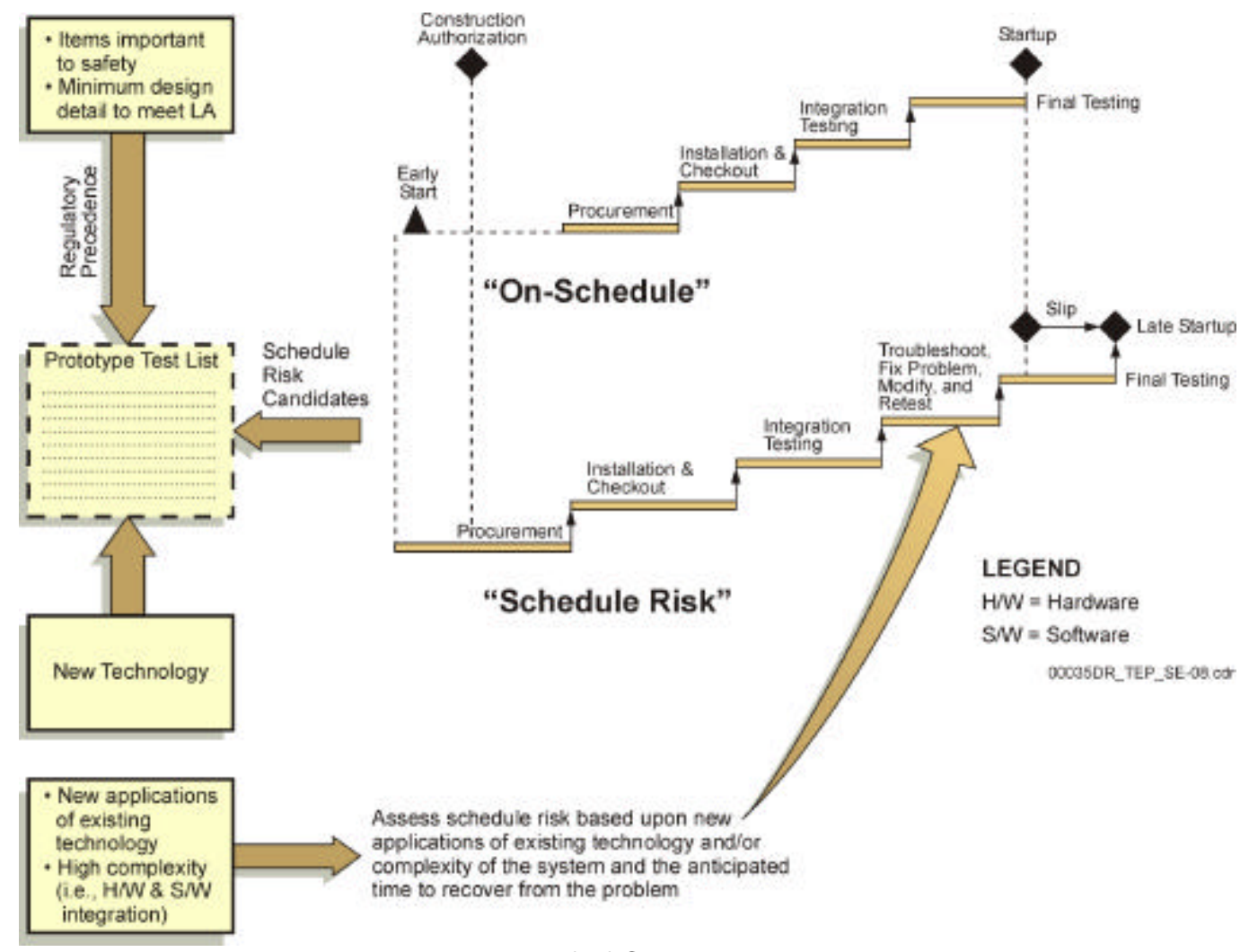

Figure A-2. Proof of Concept Testing 


\section{A3. PRE-EMPLACEMENT TESTING}

The general process flow for determining pre-emplacement tests to be performed after SR and prior to emplacement is illustrated in Figure A-3 and is explained as follows:

1. Process inputs consist of AMRs, PMRs, and the current design assumptions.

2. Inputs are evaluated using TSPA to determine important model parameters and significant design assumptions that influence postclosure performance.

3. The RSS (CRWMS M\&O 2001) evaluates important model parameters and significant design assumptions and establishes a viable safety strategy that ensures, with reasonable assurance, the safety of the public. This, in turn, provides a regulatory framework to guide further model development and to assess the importance of additional data collection activities.

4. The AMRs, PMRs, and current design concept are available during review using the AP2.14Q, Review of Technical Products and Data, process; transmitted using the AP-3.15Q, Managing Technical Product Inputs, process, or by formal distribution using the AP6.1Q, Controlled Distribution, process.

5. Residual model data needs, validation requirements, potential vulnerabilities, and significant design assumptions are evaluated in the context of the priorities established by TSPA and the RSS (CRWMS M\&O 2001). Potential enhancements to the repository safety case are also identified for potential development.

6. Candidates identified in item 5 above are then evaluated for testability within the confines of licensing strategy, approach, timelines, and budget constraints, as well as the system development schedules to determine if testing is warranted or should be pursued. This could necessitate adjustments to the safety strategy.

7. Additional interactions between the NRC and DOE on key technical issues and the licensing strategy itself may identify additional testing requirements to resolve residual NRC safety concerns.

8. Testing identified by items 6 or 7 include tests that may require completion prior to waste emplacement, but may also include tests that are initiated, yet extend beyond, the start of emplacement. Portions of these tests and information obtained during the preemplacement period are assigned to the pre-emplacement test activity. Portions of the pre-emplacement tests that are important to postclosure performance will be described and developed in more detail as part of the PC program. Testing that continues beyond 
the pre-emplacement period is considered by the process confirmation test activity (part of the PC program) if it pertains to postclosure sensitive items. Otherwise, such testing will be considered as potential candidates for post-emplacement research and development. For instance, testing pertaining to potential enhancements to the safety case that continue beyond initial emplacement would be considered by the postemplacement research and development test activity. 


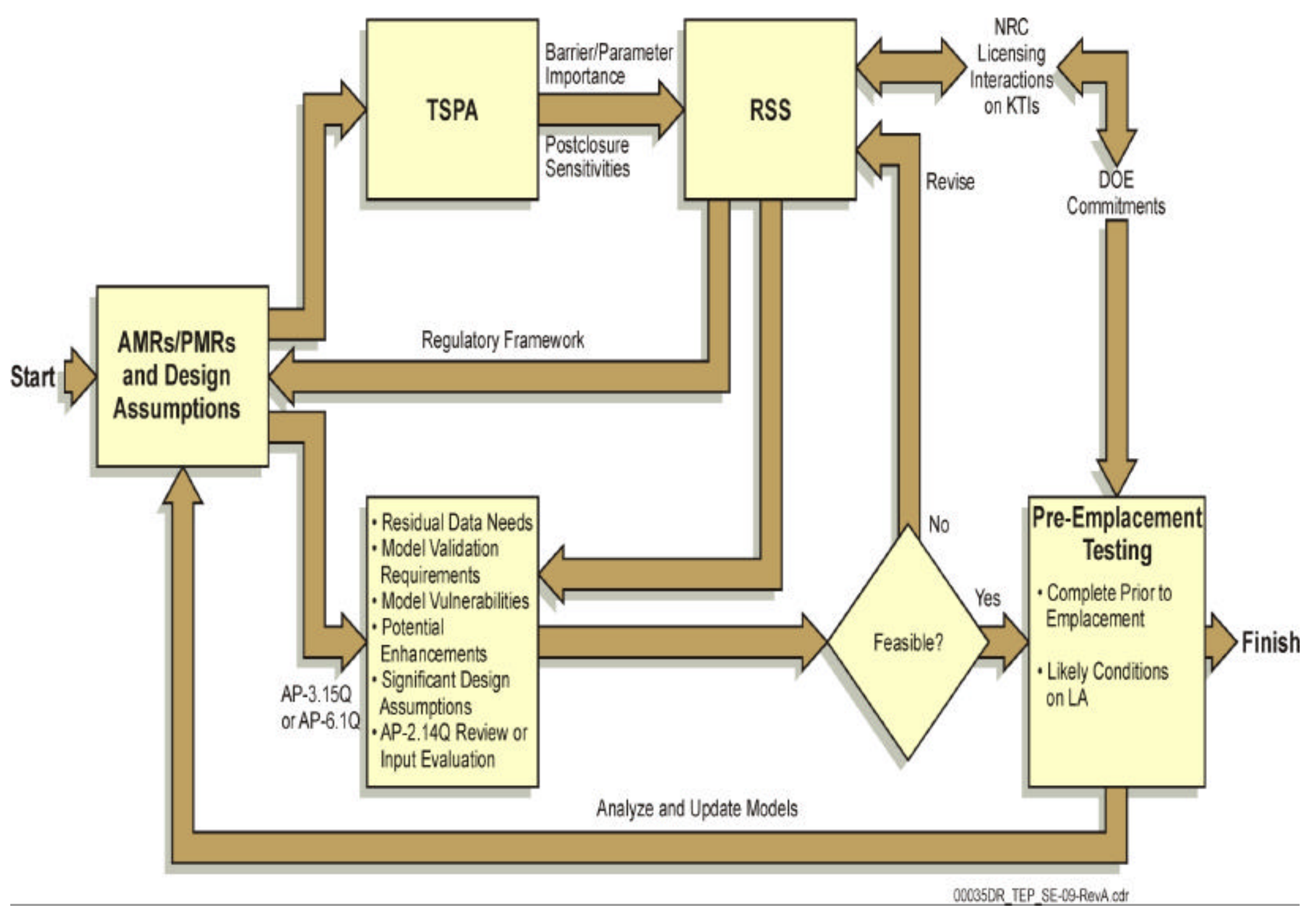

Figure A-3. Pre-Emplacement Test Development Methodology 


\section{A4. BASELINE PERFORMANCE CONFIRMATION TESTING}

The methodology for determining the testing necessary to establish baseline information for parameters to be measured in the PC program is illustrated in Figure A-4. Specific tests in this category are limited to those not already captured by Site Characterization tests and preemplacement tests. Data from each of these test activities will be used to help establish the PC baseline. The methodology for test identification is described as follows:

1. Inputs include parameters that are important to postclosure performance as derived from TSPA sensitivity analyses and the RSS (CRWMS M\&O 2001), such as those parameters to be tested under the process monitoring or postclosure simulation test activities.

2. Those parameters likely to change with time or as a result of construction, emplacement, or operations are subject to baseline data collection.

3. Confirmation of design assumptions and initial conditions encountered during MGR construction are also subject to baseline data collection.

4. Tests designed to capture parameter values in an "unaltered" state prior to construction, emplacement, testing, or operations are compared with tests already planned or underway as part of the site characterization or pre-emplacement test activities.

5. Tests already planned or being conducted for other reasons may be expanded or enhanced to satisfy PC baseline data collection requirements, or additional tests or observations may be necessary to satisfy PC baselining requirements.

These residual tests (new testing not already planned or being conducted to satisfy PC baselining requirements) define the contents of this test activity. Feedback from the tests will be used to confirm initial condition assumptions for important model parameters and for subsurface conditions encountered during construction. 


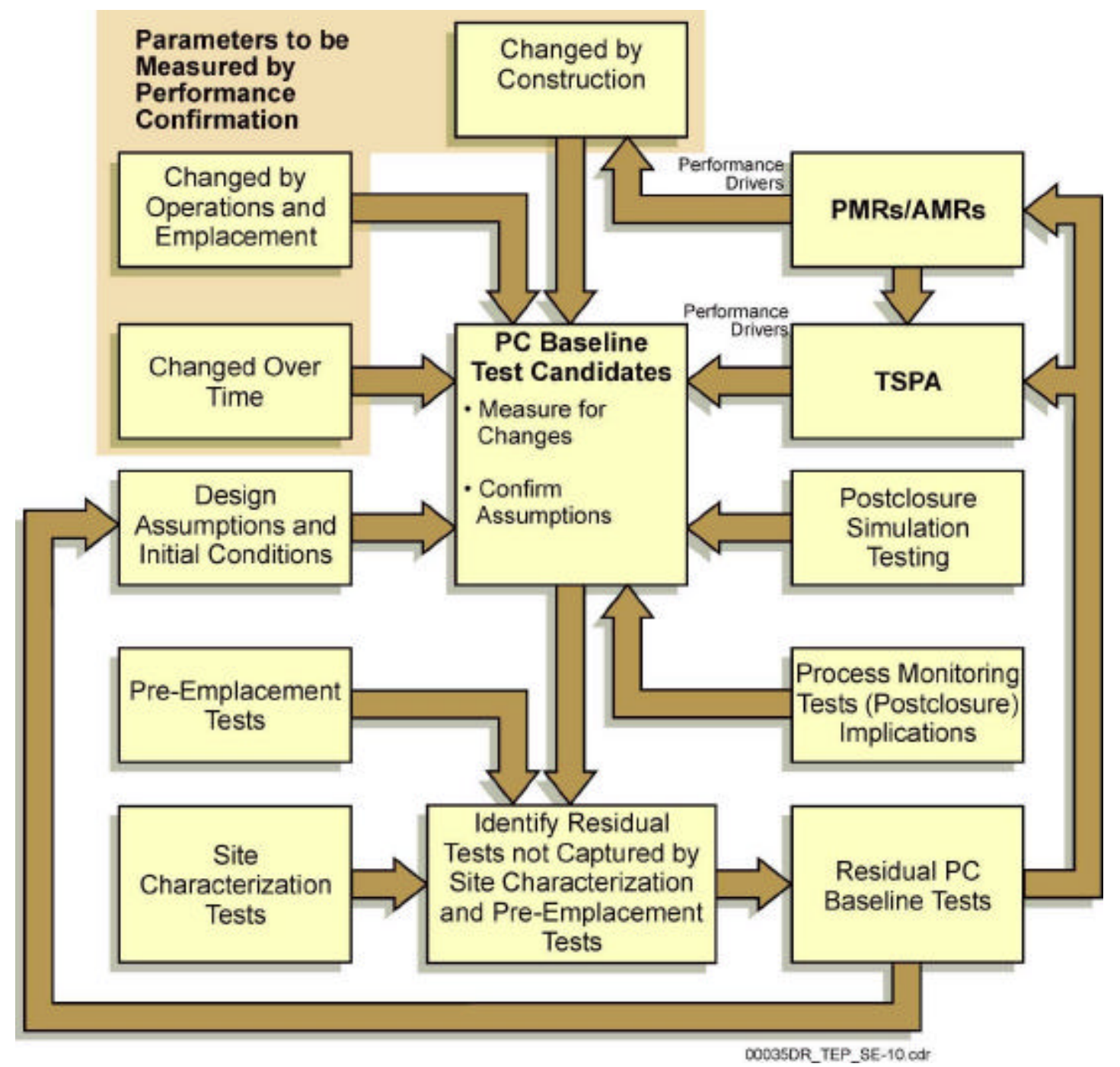

Figure A-4. Baseline Performance Confirmation Test Development Methodology 


\section{A5. COMPONENT LEVEL TESTING}

Component tests have a set of requirement specifications for performance that are determined via the design analysis depicted in Figure A-5. This may be expressed by identifying bounds that the component must operate within. During qualification testing, a limited number of units will be selected (via sampling) and tested, usually beyond bounds. Acceptance testing will provide confidence in the manufacturing process by performing tests on selected "key" measures to hedge against juvenile failure. Below are listed criteria for determining whether an item is a candidate for component testing:

1. The functional requirement as allocated by design analysis is visible only at component level; and

a) testing is required by the quality level of the SSC (i.e., the quality level is used to establish the level of design, procurement, and test controls for Q-List [YMP 2001a] items).

b) testing is identified through the environmental qualification process.

2. The functional requirement as allocated by design analysis is visible only at component level, and the requirement is a critical performance characteristic to system verification and operation.

3. Testing is required by codes, standards, or regulatory precedence, and it is not costeffective to deviate from such precedence.

4. It is the most cost-effective level to perform the test, although the function is visible at other test levels (for example, pre-operational system testing or startup).

5. Testing provides confidence that future testing at other levels will be successful. 


\section{Design Criteria}

Decompose System/Design Criteria and Allocate Requirements to Design

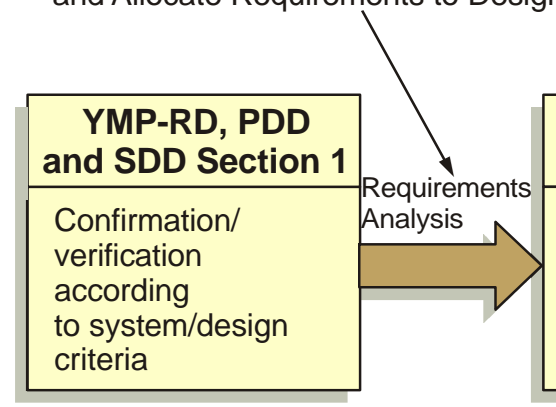

Hardware/Software

Allocate Functional Requirements to Hardware/Software

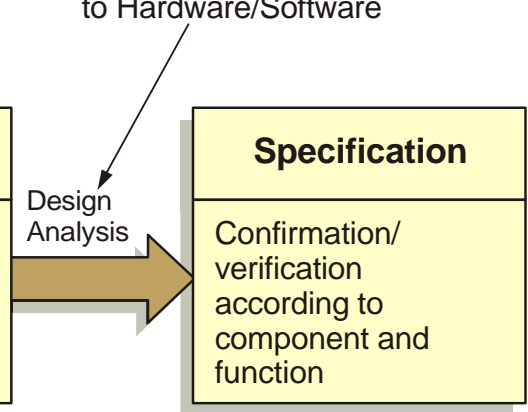

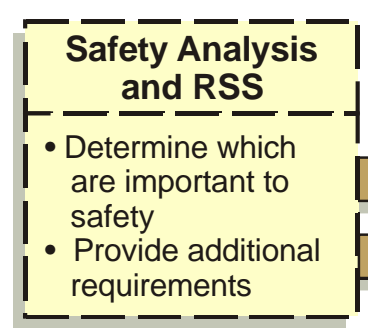
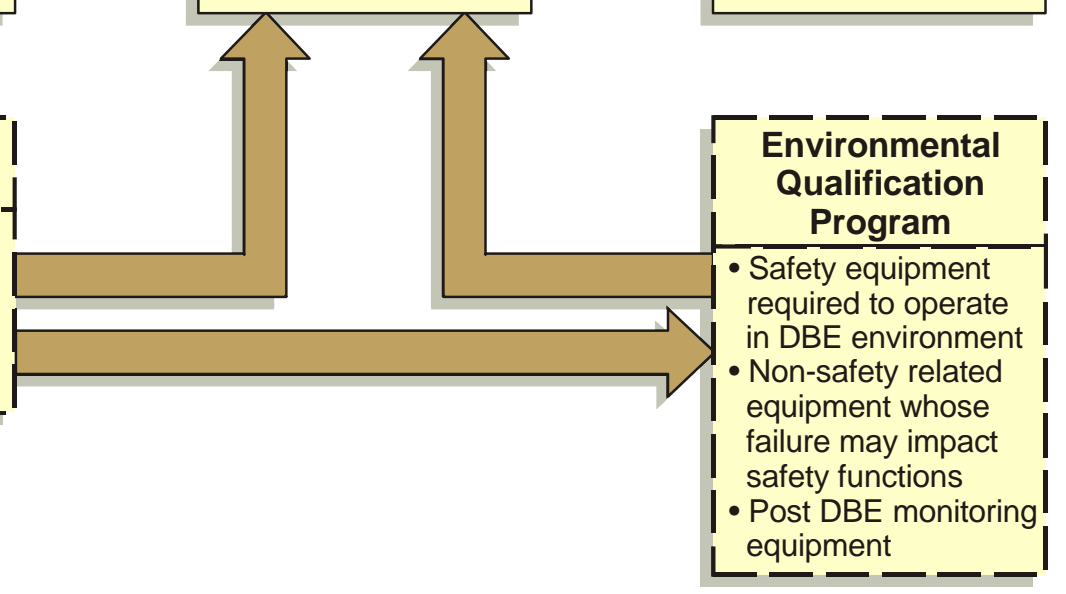

00035DR_TEP_SE-11a.cdr

Figure A-5. Component Test Selection 


\section{A6. COMPONENT LEVEL TESTING - INSTALLATION AND CHECKOUT}

All SSCs will require some degree of installation and check-out (I\&CO) testing. Confirmation verification analysis will identify those items that will require additional or more "comprehensive" testing. As depicted in Figure A-6, an SSC may require more comprehensive testing if:

1. It is an item important to safety that will require special procedures and documentation to verify proper installation and functioning.

2. ISM standards require special $\mathrm{I} \& \mathrm{CO}$ procedures to ensure worker safety during installation and to verify safety hardware/software features during future testing and/or operations.

3. It is a first time I\&CO process or high dollar item.

4. Installation reveals potential anomalies or risk to future testing or operations.

5. It is required by warranty.

6. Vendor data are incomplete, and additional procedures are recommended for future installation or to support operations and maintenance.

\section{Non-Comprehensive}

\begin{tabular}{|c|c|}
\hline Fabricate & $\begin{array}{l}\text { Installation and } \\
\text { Checkout }\end{array}$ \\
\hline $\begin{array}{l}\text { - Vendor owned } \\
\text { hardware } \\
\text { - Passed acceptance } \\
\text { test } \\
\text { - Verified as-built } \\
\text { - SSC build package }\end{array}$ & $\begin{array}{l}\text { - Make sure it works } \\
\text { - Make sure not } \\
\text { damaged } \\
\text { - Calibrate, if } \\
\text { necessary } \\
\text { - Ready for integration } \\
\text { testing }\end{array}$ \\
\hline
\end{tabular}

\section{Comprehensive}

Additional Test Objectives

- Important to nuclear and non-nuclear safety

- Special warranty

- Vendor assisted

- First of a kind

- High dollar or risk

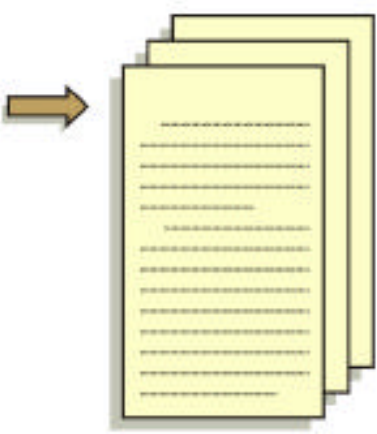

Figure A-6. Installation and Checkout Test Selection

\section{Additional Documentation}

- Required for "items important to safety"

- Integrated safety management standards or requirements

- Describing new $1 \&$ CO process

- Recommended future testing

- Warranty support

- Recommended operating and/or maintenance procedure 


\section{A7. PRE-OPERATIONAL TESTING - SYSTEM AND INTEGRATION}

Pre-operational system and integration testing will ensure that MGR SSCs operate on an integrated basis and that it is possible to proceed to cold startup. Section 2.5 of the MGR T\&EP provides a discussion of pre-operational test objectives as they apply to surface and subsurface systems. Section 3.4 of the MGR T\&EP discusses a proposed conduct of operations that would support system verification during this test phase.

As depicted in Figure A-7, testing involves multiple components. Testing will utilize the physical architecture depicted in the MGR-PDD (Curry 2001, Section 4.1) and referenced in Figure A-7 to help identify appropriate test candidates. Complexity of the system or process is key in determining whether testing is required. Additional selection criteria are listed in Figure A-7.

\section{Candidates for Pre-Operational System and Integration Testing Involve-}

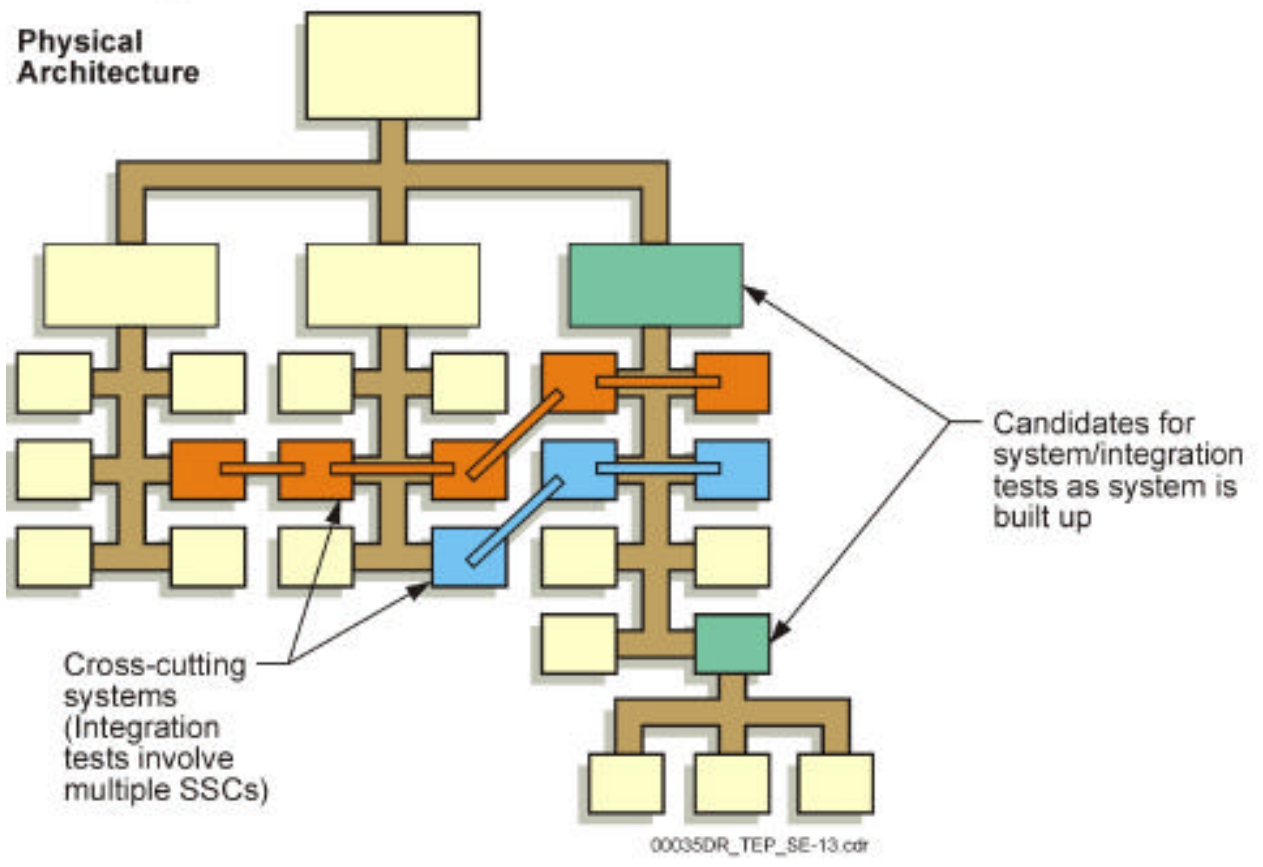

\section{Complexity is Key to Determining Whether Testing is Required and- \\ - Function visible only at system/integration level \\ - Must test if safety related \\ - Might test if non-safety related \\ - Required by code, standards, or regulations \\ - Most cost-effective level \\ - Provides confidence critical performance is achieved at this level prior to startup \\ - Tests critical interfaces}

Figure A-7. System and Integration Testing 


\section{A8. PRE-OPERATIONAL TESTING - STARTUP TESTING}

Startup testing includes cold integrated and hot startup testing. Sections 2.5.2.3 and 2.5.4 of the MGR T\&EP respectively provide a detailed discussion of cold and hot startup activities. Section 3.4 of the MGR T\&EP discusses a proposed conduct of operations that would support system verification during these test activities.

Integrated cold startup testing is the final pre-operational integration test prior to hot startup and waste receipt. Testing verifies operational readiness of physical systems and procedures and is performed for operations and procedures to receive, prepare, emplace, and move (i.e., for recovery or retrieval) waste. As depicted in Figure A-8, testing will model initial waste stream requirements.

Operational hot startup testing verifies that operational and maintenance systems work properly and confirms that the personnel radiation exposure and radiation levels fall within acceptable limits during actual repository operations. Figure A-8 summarizes key hot startup test objectives.

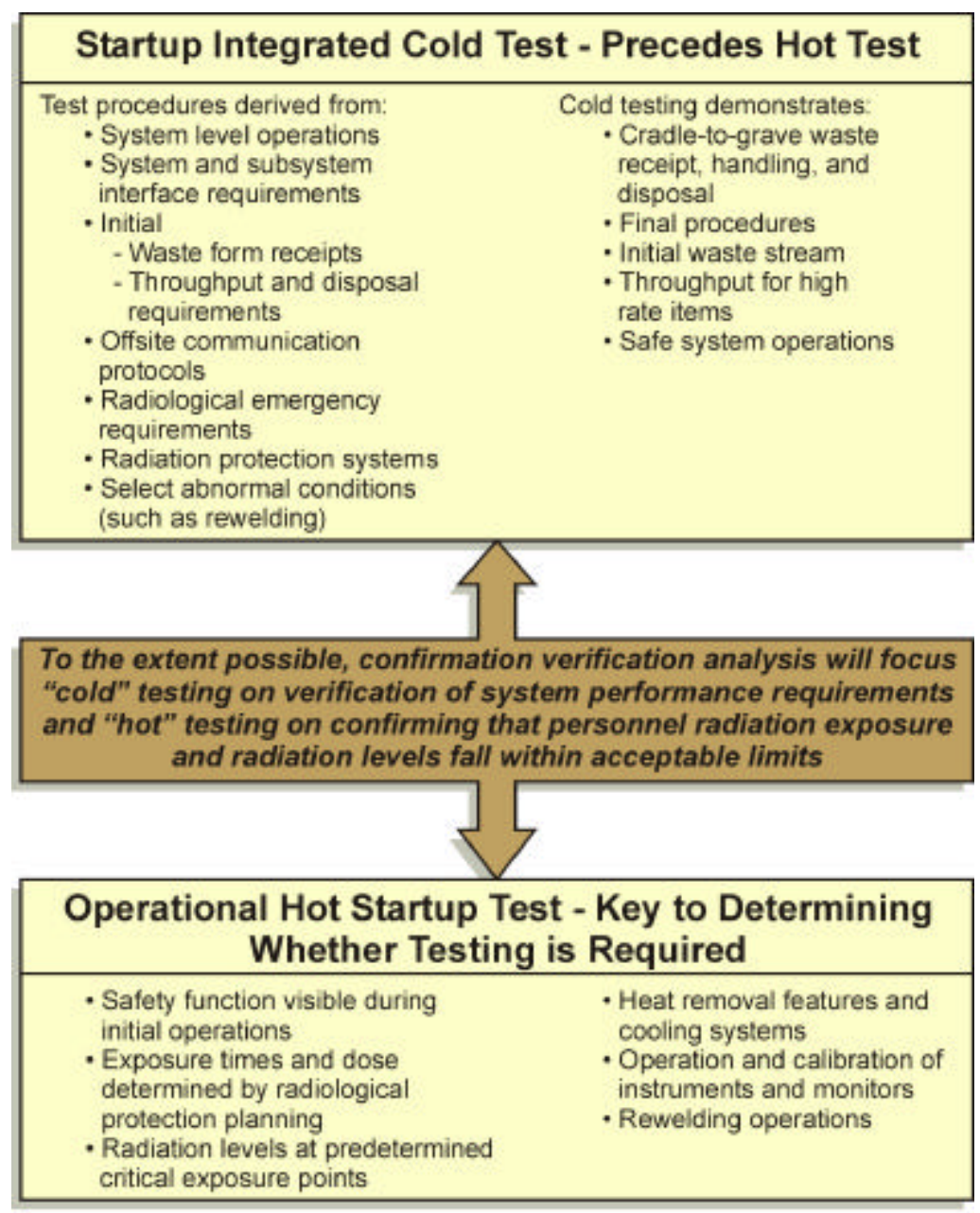

COCOSOR_TEP_8E-14.co

Figure A-8. Startup Testing 


\section{A9. DESIGN BASIS EVENT RECOVERY TESTING}

DBE recovery testing demonstrates the MGR capability to safely recover from anticipated events in a timely manner. Testing is performed prior to operations and represents initial integrated check-out of emergency response. Testing validates safety systems involved in event situations and demonstrates economic and schedule viability for recovery from expected/anticipated event scenarios. Testing may continue in a limited manner under periodic performance testing after commencement of operations.

As depicted in Figure A-9, a cost/benefit trade-off between event prevention and event mitigation and recovery is performed. If event mitigation and recovery is selected as the preferred strategy (CRWMS M\&O 1999), additional feasibility and cost/benefit trades are conducted to determine whether recovery validation is by demonstration, analysis computer simulation, or a combination of these methodologies.

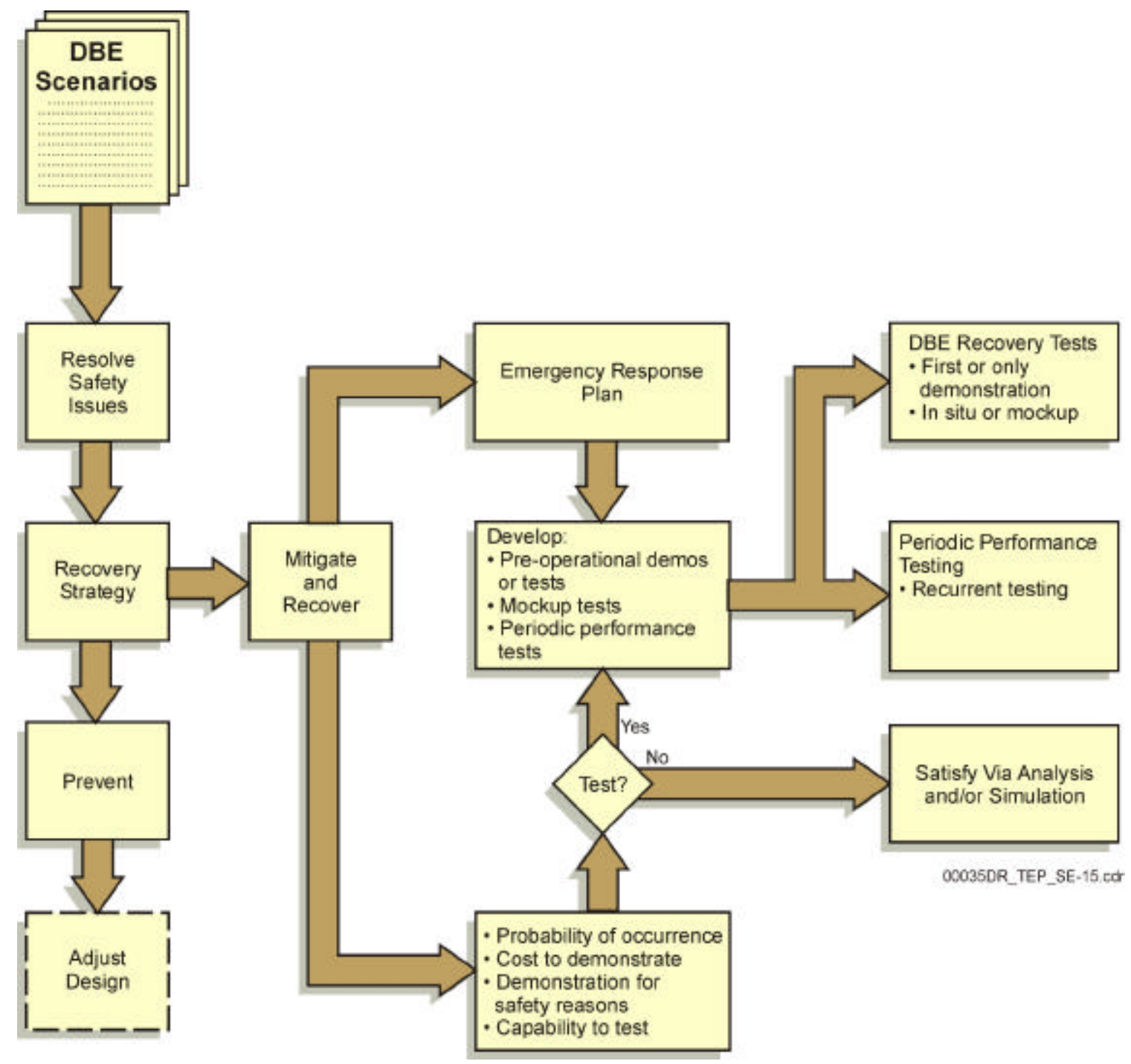

Figure A-9. Design Basis Event Testing 


\section{A10. MOCKUP PROTOTYPE TESTING}

Mockup testing is a follow-on to proof of concept prototype testing and involves simulation/demonstration with operational realism. Mockup test capability supports training, procedure development, modification development, and system verification during preoperations and emplacement. Mock up testing can be performed at a vendor plant or dedicated mockup facility. As depicted in Figure A-10, in evaluating whether a SSC or system requires mockup capability, the following pre-operational cost/schedule risk to licensing milestones should be considered:

1. Integrating capability without prior testing

2. Conducting in situ training and procedure development with other construction activities during pre-operational activities

3. Availability and cost of continued vendor support

4. Cost to implement and maintain dedicated mockup capability

5. Fidelity of existing prototype testbeds

6. Strategy to troubleshoot anomalies, maintain, upgrade, and modify the system during emplacement.

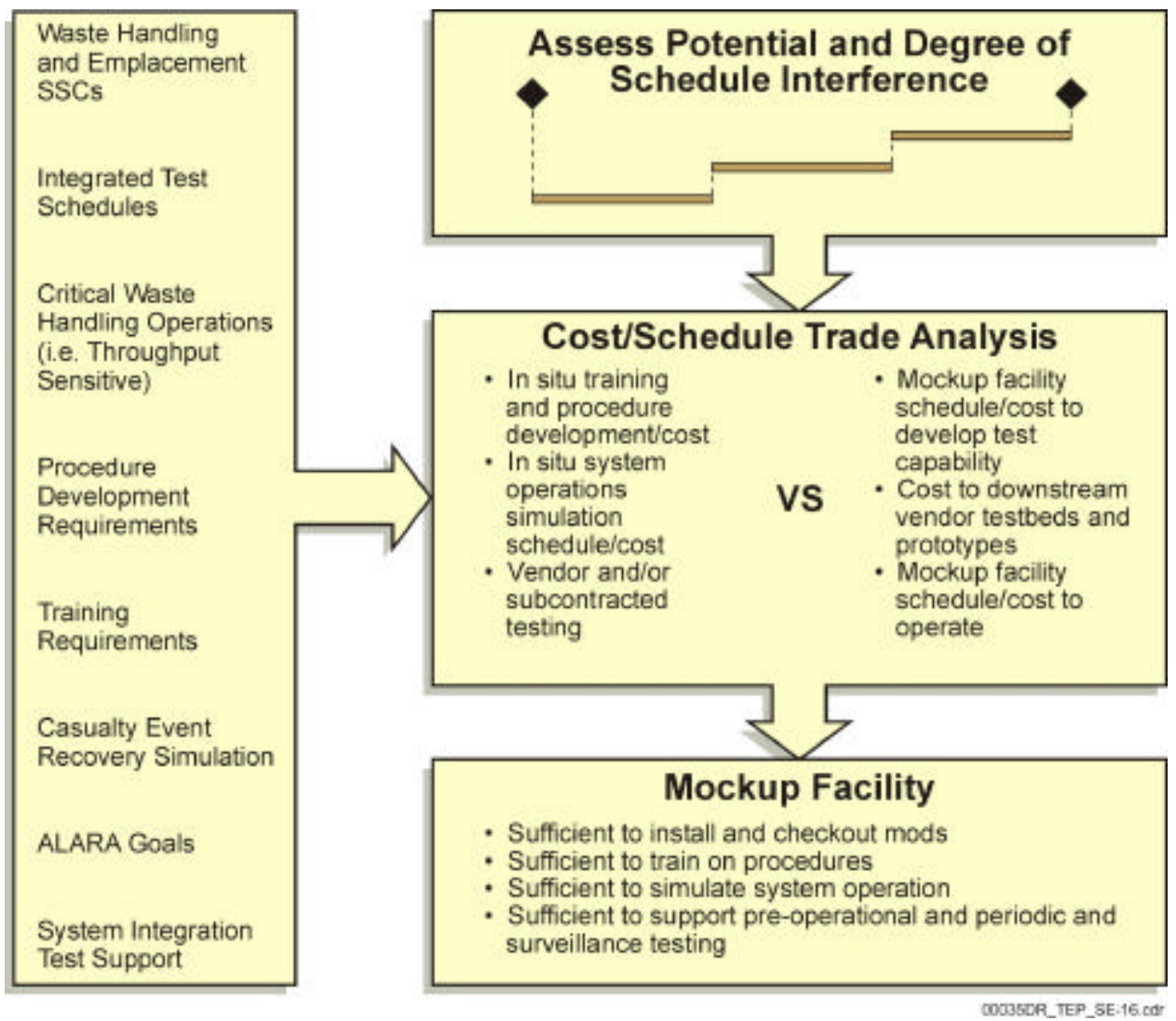

Figure A-10. Assessing Mockup Test Capability 


\section{A11. PERIODIC PERFORMANCE AND SURVEILLANCE TESTING}

Periodic performance and surveillance testing will be conducted during emplacement to ensure continued license operations and to ensure safe working conditions. Testing starts at the receipt of waste and ends at closure, and:

- verifies that system performance continues to comply with preclosure requirements

- ensures continued proper functioning of SSCs important to safety and waste isolation (as identified by an environmental qualification process), fire protection, and nonnuclear safety; and maintains repository operations

- ensures compliance with regulatory requirements and licensing specifications.

Section 2.6.1 of the MGR T\&EP provides a detailed discussion of test objectives. Section 3.4 of the MGR T\&EP discusses a proposed conduct of operations that would support system verification during this test activity. Figure A-11 lists criteria for determining if testing is required.

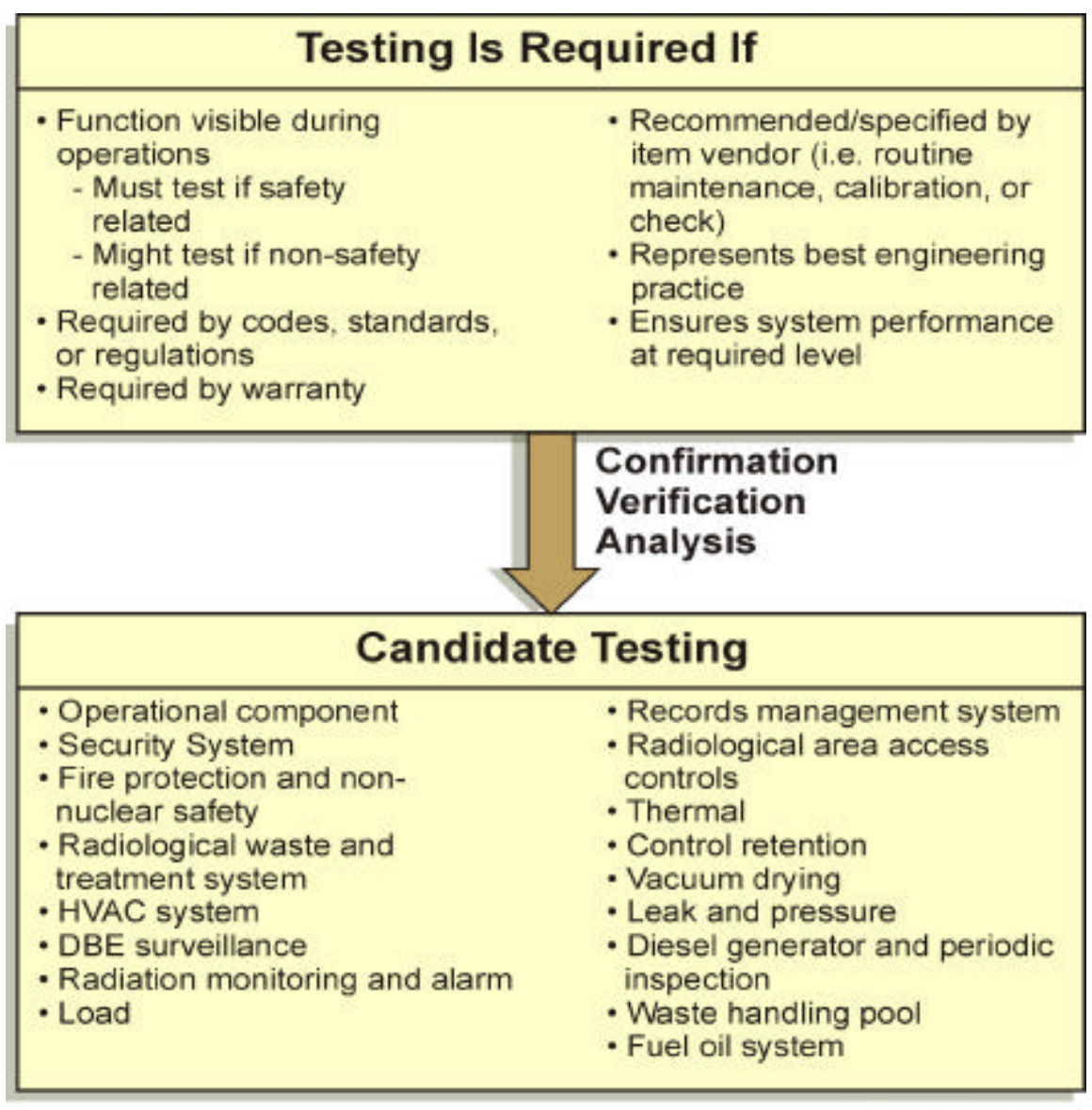

Figure A-11. Pre-Operational Testing

D00350R_TEP_SE-17 cer 


\section{A12. ENVIRONMENTAL MONITORING}

| The process for determining which tests are to be included in the Environmental Monitoring activity is illustrated in Figure A-12 and is explained as follows:

1. Environmental monitoring is largely driven by the requirements to measure environmental parameters as ascribed by permits, the NRC or the Environmental Protection Agency (EPA) regulations, or other requirements derived through the EIS process.

2. Additional environmental parameters historically measured by the program during site characterization are also considered for potential monitoring.

3. Long-term monitoring of parameters beyond those ascribed by permits, regulation, or other EIS requirements would continue if parameters are associated with postclosure sensitive items, as derived using TSPA sensitivity evaluations.

4. Feedback from environmental monitoring is used to satisfy reporting requirements and to confirm assumptions or predictions involving items with postclosure sensitivity.

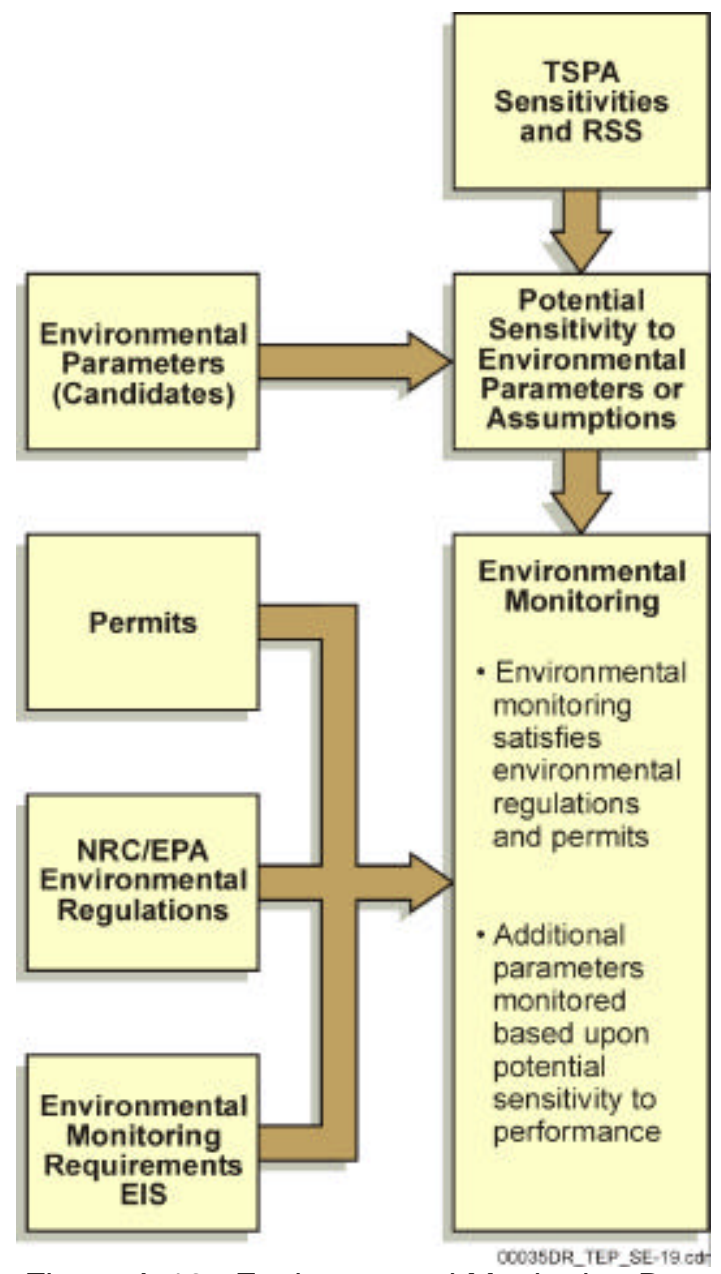

Figure A-12. Environmental Monitoring Development 


\section{A13. DISRUPTIVE EVENT TESTING}

The methodology for identifying the monitoring activities for disruptive events is illustrated in Figure A-13 and is described as follows:

1. Identify the potential disruptive event scenarios.

2. Determine whether scenarios have preclosure or postclosure safety significance.

3. For those scenarios with potential safety implications, identify those parameters likely to change either before or during the disruptive event.

4. Determine whether parameters are measurable.

5. Based upon the probability of occurrence, consequence of the scenario, and the costs to perform the measurements, determine which measurements to pursue.

6. Easily obtained measurements that provide an early or ongoing indication of disruptive events comprise the most likely candidates for this test activity.

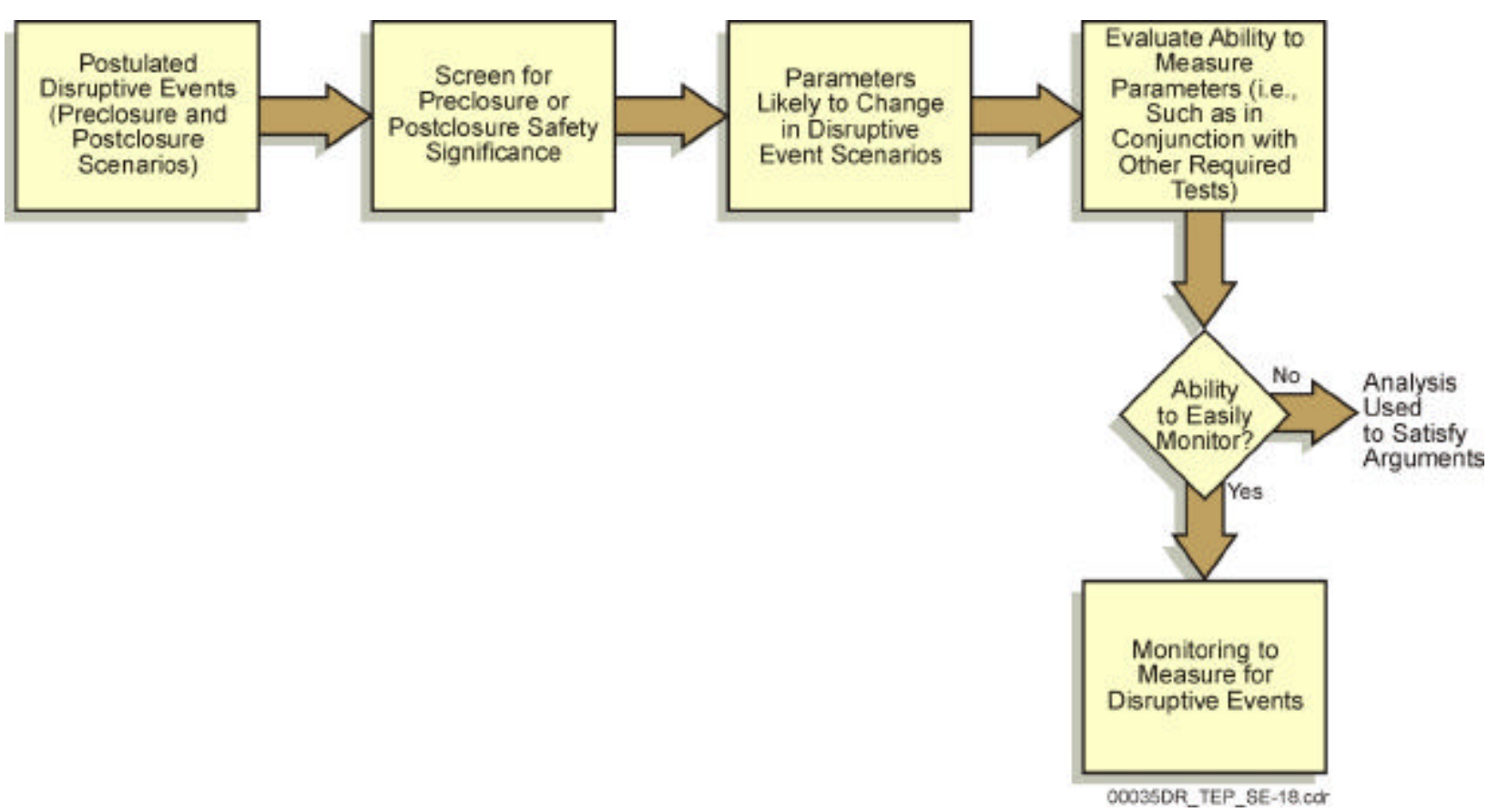

Figure A-13. Disruptive Events Monitoring Development 


\section{A14. PROCESS CONFIRMATION TESTING}

The methodology for determining the necessary set of post-emplacement process confirmation tests is briefly illustrated in Figure A-14 and summarized here. A more thorough description of the factor selection and test development process for this test activity is contained in the Performance Confirmation Plan (Lindner 2002, Chapters 3 and 5).

1. Process inputs consist of the TSPA sensitivity analyses, the RSS (CRWMS M\&O 2001) direct regulatory inputs, and requirements derived from the regulations.

2. Factors are generated from each input source to focus on those items important to postclosure performance, or those items needed to meet regulatory requirements.

3. Factors not yet confirmed during site characterization or during pre-emplacement testing are evaluated to define measurable and predictable parameters that are likely to discriminate between expected and unexpected performance.

4. Tests are developed to obtain pertinent information for each parameter; tests are preceded by test predictions and test completion criteria.

5. Additional testing may result from licensing conditions or DOE commitments, including any unresolved pre-emplacement conditions or residual test commitments.

6. Test results are analyzed with adjustments and recommended corrective actions for unexpected outcomes. 


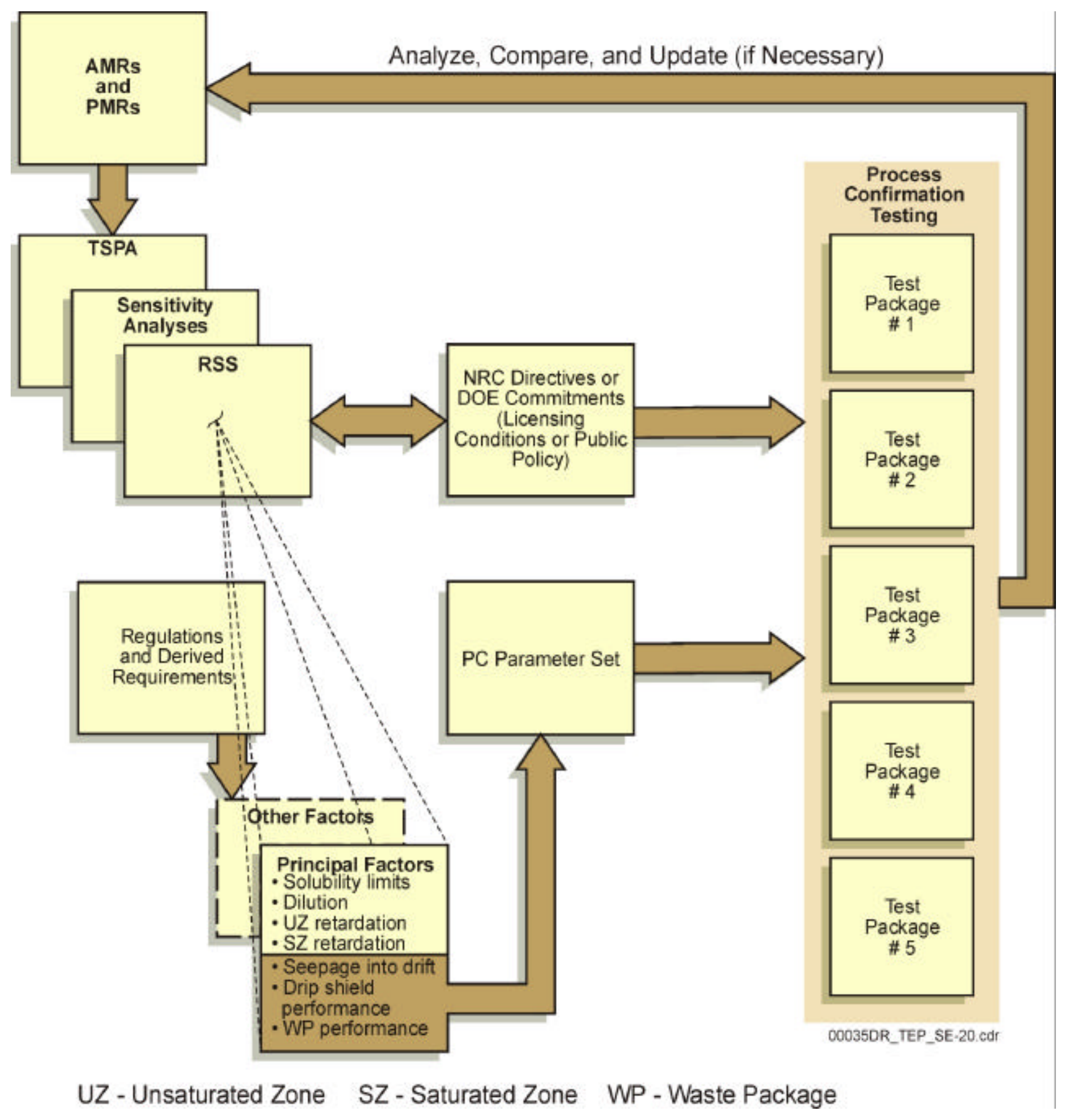

Figure A-14. Process Confirmation Testing 


\section{A15. POSTCLOSURE SIMULATION TESTING}

The postclosure simulation test is proposed as a comprehensive in-situ system-level test that focuses on confirming the interaction between the natural and engineered systems under simulated postclosure conditions. It is the most significant process monitoring-type test in the PC program. The test is described more fully in the Performance Confirmation Plan (Lindner 2002, Section 5.3.2). The process for determining the parameters to be measured in the test is illustrated in Figure A-15 and explained below.

1. Determine factors important to postclosure performance using TSPA sensitivities and the RSS (CRWMS M\&O 2001, Volume II, Section 4); these will define the focus of the testing.

2. Identify the coupled processes in the analysis and process models that can be measured in an integrated simulation test; focus on those important to postclosure performance.

3. Determine parameters to be measured that are likely to discriminate between expected and unexpected results.

4. Perform predictions; develop test success criteria for those parameters to be measured.

5. Define specific test measurements to obtain and measure information for the selected parameters.

6. Consider initial conditions and pre-conditioning of the environment to provide a meaningful simulation of the anticipated conditions at the time of closure.

7. Compare and confirm conditions at the end of the pre-conditioning period to actual conditions measured at the time of repository closure.

8. Compare and evaluate measurements obtained during the test to pre-test predictions, and recommend model adjustments or other corrective actions in response to unexpected outcomes. 


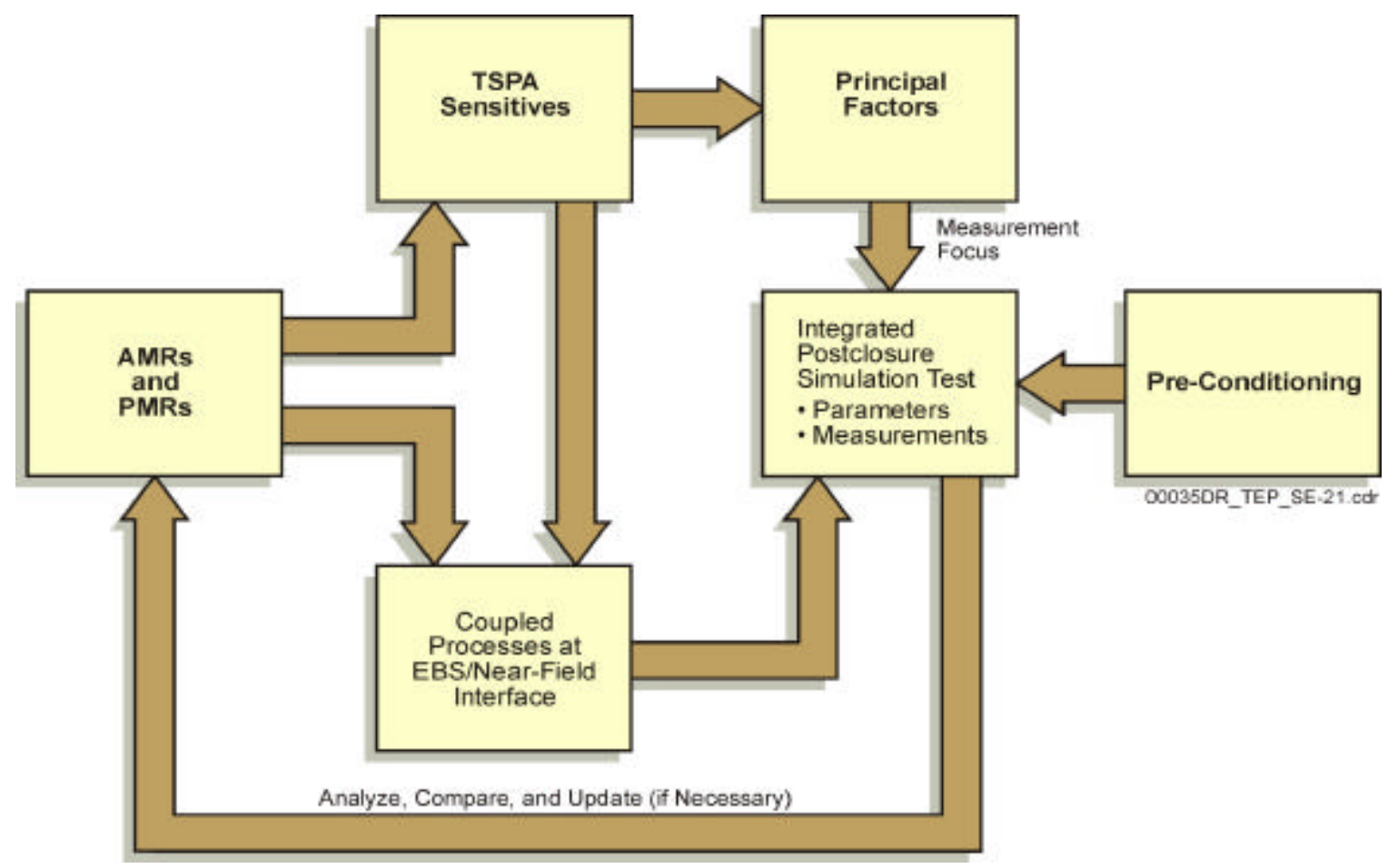

Figure A-15. Postclosure Simulation Testing 
APPENDIX B

PROPOSED PRELIMINARY DESIGN ANALYSIS/EVALUATION 


\section{APPENDIX B \\ PROPOSED PRELIMINARY DESIGN ANALYSIS/EVALUATION}

A preliminary confirmation verification activity was conducted to select verification methodologies (i.e., test, analysis, demonstration, and examination) based upon the requirements presented in the Monitored Geologic Repository Project Description Document (Curry 2001, Sections 5). Table B-1 identifies a list of those requirements that were selected as candidates for verification via design analyses. This list is preliminary and is not comprehensive for all design analysis required to support the licensing process, particularly for design analysis to be performed as part of the design process. The candidate analyses depicted in Table B-1 will be evaluated by the appropriate test working group, and successful candidates will be further defined to include cost methodology and implementation (i.e., cost, period of performance). These candidates will be recommended for timely incorporation into the appropriate work package, so that the results of the analysis can support the development of the LA. 
Table B-1. Candidate Design Analyses

\begin{tabular}{|c|c|c|}
\hline $\begin{array}{l}\text { PDD * } \\
\text { REQUIREMENT } \\
\text { No. }\end{array}$ & $\begin{array}{l}\text { PDD REQUIREMENTS, CRITERIA, GOALS, AND } \\
\text { CONSTRAINTS }\end{array}$ & DESIGN ANALYSIS DESCRIPTION \\
\hline 5.1 .1 .1 & $\begin{array}{l}\text { The MGR design shall allow the repository to } \\
\text { remain open for up to } 300 \text { years following final } \\
\text { waste emplacement, with appropriate monitoring } \\
\text { and maintenance, and could allow closure of the } \\
\text { repository } 30 \text { years following final waste } \\
\text { emplacement, with variations in thermal } \\
\text { management via operational flexibility. }\end{array}$ & $\begin{array}{l}\text { The project will perform the following } \\
\text { analyses: } \\
\text { thermal modeling } \\
\text { waste arrival/emplacement analysis } \\
\text { modeling } \\
\text { monitoring/PC simulation and modeling. }\end{array}$ \\
\hline 5.1.3.2 & $\begin{array}{l}\text { Two annual hazard frequencies of exceedance } \\
\text { shall be considered for seismic events during the } \\
\text { preclosure period: one occurrence per } 1,000 \text { years } \\
\text { (Frequency Category 1) and one occurrence per } \\
10,000 \text { years (Frequency Category } 2 \text { ). There are } \\
\text { also two design input earthquakes, one referred to } \\
\text { as the } 1 \text { to } 2 \mathrm{HZ} \text { earthquake, and the other referred } \\
\text { to as the } 5 \text { to } 10 \mathrm{HZ} \text { earthquake. Vibratory ground } \\
\text { motions corresponding to both earthquakes for } \\
\text { both categories shall be considered in the design } \\
\text { of SSCs. Additional seismic design criteria will be } \\
\text { provided in future revisions of this document. }\end{array}$ & $\begin{array}{l}\text { Organizations will use models to predict } \\
\text { the design upper and lower boundary } \\
\text { constraints necessary for the MGR to } \\
\text { comply with the PDD requirement. }\end{array}$ \\
\hline 5.1.4.3 & $\begin{array}{l}\text { The MGR shall be capable of receiving, packaging, } \\
\text { emplacing, and isolating commercial SNF that } \\
\text { arrives via rail, heavy-haul vehicle, and legal- } \\
\text { weight truck, in accordance with the YMP RD } \\
\text { accommodating any of the CSNF annual arrival } \\
\text { scenarios depicted in Tables 5-1, 5-2, and 5-3 of } \\
\text { the Monitored Geologic Repository Project } \\
\text { Description Document (Curry } 2001 \text {, Tables 5-1, 5- } \\
2 \text {, and 5-3). These values are to be used for the } \\
\text { purpose of specifying the throughput and are not } \\
\text { meant to imply any finite quantity of waste and } \\
\text { shall not be used to determine total inventory, total } \\
\text { heat load, or total radionuclide inventory of the } \\
\text { waste to be emplaced in the repository. }\end{array}$ & $\begin{array}{l}\text { Design will utilize throughput models to } \\
\text { analyze the surface operations required } \\
\text { to accommodate the CSNF arrival } \\
\text { scenario. }\end{array}$ \\
\hline 5.2 .13 & $\begin{array}{l}\text { Individual WPs shall have a maximum heat output } \\
\text { of } 11.8 \mathrm{~kW} \text { at the time of emplacement. }\end{array}$ & $\begin{array}{l}\text { Computer analysis will be conducted to } \\
\text { predict the thermal constraints of the } \\
\text { cladding, drift wall, etc., to ensure that } \\
\text { the boundary constraints are not } \\
\text { exceeded. }\end{array}$ \\
\hline 5.2 .14 & $\begin{array}{l}\text { The surface facilities shall accommodate a } \\
\text { blending inventory of up to } 5,000 \text { MTHM and the } \\
\text { aging of up to 40,000 MTHM for as long as } 30 \\
\text { years. }\end{array}$ & $\begin{array}{l}\text { Engineering will perform design analysis } \\
\text { and modeling to determine the surface } \\
\text { facility space requirements necessary to } \\
\text { accommodate a blending inventory of up } \\
\text { to } 5,000 \text { MTHM, and an aging inventory } \\
\text { of up to } 40,000 \text { MTHM. }\end{array}$ \\
\hline
\end{tabular}

${ }^{*}$ Curry 2001 


\section{APPENDIX C}

\section{PROPOSED PROTOTYPE TESTS}




\section{APPENDIX C}

\section{PROPOSED PROTOTYPE TESTS}

Table C-1 of Appendix C provides a candidate list of hardware, processes, and operations for proof of concept prototype testing to support the design process. Figure $\mathrm{C}-1$ provides a proposed schedule for these candidate tests. Near-term test planning activities involve the candidate tests depicted in Table $\mathrm{C}-1$ to be evaluated by the appropriate test working group according to the methodology for prototype test selection depicted in Appendix A. Successful candidates will be further defined to include cost methodology and implementation (i.e., cost, period of performance). These candidates will be recommended for incorporation into the appropriate work package.

Tests described in Table C-1 represent a cost effective design support strategy of technology selection, technology tailoring, and integration risk mitigation.

Tests:

- 1 through 6 represent testing used to evaluate alternative design solutions.

- 7 through 12 represent testing used to confirm a given design concept.

- 13 through 16 represent prototype testing to support system-level integration testing.

As stated above, tests 1 through 6 will be used to evaluate alternative design solutions. These tests will investigate technologies that have little or no data from existing DOE or nuclear programs, no data from like environments (i.e., nuclear or non-nuclear), or have not been subjected to a structured test program from which data was collected and analyzed. As shown in Figure C-1, testing should be conducted early in the 2002 to 2004 time frame.

Tests 7 through 12 are full scale pre-production prototype tests that will examine and validate system form, fit, and function and provide feedback to design engineers developing the final production design. The bulk of this testing should be conducted in the 2004 to 2007 time frame and at the vendor's facility in order to facilitate real time support to the detailed design effort and the licensing process (see Figure C-1).

As mentioned above, tests 13 through 16 represent prototype system-level integration testing. This testing is necessary to reduce design risk and to ensure that SSCs will operate on an integrated basis, meeting system, licensing, performance, cost, and schedule constraints during construction, training, and pre-operations; and maintaining system integrity by ensuring that licensing requirements are met and maintained during operations.

System testing is key to ensuring the successful integration of diverse state-of-the-art and offthe-shelf systems, products, components, and technologies into more complex systems. Repository remote systems are composed of diverse subsystem technologies, including locomotion, power, communications, control, video systems, manipulation, actuators, sensors, instrumentation, and thermal control systems. Many design issues that affect preclosure safety, such as control and reliability, are not identifiable during design development testing and are only addressable during prototype system-level integration testing. 
Candidate tests 14 through 16 respectively call for the construction of surface and subsurface integration facility testbeds. The plan would be to downstream these testbed capabilities to a mockup test facility that would support pre-operational and operational test and support phases and activities described in Section 2 of the MGR T\&EP. Current surface facility design layout shows a mockup capability to be complete in late 2008 .

Consideration should also be given for locating a surface/subsurface system testbed at Yucca Mountain somewhere on the perimeter of the repository. This would facilitate a quick transition to mockup capability and could also support considerations for early waste receipt by providing a testbed capability that could accelerate integration and startup testing.

Table C-1. Proposed Prototype Tests

\begin{tabular}{|c|c|c|}
\hline$\#$ & TITLE & DESIGN ALTERNATIVE SELECTION \\
\hline 1 & $\begin{array}{l}\text { Remotely } \\
\text { Operated } \\
\text { Vehicle (ROV) } \\
\text { Testbed }\end{array}$ & $\begin{array}{l}\text { The ROV Testbed will develop and test engineering models of ROVs. The testbed will } \\
\text { incorporate mechanical drives, chassis, electronic controls, software controls, mobile } \\
\text { power supplies, remote communications, machine vision, and environmental sensors } \\
\text { and instrumentation. }\end{array}$ \\
\hline 2 & $\begin{array}{l}\text { Control Station } \\
\text { Integration } \\
\text { Testbed }\end{array}$ & $\begin{array}{l}\text { The Control Station Testbed will develop and demonstrate control room technologies } \\
\text { and techniques, including: human machine interfaces (HMls), user interfaces, operator } \\
\text { work load modeling, control panels and screens, control room layout, emergency } \\
\text { response simulations, control of remote systems, and repository-wide communications, } \\
\text { supervisory controls, and monitoring capabilities. }\end{array}$ \\
\hline 3 & $\begin{array}{l}\text { Repository } \\
\text { Instrumentation } \\
\text { \& Control } \\
\text { Testbed }\end{array}$ & $\begin{array}{l}\text { This activity will investigate multiple I\&C related design issues. Engineers will evaluate } \\
\text { the suitability and effectiveness of various geotechnical, hydrological, and seismic } \\
\text { instruments. This includes various borehole instruments, acoustic and seismic } \\
\text { tomography, optical convergence monitoring techniques, etc. It also includes other } \\
\text { engineering models developed to investigate radioactive contamination detection } \\
\text { thresholds and approaches for conditions similar to those anticipated within the } \\
\text { emplacement drifts. }\end{array}$ \\
\hline 4 & $\begin{array}{l}\text { Waste Handling } \\
\text { Equipment } \\
\text { Prototypes }\end{array}$ & $\begin{array}{l}\text { This activity will test surface waste handling equipment that presents a potential design } \\
\text { risk. Equipment design risk is considered high if the design cannot be licensed, } \\
\text { constructed, or operated safely, reliably, or at sufficient speed to meet waste handling } \\
\text { throughput. If design indicated that two or more equipment items must operate as a } \\
\text { unit to perform the surface waste handling operations, these equipment items will be } \\
\text { tested as a unit. For example, a disposal container (DC) welding station jib crane test } \\
\text { will demonstrate engagement and lifting of the sealing device and DC lid using a } \\
\text { grapple, and remote engagement of the sealing device inerting port by the jib crane } \\
\text { inerting head. An extensive listing and description of these tests are provided in the } \\
\text { Waste Handling Equipment Development Test and Evaluation Study (CRWMS M\&O } \\
1998 \text {, pp. 17-22). Some testing may be beyond the scope of a vendor testbed and } \\
\text { may require testbed capabilities provided by an integration test facility described in } 14 \\
\text { below. }\end{array}$ \\
\hline 5 & $\begin{array}{l}\text { Emplacement } \\
\text { Pallet Prototype } \\
\text { Testing }\end{array}$ & $\begin{array}{l}\text { The technical objectives of this activity include all engineering efforts to develop and } \\
\text { conduct a test program on the WP structural support prototype. This testing program } \\
\text { covers thermal, static, and dynamic conditions including drop and seismic events. This } \\
\text { activity includes developing test criteria, performing test planning analysis, and } \\
\text { developing detailed test plans. }\end{array}$ \\
\hline 6 & $\begin{array}{l}\text { Drip Shield } \\
\text { Prototype } \\
\text { Testing }\end{array}$ & $\begin{array}{l}\text { The technical objectives of this activity include all engineering efforts to develop and } \\
\text { conduct a test program on the drip shield prototype. This testing program covers } \\
\text { thermal, static, and dynamic conditions including drop and seismic events. This activity } \\
\text { includes developing test criteria, performing test planning analysis, and developing } \\
\text { detailed test plans. }\end{array}$ \\
\hline
\end{tabular}


Table C-1. Proposed Prototype Tests (Continued)

\begin{tabular}{|c|c|c|}
\hline \# & TITLE & PRE-PRODUCTION \\
\hline 7 & $\begin{array}{l}\text { WP Prototype } \\
\text { Testing }\end{array}$ & $\begin{array}{l}\text { This activity will evaluate WP design for normal conditions of transport to include a full } \\
\text { scale prototype that will be fabricated for drop, compression, and puncture testing. As } \\
\text { a result of testing, necessary changes will be implemented via design modifications } \\
\text { and engineering changes. }\end{array}$ \\
\hline 8 & $\begin{array}{l}\text { Waste } \\
\text { Emplacement } \\
\text { Gantry Prototype }\end{array}$ & $\begin{array}{l}\text { This activity will develop and test a full-scale pre-production fully operational prototype } \\
\text { of the waste emplacement gantry. The prototype will include all mechanical, } \\
\text { electrical, software, and controls necessary to perform its function. The prototype will } \\
\text { undergo a battery of preliminary operational and environmental testing. This } \\
\text { prototype will be used to examine and validate system form, fit, and function and to } \\
\text { provide feedback to design engineers developing the final production design. }\end{array}$ \\
\hline 9 & $\begin{array}{l}\text { Transport } \\
\text { Locomotive } \\
\text { Prototype }\end{array}$ & $\begin{array}{l}\text { This activity will develop and test a full-scale pre-production fully operational prototype } \\
\text { of the transport locomotive. The prototype will include all mechanical, electrical, } \\
\text { software, and controls necessary to perform its function. The prototype will undergo a } \\
\text { battery of preliminary operational and environmental testing. }\end{array}$ \\
\hline 10 & $\begin{array}{l}\text { WP Transporter } \\
\text { Prototype }\end{array}$ & $\begin{array}{l}\text { This activity will develop and test a full-scale pre-production fully operational prototype } \\
\text { of the WP transporter. The prototype will include all mechanical, electrical, software, } \\
\text { and controls necessary to perform its function. The prototype will undergo a battery of } \\
\text { preliminary operational and environmental testing. }\end{array}$ \\
\hline 11 & $\begin{array}{l}\text { Remote } \\
\text { Inspection } \\
\text { Gantry Prototype }\end{array}$ & $\begin{array}{l}\text { This activity will develop and test a full-scale pre-production fully operational prototype } \\
\text { of the remote inspection gantry for PC. The prototype will include all mechanical, } \\
\text { electrical, software, and controls necessary to perform its function. The prototype will } \\
\text { undergo a battery of preliminary operational and environmental testing. }\end{array}$ \\
\hline 12 & $\begin{array}{l}\text { WP Welding \& } \\
\text { Non Destructive } \\
\text { Examination } \\
\text { Tests }\end{array}$ & $\begin{array}{l}\text { The technical objective of this activity include all engineering efforts to develop and } \\
\text { conduct a test program on the remote welding system, weld stress relief } \\
\text { methodologies (to include laser peening and solution annealing), and remote non- } \\
\text { destructive examination and inspection techniques to verify weld integrity. This } \\
\text { activity includes tasks to develop test criteria, perform test planning analysis, develop } \\
\text { detailed test plans, conduct tests, analyze results to determine if design modifications } \\
\text { are required, and report results. }\end{array}$ \\
\hline 13 & $\begin{array}{l}\text { Control and } \\
\text { Communication } \\
\text { System } \\
\text { Prototype }\end{array}$ & $\begin{array}{l}\text { This activity will develop a preliminary, fully operational control and communication } \\
\text { center. It will be used to remotely control and monitor other prototype equipment such } \\
\text { as the emplacement gantry and transport locomotive. The facility will demonstrate } \\
\text { control room technologies and techniques, including: human machine interfaces } \\
\text { (HMls), user interfaces, operator work load modeling, control panels and screens, } \\
\text { control room layout, emergency response simulations, control of remote systems, and } \\
\text { repository-wide data, voice, and video communications, supervisory controls, and } \\
\text { monitoring capabilities. The prototype control facility will include all mechanical, } \\
\text { electrical, software, and controls necessary to perform its function and provide } \\
\text { feedback to design engineers. }\end{array}$ \\
\hline 14 & $\begin{array}{l}\text { Surface Facility } \\
\text { Integration } \\
\text { Testbed }\end{array}$ & $\begin{array}{l}\text { This activity will develop a surface test facility that will serve as a integration testbed } \\
\text { for surface facility systems. Test capabilities include: WP welding, WP remediation, } \\
\text { cask transfer cart, waste handling grapples and lifting devices, control, cask } \\
\text { preparation manipulator, DC lid lifting, DC inerting, disposal container or WP } \\
\text { decontamination, and wet assembly transfer. The test facility will include all } \\
\text { mechanical, electrical, software, and controls necessary to perform functions for } \\
\text { carrier/cask handling, assembly transfer, canister transfer, and DC handling } \\
\text { operations. This test facility will be used to examine and validate system form, fit, and } \\
\text { function and to provide feedback to design engineers developing the final production } \\
\text { design. (Waste Handling Equipment Development Test and Evaluation Study } \\
\text { [CRWMS M\&O 1998c, pp. 17-22]) }\end{array}$ \\
\hline
\end{tabular}


Table C-1. Proposed Prototype Tests (Continued)

\begin{tabular}{|c|l|l|}
\hline$\#$ & \multicolumn{1}{|c|}{ TITLE } & \multicolumn{1}{c|}{ PRE-PRODUCTION } \\
\hline 15 & $\begin{array}{l}\text { ALARA Related } \\
\text { Prototype } \\
\text { Testing }\end{array}$ & $\begin{array}{l}\text { These tests will cover a variety of waste handling procedures planned at various } \\
\text { operating stations in the radiologically controlled area of the repository. The ideal } \\
\text { facility for these tests would be the surface prototype and emplacement drift dock area } \\
\text { testbeds referenced above. The primary purpose of these tests is to perform a variety } \\
\text { of test procedures developed to minimize cask/carrier preparation, waste handling, } \\
\text { and a variety of equipment maintenance durations where ALARA goals are prominent. }\end{array}$ \\
\hline 16 & $\begin{array}{l}\text { This activity will develop an integration test facility that enables operational testing and } \\
\text { evaluation of the waste transfer and handling systems at the emplacement drift dock } \\
\text { area. This test facility will be used in conjunction with other full-scale prototypes of the } \\
\text { transport locomotive, waste emplacement transporter, and the emplacement gantry to } \\
\text { demonstrate and validate that waste can be reliably and safely emplaced within the } \\
\text { repository. The test facility will include all mechanical, electrical, software, and } \\
\text { controls necessary to perform its function. This test facility will be used to examine } \\
\text { and validate system form, fit, and function and to provide feedback to design } \\
\text { engineers developing the final production design. }\end{array}$ \\
\hline $\begin{array}{l}\text { Emplacement } \\
\text { Testbed Ared Area }\end{array}$
\end{tabular}




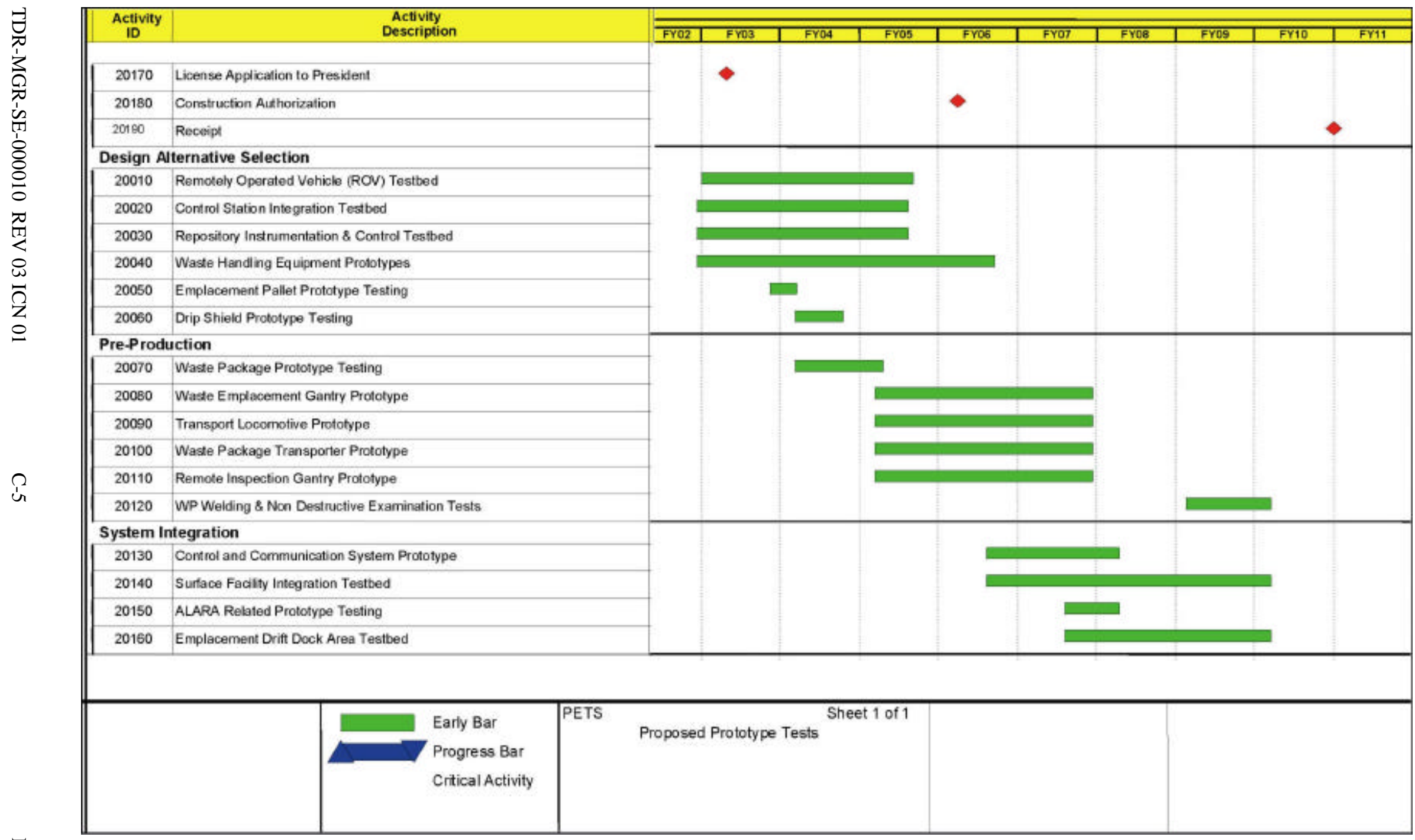


INTENTIONALLY LEFT BLANK 


\section{APPENDIX D}

\section{NEAR-TERM PRE-EMPLACEMENT TESTING}




\begin{abstract}
APPENDIX D
NEAR-TERM PRE-EMPLACEMENT TESTING

Near-term pre-emplacement testing is driven primarily by anticipated residual analysis model and process model data needs necessary to support the LA submittal. Additionally, potential enhancements to the postclosure safety case and data collection to resolve design assumptions or to address specific design data needs were considered in developing the candidate list of preemplacement tests for the next several years. Identified tests exclude those to be completed during site characterization. The following table (Table D-1) summarizes specific preemplacement tests proposed over the next several years, followed by a preliminary draft schedule (Figure D-1) to illustrate the timing and duration of the proposed tests. Extension of testing into the long-term PC or post-emplacement research and development testing programs is not indicated by the figure. Tests are divided into major test areas consistent with functional responsibilities. The draft schedule for the identified tests represent lower level detail to current project summary schedules and provide a potential input to more detailed annual planning efforts.
\end{abstract}


Table D-1. Pre-Emplacement Tests

\begin{tabular}{|c|c|}
\hline \multicolumn{2}{|r|}{ Unsaturated Zone } \\
\hline $\begin{array}{l}\text { Crossover Alcove } \\
\text { Testing }\end{array}$ & $\begin{array}{l}\text { Testing to evaluate flow and seepage processes in potential repository horizon rocks at a scale } \\
\text { of tens of meters. Test verifies process models, addresses residual data needs, and meets } \\
\text { program commitments. Data is desired to support the LA submittal. Process modelers are the } \\
\text { identified users. }\end{array}$ \\
\hline $\begin{array}{l}\text { Niche } \\
\text { Testin }\end{array}$ & $\begin{array}{l}\text { Testing to evaluate drift-scale seepage processes and seepage threshold in potential repository } \\
\text { horizon rocks. Test verifies process models, addresses residual data needs, and meets } \\
\text { program commitments with near-term data available to support the LA submittal. Portions of } \\
\text { this test may continue under PC for testing of long-term processes. Process modelers are the } \\
\text { identified near-term users. }\end{array}$ \\
\hline $\begin{array}{l}\text { Systematic } \\
\text { Hydrologic } \\
\text { Characterization }\end{array}$ & $\begin{array}{l}\text { Consists of boreholes along the cross drift for air permeability measurements, as well as } \\
\text { boreholes for seepage and hydrologic parameter measurements. Test verifies process models } \\
\text { and addresses residual data needs with near-term data available to support the LA submittal. } \\
\text { Process modelers are the identified users. }\end{array}$ \\
\hline $\begin{array}{l}\text { Passi } \\
\text { Monit }\end{array}$ & $\begin{array}{l}\text { Testing consists of general moisture monitoring in the ESF not specifically covered by other } \\
\text { identified tests. Testing will likely continue long-term during long-term PC monitoring. Testing } \\
\text { helps to confirm long-term process model predictions. Data will be used to support the LA } \\
\text { submittal, as well as the update to receive and possess waste. Process modelers are the } \\
\text { identified customers. }\end{array}$ \\
\hline Borehol & $\begin{array}{l}\text { Pneumatic monitoring of unsaturated zone boreholes } 4 \text { and } 5(\mathrm{UZ}-4 / 5) \text { and north ramp geologic } \\
\text { borehole } 7 \mathrm{~A} \text { (NRG-7A) to evaluate hydrologic parameters and water potential over time, } \\
\text { including measurements for pressure, temperature, and relative humidity changes. Testing will } \\
\text { likely continue long-term to confirm long-term process model predictions. Data will be used to } \\
\text { support the LA submittal, as well as the update to receive and possess waste. Process } \\
\text { modelers are the identified users. }\end{array}$ \\
\hline toring & $\begin{array}{l}\text { Testing consists of general moisture monitoring in the cross drift and behind the cross drift } \\
\text { bulkhead not specifically covered by other identified tests. Testing will likely continue long-term } \\
\text { during long-term PC monitoring. Testing helps to confirm long-term process model predictions. } \\
\text { Data will be used to support the LA submittal, as well as the update to receive and possess } \\
\text { waste. Process modelers are the identified customers. }\end{array}$ \\
\hline $\begin{array}{l}\text { Crest Alcove } \\
\text { Testing }\end{array}$ & $\begin{array}{l}\text { Testing in an alcove directly below the Yucca Mountain crest to evaluate seepage in } \\
\text { unventilated drifts. Testing is preceded by mapping the alcove. Test results would be } \\
\text { compared to model predictions to verify process models and resolve residual data needs. Data } \\
\text { is anticipated to support licensing interactions prior to the CA. Process modelers are the } \\
\text { identified users. }\end{array}$ \\
\hline $\begin{array}{l}\text { Crest Alcove Long- } \\
\text { Term Monitoring }\end{array}$ & $\begin{array}{l}\text { Continued long-term monitoring in the crest alcove at reduced frequency and oversight. Testing } \\
\text { will provide long-term information on seepage in unventilated drifts, and may be included in the } \\
\text { long-term PC testing program. Information obtained from the test will be compared to process } \\
\text { model limits or bounds and will be used to support the LA update to receive and possess waste. } \\
\text { Process modelers are the identified users if results differ from expectations. }\end{array}$ \\
\hline $\begin{array}{l}\text { Niche } 6 \text { Seepage } \\
\text { Testing }\end{array}$ & $\begin{array}{l}\text { Testing in an alcove in the lower non-lithographic unit comprising the majority of the potential } \\
\text { repository horizon. Test focuses on evaluation of seepage in unventilated drifts. Results would } \\
\text { be compared to model predictions to verify process models and confirm predictions and to } \\
\text { support licensing interactions prior to CA. Process modelers are the identified users if results } \\
\text { differ from expectations. }\end{array}$ \\
\hline
\end{tabular}


Table D-1. Pre-Emplacement Tests (Continued)

\begin{tabular}{|c|c|}
\hline $\begin{array}{l}\text { Niche } 6 \text { Long-Term } \\
\text { Seepage Monitoring }\end{array}$ & $\begin{array}{l}\text { Continued long-term monitoring in Niche } 6 \text { at reduced frequency and oversight. Testing will } \\
\text { provide long-term information on seepage in unventilated drifts, and may be included in the } \\
\text { long-term PC testing program. Information obtained from the test will be compared to process } \\
\text { model limits or bounds and will be used to support the LA update to receive and possess waste. } \\
\text { Process modelers are the identified users if results differ from expectations. }\end{array}$ \\
\hline $\begin{array}{l}\text { Characterize Ghost } \\
\text { Dance Fault in } \\
\text { Calico Hills }\end{array}$ & $\begin{array}{l}\text { Testing of fracture flow properties unique to the Ghost Dance Fault in the Calico Hills Unit to } \\
\text { verify parameters are within model assumptions. Data is anticipated to support licensing } \\
\text { interactions prior to CA. Process modelers are the identified users if results differ from } \\
\text { expectations. }\end{array}$ \\
\hline $\begin{array}{l}\text { Char } \\
\text { Solit }\end{array}$ & $\begin{array}{l}\text { Characterization of fracture flow properties unique to the Solitario Canyon Fault to satisfy } \\
\text { residual data needs. Test is preceded by mapping of the Alcove. Data is anticipated to support } \\
\text { licensing interactions prior to CA. Process modelers are the identified users. }\end{array}$ \\
\hline $\begin{array}{l}\text { Cross } \\
\text { Char }\end{array}$ & $\begin{array}{l}\text { Testing evaluates thermomechanical properties of the lower lithophysal unit in laboratory tests } \\
\text { using fist-sized samples taken from the cross drift. Data is used to confirm subsurface design } \\
\text { assumptions to support the LA submittal. Designers are the identified users of the data. }\end{array}$ \\
\hline $\begin{array}{l}\text { te } \\
\text { lat }\end{array}$ & $\begin{array}{l}\text { Specific testing to address model vulnerabilities related to water level rising to the potential } \\
\text { repository horizon. Testing will evaluate whether water levels were previously high enough to } \\
\text { create hot springs in Crater Flat. Testing will be complete prior to the LA submittal. Process } \\
\text { modelers are the identified users. }\end{array}$ \\
\hline $\begin{array}{l}\text { nalog } \\
\text { Pena }\end{array}$ & $\begin{array}{l}\text { Testing consists of mobility of Uranium and related radionuclides in a natural setting similar to } \\
\text { that found at Yucca Mountain (unsaturated tuff). Testing is near-term to provide further } \\
\text { validation of process models. The activity also includes an overall synthesis of all unsaturated } \\
\text { zone natural analog information. Results will support the LA submittal. Process modelers are } \\
\text { the identified users. }\end{array}$ \\
\hline$y$ & $\begin{array}{l}\text { Testing evaluates water collected from the potential repository horizon for chemical similarities } \\
\text { and differences to those collected from the } \mathrm{J}-13 \text { well. Results will confirm the applicability of } \mathrm{J} \text { - } \\
13 \text { water for use as a surrogate for water found in the potential repository horizon. Results will } \\
\text { support the LA submittal and subsequent licensing interactions prior to CA. }\end{array}$ \\
\hline $\begin{array}{l}\text { Alcove } 3 / 4 \text { Testing } \\
\text { in Paintbrush Tuff } \\
\text { Unit }\end{array}$ & $\begin{array}{l}\text { Long-term testing of flow through the Paintbrush Tuff Unit. Testing measures water potential } \\
\text { distributions across the entire Paintbrush Tuff Unit to refine properties for flow models. Testing } \\
\text { will provide long-term confirmatory results for model parameter predictions. Data will be used to } \\
\text { support the LA submittal, as well as the update to receive and possess waste. Process } \\
\text { modelers are the identified users. }\end{array}$ \\
\hline \multicolumn{2}{|l|}{ Near-Field } \\
\hline $\begin{array}{l}\text { Drift } \varsigma \\
\text { Test }\end{array}$ & $\begin{array}{l}\text { Testing includes completion of the four year heating phase, followed by four years of controlled } \\
\text { cooling. Automatic data collection and analysis of temperature, humidity, and mechanical } \\
\text { deformation, as well as periodic borehole testing to sample gas and water from the rock is } \\
\text { conducted. Testing will verify fundamental near-field thermally coupled processes and is } \\
\text { needed to satisfy residual data needs and to address model vulnerabilities. Data will support } \\
\text { the LA submittal, as well as the update to receive and possess waste. Process modelers are } \\
\text { the identified users. }\end{array}$ \\
\hline $\begin{array}{l}\text { Cross Drift Thermal } \\
\text { Test }\end{array}$ & $\begin{array}{l}\text { Thermal testing in the lower non-lithophysal portion of the proposed repository horizon to } \\
\text { evaluate thermally driven coupled processes. Information on thermohydrology, water chemistry, } \\
\text { thermomechanical deformation, and permeability will be analyzed to confirm process model } \\
\text { assumptions or to improve process model predictions. Data will support the LA submittal and } \\
\text { licensing interactions prior to CA. Process modelers are the identified users. }\end{array}$ \\
\hline
\end{tabular}


Table D-1. Pre-Emplacement Tests (Continued)

\begin{tabular}{|c|c|}
\hline \multicolumn{2}{|r|}{ Saturated Zone } \\
\hline $\begin{array}{l}\text { Nye County Early } \\
\text { Warning Drilling } \\
\text { Program }\end{array}$ & $\begin{array}{l}\text { Testing performed in conjunction with Nye County to monitor the saturated zone along possible } \\
\text { transport pathways from Yucca Mountain for radionuclides that would be present in the } \\
\text { inventory of the potential repository. Testing measures hydraulic parameters for the alluvial and } \\
\text { tuff aquifers. Information will enhance the database of aquifer properties for the carbonate } \\
\text { aquifer downgradient from Yucca Mountain, and will enhance understanding of interconnections } \\
\text { of the deeper carbonate aquifer with the shallower alluvial and volcanic aquifers. Monitoring will } \\
\text { likely continue long-term. Data will support the LA submittal, as well as the update to receive } \\
\text { and possess waste. Process modelers are the identified users. }\end{array}$ \\
\hline $\begin{array}{l}\text { Alluvial Testing } \\
\text { Complex Tracer } \\
\text { Tests }\end{array}$ & $\begin{array}{l}\text { Tracer testing program to evaluate hydraulic parameters, effective flow porosity, longitudinal } \\
\text { dispersivity, colloid transport parameters and sorption, along with a comparison of field data to } \\
\text { laboratory data to confirm applicability of such data. Data will address residual data needs and } \\
\text { will be used to support the LA submittal and subsequent licensing interactions prior to CA. } \\
\text { Process modelers are the identified users. }\end{array}$ \\
\hline $\begin{array}{l}\text { Alluvial Testing } \\
\text { Complex Long-Term } \\
\text { Monitoring }\end{array}$ & $\begin{array}{l}\text { Continued monitoring in the alluvial testing complex to confirm long-term variability in hydraulic } \\
\text { parameters remain within predicted bounds. Data will support the license update to receive and } \\
\text { possess waste. Process modelers are the identified users if information differs from } \\
\text { expectations. }\end{array}$ \\
\hline $\begin{array}{l}\text { Farm Soils } \\
\text { Properties }\end{array}$ & $\begin{array}{l}\text { Tests are anticipated to confirm soils sorptive properties are within expectations predicted or } \\
\text { assumed in process models. Data will support the license update to receive and possess } \\
\text { waste. Process modelers are the identified users. }\end{array}$ \\
\hline \multicolumn{2}{|c|}{ Environmental/Disruptive Events } \\
\hline $\begin{array}{l}\text { Water Level } \\
\text { Monitoring }\end{array}$ & $\begin{array}{l}\text { Part of the long-term monitoring program to monitor water levels in the Yucca Mountain area. } \\
\text { Monitors for water level changes as potential precursors to certain disruptive events. Monitoring } \\
\text { is considered confirmatory for model assumptions. Process modelers are the identified users if } \\
\text { monitoring results differ from expectations. Data will be available to support the license update } \\
\text { to receive and possess waste. }\end{array}$ \\
\hline \multicolumn{2}{|r|}{ Design Testing } \\
\hline $\begin{array}{l}\text { Construction } \\
\text { Monitoring }\end{array}$ & $\begin{array}{l}\text { Testing consists of long-term convergence monitoring in the exploratory study facility to obtain } \\
\text { long-term convergence data to confirm assumptions and expectations regarding rock properties } \\
\text { and ground support design. Subsurface designers are the identified users. Data will be used to } \\
\text { support the LA submittal, as well as subsurface construction. }\end{array}$ \\
\hline $\begin{array}{l}\text { Waste Handling } \\
\text { Building Analysis of } \\
\text { Borrows }\end{array}$ & $\begin{array}{l}\text { Testing will obtain site specific soils data pertinent to the waste handling building design that } \\
\text { needs to be gathered prior to construction of the facility to verify specific design assumptions. } \\
\text { Data will support surface design prior to CA. Surface designers are the identified users. }\end{array}$ \\
\hline \multicolumn{2}{|r|}{ Engineered Barrier System Testing } \\
\hline $\begin{array}{l}\text { Drip Shield \& Waste } \\
\text { Package Scale } \\
\text { Testing }\end{array}$ & $\begin{array}{l}\text { Testing would evaluate the final design configurations of the WP and drip shield in scaled testing } \\
\text { under simulated drift conditions with various flux rates and temperatures. Testing would } \\
\text { address residual process model data needs and would compare results against assumed model } \\
\text { bounds for relevant parameters. Initial results could support licensing interactions prior to CA. } \\
\text { Designers and process modelers are the identified users if results differ from expectations. }\end{array}$ \\
\hline
\end{tabular}


Table D-1. Pre-Emplacement Tests (Continued)

\begin{tabular}{|c|c|}
\hline $\begin{array}{l}\text { Materials Property } \\
\text { Testing - Invert } \\
\text { Diffusion }\end{array}$ & $\begin{array}{l}\text { Testing is in anticipation of postclosure performance allocation to the invert system as a } \\
\text { diffusion limiting barrier. Testing would evaluate diffusive characteristics of the final invert } \\
\text { design to confirm anticipated performance under bounding conditions. Results would support } \\
\text { licensing interactions prior to CA. Designers and process modelers are the identified users if } \\
\text { results differ from expectations. }\end{array}$ \\
\hline $\begin{array}{l}\text { Introduced Materials } \\
\text { in In-Drift } \\
\text { Environments }\end{array}$ & $\begin{array}{l}\text { Testing would evaluate the effects of materials introduced to the emplacement drift environment } \\
\text { on processes such as the formation of colloids. Testing would parallel licensing interactions to } \\
\text { confirm bounding model assumptions with results available to support the license update to } \\
\text { receive and possess waste. Process modelers would be the identified users of the information if } \\
\text { results differ from expectations. }\end{array}$ \\
\hline $\begin{array}{l}\text { Preclosure } \\
\text { Ventilation Tests }\end{array}$ & $\begin{array}{l}\text { Tests are focused on validating predictive codes for ventilation effects on a simulated drift } \\
\text { environment. Testing is conducted on scaled models of an emplaced drift with simulated } \\
\text { ventilation flow through the drift. Testing is needed to validate significant design assumptions } \\
\text { with results available to support the LA submittal. Designers and process modelers are the } \\
\text { identified users. }\end{array}$ \\
\hline inage Field & $\begin{array}{l}\text { Tests consist of a limited set of bench tests in the subsurface exploratory study facility to } \\
\text { evaluate the drainage characteristics for various fracture frequencies in the potential host rock. } \\
\text { Test results will be compared against process model assumptions and predictions to test the } \\
\text { models. Residual data needs and model vulnerabilities are addressed with results available to } \\
\text { support the LA submittal. Engineered barrier system and unsaturated zone process modelers } \\
\text { are the identified users. }\end{array}$ \\
\hline $\begin{array}{l}\text { Large } \\
\text { Verific }\end{array}$ & $\begin{array}{l}\text { Testing consists of a larger scale simulation of the final subsurface and engineered barrier } \\
\text { system design configuration under bounding in-drift conditions, including flux rates and } \\
\text { temperatures. Testing may continue long-term to evaluate potential cost saving design } \\
\text { enhancements under post-emplacement research and development testing. Results would be } \\
\text { compared against process model predictions to confirm ability of the models to accurately } \\
\text { predict results. Designers and process modelers would be the identified users. Initial results } \\
\text { would support the license update to receive and possess waste. }\end{array}$ \\
\hline $\begin{array}{l}\text { Waste Package } \\
\text { Evaporation Tests } \\
\text { (if needed) }\end{array}$ & $\begin{array}{l}\text { Potential testing to evaluate the ability of the WP in conjunction with the in-drift environment to } \\
\text { effectively evaporate water around WPs. Testing is associated with a potential design } \\
\text { enhancement to significantly reduce repository costs by eliminating the dependence upon the } \\
\text { drip shields from the postclosure safety case. If pursued, process model development, } \\
\text { verification, and confirmation would be required. Results would support adjustments or changes } \\
\text { to the LA if pursued. }\end{array}$ \\
\hline $\begin{array}{l}\text { Seismic Testing of } \\
\text { Engineered Barriers }\end{array}$ & $\begin{array}{l}\text { Testing would evaluate ability of engineered barrier system to maintain its ability to effectively } \\
\text { function during and following seismic events. Testing would be conducted on the final } \\
\text { configuration presented in the LA, and would utilize bounding seismic environments. Testing } \\
\text { must also await facility development or availability. Testing would verify significant design } \\
\text { assumptions during licensing interactions with results available to support the license update to } \\
\text { receive and possess waste. }\end{array}$ \\
\hline $\begin{array}{l}\text { Rockfall Effects on } \\
\text { Waste Package \& } \\
\text { Drip Shield }\end{array}$ & $\begin{array}{l}\text { Testing would evaluate the ability of the drip shield and WP design to withstand design basis } \\
\text { rockfalls, and would evaluate their ability to continue to perform under various rockfall scenarios. } \\
\text { Testing would be conducted on the final designs presented in the LA. Testing would verify } \\
\text { significant design assumptions during licensing interactions with results available prior to CA. }\end{array}$ \\
\hline
\end{tabular}


Table D-1. Pre-Emplacement Tests (Continued)

\begin{tabular}{|c|c|}
\hline \multicolumn{2}{|r|}{ Waste Package Testing } \\
\hline $\begin{array}{l}\text { Waste Package } \\
\text { Degradation } \\
\text { Materials Testing }\end{array}$ & $\begin{array}{l}\text { Evaluation of both general and localized corrosion of WP and drip shield. It includes testing to } \\
\text { support the LA submittal and the licensing update to receive and possess waste, and testing to } \\
\text { continue long-term under the PC program. Corrosion rates and corrosion mechanisms are to be } \\
\text { confirmed by the tests. Process modelers are the identified users. }\end{array}$ \\
\hline $\begin{array}{l}\text { Microbial Induced } \\
\text { Corrosion Tests }\end{array}$ & $\begin{array}{l}\text { Testing addresses the influence of microbes on corrosion of WP and drip shield materials. } \\
\text { Testing includes soluble and suspended particle chemistry evaluations and organic impacts on } \\
\text { material performance. Near-term effort to resolve process model data needs and confirm } \\
\text { assumptions will decrease during the licensing interactions when issues or assumptions are } \\
\text { confirmed. Near-term data will support the LA submittal. Subsequent data will support licensing } \\
\text { interactions prior to CA. Process modelers are the identified users. Testing will also help to } \\
\text { establish limits on organic material introduction to the subsurface environment. }\end{array}$ \\
\hline $\begin{array}{l}\text { Long-Term } \\
\text { Corrosion Potential } \\
\text { Measurements }\end{array}$ & $\begin{array}{l}\text { Testing is part of the long-term PC program to confirm corrosion rates for WP and drip shield } \\
\text { materials under a range of expected water chemistries, and potential in-drift environments. } \\
\text { Periodic sampling over the life cycle of the potential repository will be used to confirm process } \\
\text { model predictions. Data can also be used to support the LA submittal and the subsequent } \\
\text { license update to receive and possess waste. Process modelers are the identified users. }\end{array}$ \\
\hline $\begin{array}{l}\text { Corrosion Resistant } \\
\text { Material Electro- } \\
\text { Chemical }\end{array}$ & $\begin{array}{l}\text { Testing focuses on localized corrosion model parameters for WP and drip shield materials. } \\
\text { Effort to resolve residual process model parameter needs will reduce during licensing } \\
\text { interactions with continued long-term confirmatory testing. Near-term data will support the LA } \\
\text { submittal. Subsequent data will support the license update to receive and possess waste. } \\
\text { Process modelers are the identified users. }\end{array}$ \\
\hline $\begin{array}{l}\text { Corrosion Resistant } \\
\text { Material Cyclic } \\
\text { Polarization }\end{array}$ & $\begin{array}{l}\text { Testing is tied to electrochemical test program, focusing on localized corrosion mechanisms. } \\
\text { Testing will address residual data needs with long-term testing at reduced levels for confirmation } \\
\text { purposes. Near-term data will support the LA submittal. Subsequent data will support the } \\
\text { license update to receive and possess waste. Process modelers are the identified users. }\end{array}$ \\
\hline $\begin{array}{l}\text { Corrosion Resistant } \\
\text { Material } \\
\text { Potentiostatic Test }\end{array}$ & $\begin{array}{l}\text { Testing is performed in conjunction with electrochemical and cyclic polarization tests, focusing } \\
\text { on localized corrosion mechanisms. Testing will address residual data needs with long-term } \\
\text { testing at reduced levels for confirmation purposes. Near-term data will support the LA } \\
\text { submittal. Subsequent data will support the license update to receive and possess waste. } \\
\text { Process modelers are the identified users. }\end{array}$ \\
\hline $\begin{array}{l}\text { Stress Corrosion } \\
\text { Cracking Tests - } \\
\text { Weld Stability }\end{array}$ & $\begin{array}{l}\text { Tests evaluate welding process to evaluate stress corrosion cracking mechanisms. Testing is } \\
\text { ongoing and will continue through fabrication of WPs on a reduced, sampling basis. Testing will } \\
\text { evaluate effectiveness of welding approach using weld samples, will resolve residual process } \\
\text { model data needs, and will provide confirmatory information during WP fabrication. Near-term } \\
\text { data will support the LA submittal. Subsequent data will support the license update to receive } \\
\text { and possess waste. Process modelers are the identified users. }\end{array}$ \\
\hline $\begin{array}{l}\text { Slow Strain Rate \& } \\
\text { Film Rupture Tests }\end{array}$ & $\begin{array}{l}\text { Testing will evaluate the effects of welding on long-term mechanical and corrosion response of } \\
\text { WP and drip shield materials, including long-term stability of passive films. Testing addresses } \\
\text { residual data needs and continues at reduced levels during the confirmation period. Near-term } \\
\text { data will support the LA submittal. Subsequent data will support the license update to receive } \\
\text { and possess waste. Process modelers are the identified users. }\end{array}$ \\
\hline
\end{tabular}


Table D-1. Pre-Emplacement Tests (Continued)

\begin{tabular}{|c|c|}
\hline $\begin{array}{l}\text { Stress Corrosion } \\
\text { Cracking Tests - } \\
\text { Aging Samples }\end{array}$ & $\begin{array}{l}\text { Testing of WP and drip shield materials for long-term thermal stability with reduced sampling } \\
\text { and evaluations during the confirmatory period. Testing addresses residual data needs, and will } \\
\text { confirm model assumptions. Near-term data will support the LA submittal. Subsequent data will } \\
\text { support the license update to receive and possess waste. Process modelers are the identified } \\
\text { users. }\end{array}$ \\
\hline $\begin{array}{l}\text { Stress Corrosion } \\
\text { Crack Initiation \& } \\
\text { Growth Tests }\end{array}$ & $\begin{array}{l}\text { Testing includes stress corrosion crack tests and hydrogen-induced cracking of WP and drip } \\
\text { shield materials. Testing resolves residual data needs and confirms model parameters, with } \\
\text { reduced testing concluding during licensing interactions. Testing supports the LA submittal and } \\
\text { licensing interactions prior to CA. Process modelers are the identified users. }\end{array}$ \\
\hline $\begin{array}{l}\text { Stress Corrosion } \\
\text { Crack - Laser } \\
\text { Concept Stress }\end{array}$ & $\begin{array}{l}\text { Testing evaluates the effectiveness of weld stress relief using lasers and ability to reduce the } \\
\text { potential for stress corrosion cracking. Tests will help support decisions regarding the use of } \\
\text { this technique in a production environment, with confirmatory tests planned coincident with } \\
\text { licensing interactions assuming its use. Testing supports the LA submittal and licensing } \\
\text { interactions prior to CA. WP design engineers and process modelers are the identified users. } \\
\text { Testing is performed in conjunction with prototype tests. }\end{array}$ \\
\hline & $\begin{array}{l}\text { Testing evaluates the effectiveness of weld stress relief using induction annealing and heating to } \\
\text { reduce the potential for stress corrosion cracking. Tests will help support decisions regarding } \\
\text { the use of this technique in a production environment, with confirmatory tests planned coincident } \\
\text { with licensing interactions. Testing supports the LA submittal and licensing interactions prior to } \\
\text { CA. WP design engineers and process modelers are the identified users. Testing is performed } \\
\text { in conjunction with prototype tests. }\end{array}$ \\
\hline ions of & $\begin{array}{l}\text { Testing includes evaluation of bicarbonates, precipitates, and brines from Yucca Mountain water } \\
\text { and J-13 water, as well as the evaluation of relative humidity thresholds. Testing will resolve } \\
\text { residual data needs prior to LA for water chemistries used in process models. Process } \\
\text { modelers are the identified users. }\end{array}$ \\
\hline $\begin{array}{l}\text { Long } \\
\text { Corro } \\
\text { Char }\end{array}$ & $\begin{array}{l}\text { Testing provides baseline data for samples to be placed in long-term corrosion tests. Baseline } \\
\text { data is required by the PC program for comparison to information obtained during or after the } \\
\text { tests. Baseline data will be obtained from samples procured throughout the license submittal } \\
\text { process and during NRC interactions, consistent with the final design approach. Process } \\
\text { modelers will use baseline data to support later comparisons. }\end{array}$ \\
\hline $\begin{array}{l}\text { Sterile \& } \\
\text { e } \\
\text { Matter }\end{array}$ & $\begin{array}{l}\text { Testing consists of evaluations of microbial growth and effects on corrosion in sterile and non- } \\
\text { sterile saturated conditions to resolve residual process model data needs. Process modelers } \\
\text { are the identified users with initial test results available to support the LA and subsequent data } \\
\text { to support licensing interactions prior to CA. Testing will also assist development of organic } \\
\text { limits for emplacement drift environments. }\end{array}$ \\
\hline $\begin{array}{l}\text { Growth Kinetics \& } \\
\text { Composition } \\
\text { Passive Film Test }\end{array}$ & $\begin{array}{l}\text { Testing focuses on stability of passive films with anticipated continuation in the long-term testing } \\
\text { program. Tests address residual data needs and will support confirmation of model predictions. } \\
\text { Near-term data will support the LA submittal. Subsequent data will support the license update to } \\
\text { receive and possess waste. Process modelers are the identified customers. }\end{array}$ \\
\hline $\begin{array}{l}\text { Microbial } \\
\text { Contributions to } \\
\text { Waste Packages }\end{array}$ & $\begin{array}{l}\text { Test focuses on evaluation of samples from the Drift Scale Test. Samples will not be available } \\
\text { until } 2005 \text { or } 2006 \text {. Testing will evaluate microbial effects on corrosion using pre-doped samples } \\
\text { placed in the Drift Scale Test. Evaluations will be used to compare against pre-test predictions } \\
\text { and will support the license update to receive and possess waste. Process modelers are the } \\
\text { identified users if results differ from expectations. }\end{array}$ \\
\hline
\end{tabular}


Table D-1. Pre-Emplacement Tests (Continued)

\begin{tabular}{|c|c|}
\hline $\begin{array}{l}\text { Pre-Exposure } \\
\text { Characterization of } \\
\text { Specimens }\end{array}$ & $\begin{array}{l}\text { Testing consists of PC baseline data collection to characterize samples collected from the first } \\
\text { five years of WP fabrication prior to long-term corrosion testing. Test results will be compared to } \\
\text { expectations of material properties for fabricated WPs, and will be used as the basis for long- } \\
\text { term performance predictions and for comparison to later test results. Process modelers will be } \\
\text { the primary users of the information. }\end{array}$ \\
\hline $\begin{array}{l}\text { Radiolysis Effects } \\
\text { on Chemical } \\
\text { Environments }\end{array}$ & $\begin{array}{l}\text { Testing will evaluate the effects of high radiation environments on the chemical environments for } \\
\text { WP and drip shield materials. Results will be compared against expectations to confirm process } \\
\text { model assumptions and to resolve residual data needs. Testing is anticipated in conjunction } \\
\text { with licensing interactions prior to CA. Process modelers are the identified users if results differ } \\
\text { from expectations. }\end{array}$ \\
\hline $\begin{array}{l}\text { Corro } \\
\text { Field }\end{array}$ & $\begin{array}{l}\text { Testing will evaluate samples currently emplaced in testing at the Atlas Facility, in the Drift Scale } \\
\text { Test, and at Busted Butte. Testing will evaluate the extent of corrosion on samples, if any. } \\
\text { Results will be compared against pre-test predictions to confirm model predictions. Results will } \\
\text { be available to support licensing interactions prior to CA. Process modelers are the identified } \\
\text { users. }\end{array}$ \\
\hline \multicolumn{2}{|r|}{ Waste Form Testing } \\
\hline $\begin{array}{l}\text { Waste Form } \\
\text { Degradation } \\
\text { Materials Testing }\end{array}$ & $\begin{array}{l}\text { Testing evaluates the performance of candidate waste form materials under anticipated } \\
\text { repository conditions. It includes testing to support the LA submittal and the licensing update to } \\
\text { receive and possess waste, and testing will continue long-term under the PC program. Short } \\
\text { and long duration unsaturated drip conditions will be conducted for commercial and DOE spent } \\
\text { nuclear fuel, as well as high level waste glass under anticipated repository conditions. Process } \\
\text { modelers are the identified customers. }\end{array}$ \\
\hline $\begin{array}{l}\text { Testing for In- } \\
\text { Package Chemistry } \\
\text { \& Transport }\end{array}$ & $\begin{array}{l}\text { Testing evaluates waste form degradation under anticipated in-package chemical environments } \\
\text { and improves understanding of in-package transport mechanisms. Testing resolves residual } \\
\text { data needs and coincides with the LA submittal and anticipated licensing interactions prior to } \\
\text { CA. Process modelers are the identified users. }\end{array}$ \\
\hline $\begin{array}{l}\text { Testin } \\
\text { Model }\end{array}$ & $\begin{array}{l}\text { Testing will evaluate bounding rates for colloidal concentrations and transport characteristics. } \\
\text { Testing will decrease after LA submittal, but will continue as new fuels and glass waste form } \\
\text { samples are created and provided throughout the fuel and glass waste fabrication phases. } \\
\text { Testing will resolve residual process model data needs and will confirm model bounds and } \\
\text { assumptions through continued long-term tests. Near-term data will support the LA submittal. } \\
\text { Subsequent data will support the license update to receive and possess waste. Process } \\
\text { modelers are the identified users. }\end{array}$ \\
\hline $\begin{array}{l}\text { Testing for } \\
\text { Radionuclide } \\
\text { Solubilities }\end{array}$ & $\begin{array}{l}\text { Testing will evaluate bounding values for radionuclide solubilities in bounding in-drift chemical } \\
\text { environments. Testing will decrease after LA submittal, but will continue as new fuels and glass } \\
\text { waste form samples are created and provided throughout the fuel and glass waste fabrication } \\
\text { phases. Testing will resolve residual process model data needs and will confirm model bounds } \\
\text { and assumptions through continued long-term tests. Near-term data will support the LA } \\
\text { submittal. Subsequent data will support the license update to receive and possess waste. } \\
\text { Process modelers are the identified users. }\end{array}$ \\
\hline $\begin{array}{l}\text { Secondary } \\
\text { Alteration Phases } \\
\text { Tests }\end{array}$ & $\begin{array}{l}\text { Testing will evaluate bounding values for radionuclide stability in secondary phases of corrosion } \\
\text { products of spent fuel and glass samples. Testing will decrease after LA submittal, but will } \\
\text { continue as new fuels and glass waste form samples are created and provided throughout the } \\
\text { fuel and glass waste fabrication phases. Testing will resolve residual process model data needs } \\
\text { and will confirm model bounds and assumptions through continued long-term tests. Near-term } \\
\text { data will support the LA submittal. Subsequent data will support the license update to receive } \\
\text { and possess waste. Process modelers are the identified users. }\end{array}$ \\
\hline
\end{tabular}




\section{Table D-1. Pre-Emplacement Tests (Continued)}

\begin{tabular}{|c|c|}
\hline $\begin{array}{l}\text { Unsaturated Testing } \\
\text { of Commercial Fuel }\end{array}$ & $\begin{array}{l}\text { Testing will evaluate degradation of commercial fuel in bounding unsaturated environments. } \\
\text { Testing will decrease after LA submittal, but will continue as new fuels are created and provided } \\
\text { throughout the fabrication phases. Testing will resolve residual process model data needs and } \\
\text { will confirm model bounds and assumptions through continued long-term tests. Near-term data } \\
\text { will support the LA submittal. Subsequent data will support the license update to receive and } \\
\text { possess waste. Process modelers are the identified users. }\end{array}$ \\
\hline $\begin{array}{l}\text { Flow Through \& } \\
\text { Oxidation Testing of } \\
\text { Fuels }\end{array}$ & $\begin{array}{l}\text { Testing evaluates oxidation of fuels and evaluates relative humidity effects on oxidation. Testing } \\
\text { addresses residual process model data needs and supports the LA submittal. Process } \\
\text { modelers are the identified users. }\end{array}$ \\
\hline $\begin{array}{l}\text { High Burn-up Fuel } \\
\text { Characterization }\end{array}$ & $\begin{array}{l}\text { Testing will focus on characterizing high burn-up fuels recently procured to evaluate whether } \\
\text { characteristics fall within assumed model bounds. Testing includes evaluation of oxidation and } \\
\text { relative humidity effects. Results support the ILA submittal. Process modelers are the identified } \\
\text { users. }\end{array}$ \\
\hline $\begin{array}{l}\text { Glass - Vapor, } \\
\text { Saturated, and Drip } \\
\text { Tests }\end{array}$ & $\begin{array}{l}\text { Testing evaluates waste form degradation of glass waste under vaporous, saturated, and drip } \\
\text { conditions. Testing will be limited until glass waste forms are manufactured, at which time } \\
\text { testing will be conducted to demonstrate characteristics are within assumed bounds. Data will } \\
\text { support licensing interactions prior to CA, as well as the license update to receive and possess } \\
\text { waste. Process modelers are the identified users if results differ from expectations. }\end{array}$ \\
\hline $\begin{array}{l}\text { Cladding Tests (if } \\
\text { needed) }\end{array}$ & $\begin{array}{l}\text { Potential cladding tests include evaluations of cladding corrosion, hydride formation, and wet } \\
\text { unzipping tests. Execution of tests depends upon degree of cladding credit the project intends } \\
\text { to pursue and the relationship of cladding to the postclosure safety case. Testing would address } \\
\text { residual process model data needs and model vulnerabilities with data available to support } \\
\text { licensing interactions and the subsequent license update to receive and possess waste. } \\
\text { Process modelers would be the users of the information. }\end{array}$ \\
\hline
\end{tabular}




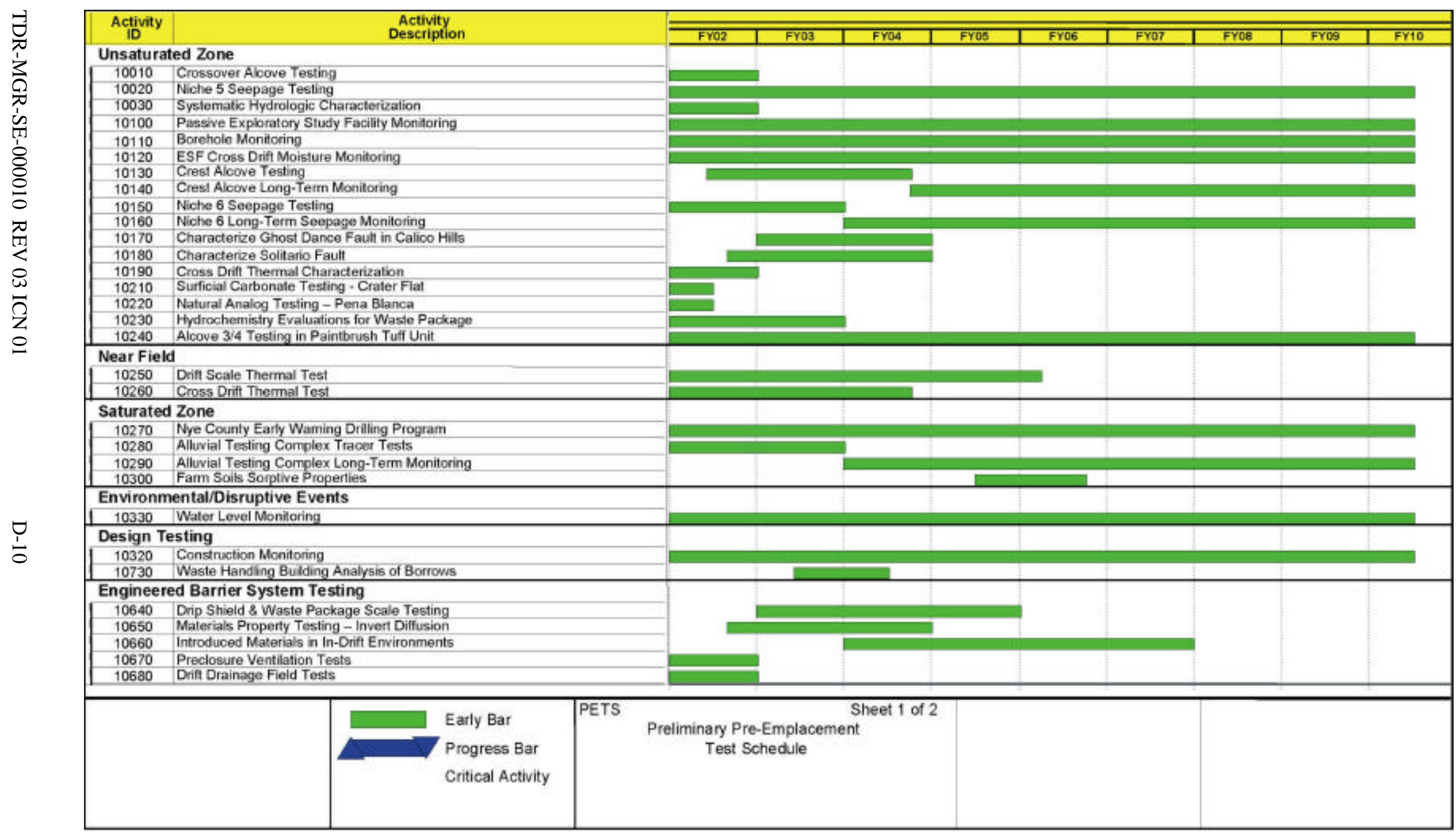

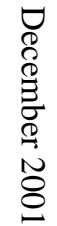

Figure D-1. Near-Term Pre-Emplacement Test Schedule 


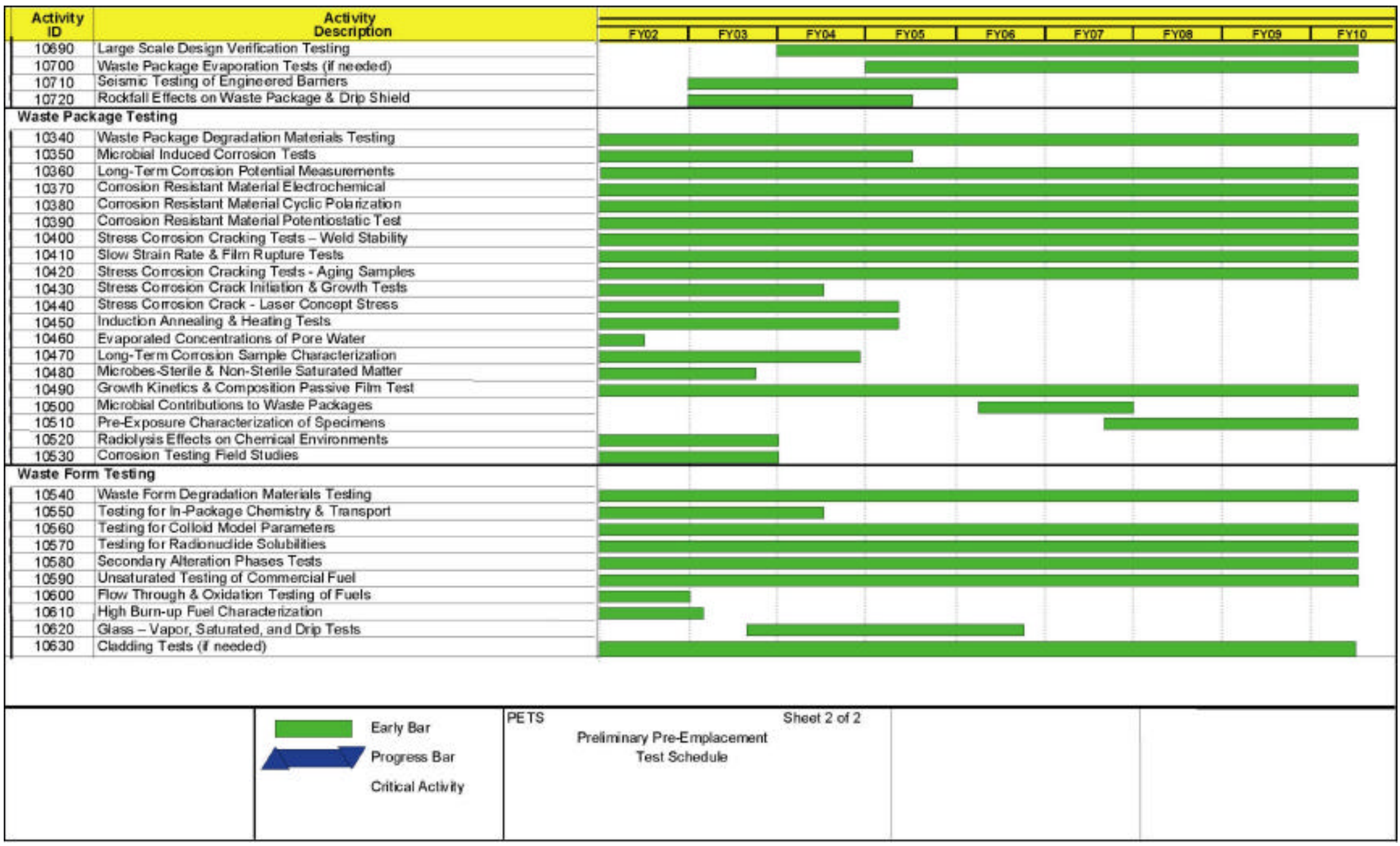

Figure D-1. Near-Term Pre-Emplacement Test Schedule (Continued) 


\section{INTENTIONALLY LEFT BLANK}

